\title{
Glass-Polymer Composite Pipes and Joints: Manufacturing, Testing, and Characterization
}

\author{
Ben William Imes
}

Follow this and additional works at: https://researchrepository.wvu.edu/etd

\section{Recommended Citation}

Imes, Ben William, "Glass-Polymer Composite Pipes and Joints: Manufacturing, Testing, and Characterization" (2018). Graduate Theses, Dissertations, and Problem Reports. 5857.

https://researchrepository.wvu.edu/etd/5857

This Thesis is protected by copyright and/or related rights. It has been brought to you by the The Research Repository @ WVU with permission from the rights-holder(s). You are free to use this Thesis in any way that is permitted by the copyright and related rights legislation that applies to your use. For other uses you must obtain permission from the rights-holder(s) directly, unless additional rights are indicated by a Creative Commons license in the record and/ or on the work itself. This Thesis has been accepted for inclusion in WVU Graduate Theses, Dissertations, and Problem Reports collection by an authorized administrator of The Research Repository @ WVU. For more information, please contact researchrepository@mail.wvu.edu. 


\title{
Glass-Polymer Composite Pipes and Joints: Manufacturing, Testing, and Characterization
}

\author{
Benjamin William Imes
}

\author{
Problem Report submitted to the \\ College of Engineering and Mineral Resources at \\ West Virginia University in \\ partial fulfillment of the requirements \\ for the degree of
}

\author{
Master of Science \\ in \\ Civil Engineering
}

\author{
Hota V.S. GangaRao, PhD, PE, Chair \\ Udaya Halabe, PhD, PE \\ Mark Skidmore, PE
}

\section{Department of Civil and Environmental Engineering}

\author{
Morgantown, West Virginia \\ 2018
}

Keywords: Glass FRP, composites, hydrostatic pressure testing, split ring testing, lamination theory, natural gas transmission

Copyright 2018 Benjamin William Imes 


\title{
ABSTRACT \\ Glass-Polymer Composite Pipes and Joints: Manufacturing, Testing, and Characterization
}

\author{
Benjamin William Imes
}

Over the last fifty years, Fiber Reinforced Polymer (FRP) composite materials have been employed in civil engineering applications for rehabilitation of deteriorated infrastructure and for new construction. In addition to steel and high-density polyethylene, glass-fiber reinforced polymer pipes (GFRP) are now being employed in natural gas gathering and distribution lines. As energy demands have grown, researchers have begun to investigate feasibility of GFRP pipe implementation in high- pressure, transmission lines. These investigations have sought to determine GFRP pipe properties of strength, stiffness, corrosion resistance, failure modes, and long-term behavior.

During this project, hydrostatic burst pressure testing (internal water pressure) and split ring testing were conducted on 6-inch and 10-inch diameter, pultruded and filament wound pipes, as well as 10-inch diameter filament wound, butt joints. These tests were conducted to determine elastic properties, failure progression, and failure predictions for short time loadings. In addition to testing, the Classical Lamination Theory (CLT) was employed to predict elastic behavior, including strength and stiffness of the pipes. Testing and analysis of the pipes were conducted to determine the strength of pipes under sustained pressure, which is approximately 30 percent of the short time, burst pressure failure strength.

The results from the tests indicate that filament wound pipes provide better resistance to internal pressures than pultruded pipes and that joints continue to be the limiting component in pipelines. A 6-inch diameter pultruded pipe was tested to a burst pressure of 1,000 psi. Three 10inch diameter, pultruded pipes were tested to internal pressures of $300 \mathrm{psi}$. Three 10 -inch diameter, thin-walled, filament wound pipes ( 0.45 inch thick) were tested to pressures of 3,000 psi, while three 10 inch diameter, thick walled, filament wound pipes ( 0.8 inch thick) were tested to burst pressures between 4,000 and 5,200 psi. Two GFRP filament wound butt joints were tested to pressures of 1,000 psi.

The research resulted in an excellent methodology for burst pressure testing. The hydrostatic test method was found to produce elastic results matching well with CLT predictions and split-ring test results. The hydrostatic test method results did not match well with CLT predictions or split-ring test results in terms of failure progression and failure predictions. 


\section{ACKNOWLEDGEMENTS}

Above all others, I would like to give praise, honor, and glory to Jesus Christ, my God and savior. He has given his life to rescue me from my sin, secure for me an eternal salvation, and fill my life with purpose, joy, and peace. I owe everything that I have and everything that I am to his undeserved favor. By his grace, he has guided me, helped me, protected me, taught me, and molded me. In the same way that my life is a product of God's grace, this work is the product of his grace. I pray it is an offering pleasing to him, and I pray that the words offered here will be of benefit to the engineering community.

I would like to give tremendous thanks to Dr. Hota GangaRao for offering me this research assistantship, for agreeing to Chair my committee, sharing his wisdom, offering guidance, and pushing me to think critically and seek understanding throughout these last 21 months. I would also like to offer thanks to Mark Skidmore and Jerry Nestor. These two helped this work progress through their wise counsel, technical competence, and masterful knowledge of engineering and manufacturing. I would also like to thank Dr. Udaya Halabe for his participation as a member of my committee. Without these men, I know that this work would not have been completed. I would also like to thank the other WVU professors, staff, and students who have helped me during my time here.

John Harper and Maria Martinez, my fellow graduate students and dear friends, have helped me in incalculable ways. They have encouraged me, pushed me, helped me think through challenging concepts, and walked with me through this incredible graduate school experience. Along with these dear friends, I would like to thank my church family for their encouragement and willingness to be a part of my life. Among them, Charis Lowe, Adam and Morgan Canady, Zach Walton, Elizabeth Moore, Bettina Burns, Emily, Nathan, and Sydney Almquist, Hannah Hager, Andrew Mayer, Ben Larrick, and Rob Johnson. Many other friends have walked with me through these last few years, even though they are spread across the country. It is not possible to declare how much these friends mean to me; Thomas Garrigan, Sam Hodges, Andy McCoy, Ryan and Mariah Ferkel, and Sam Francis.

As an undergraduate student, I was deeply impacted by my professors at LeTourneau University; Dr. Stephen Ayers, Dr. David Dittenber, Dr. Gustavo Cortes, and Dr. Darryl Low. I am very grateful for the way these men pushed me and encouraged me to pursue excellence and diligently labor in gospel mission. Specifically, I am grateful to Dr. David Dittenber and Dr. Stephen Ayers for encouraging me to pursue graduate school and for helping me to navigate the process.

My greatest help has come from my beloved family; Dad, Mom, Matt, Cally, Paul, and Janna. They have prayed for me, encouraged, guided me, listened to my frustrations, poured out wisdom, and steadfastly pointed me to the love of God, displayed in Christ. I am grateful to God for the family he has given me. I love them dearly.

Thanks is also given to Kenway Corporation (a subsidiary of Creative Pultrusion Inc) for providing pipes to test and to the Department of Transportation (Pipelines Hazardous Materials Safety Administration) for funding this work. 


\section{TABLE OF CONTENTS}

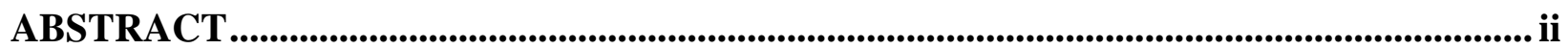

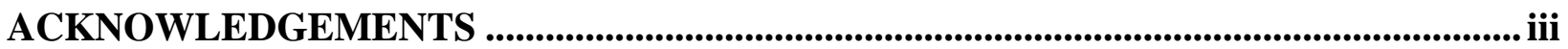

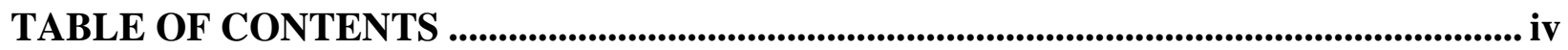

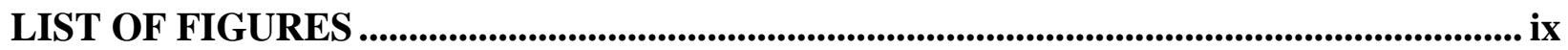

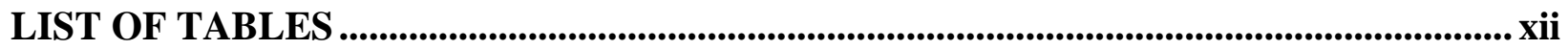

CHAPTER 1 INTRODUCTION ........................................................................................ 1

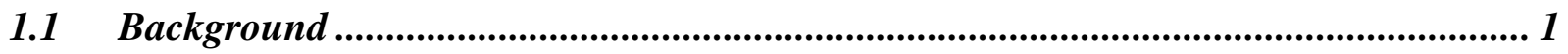

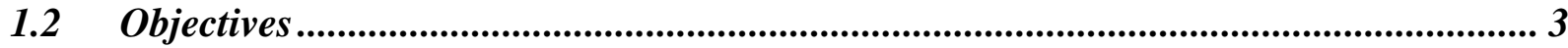

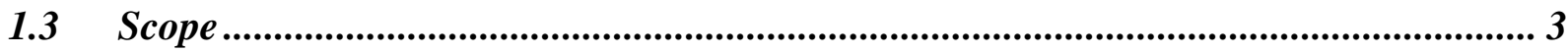

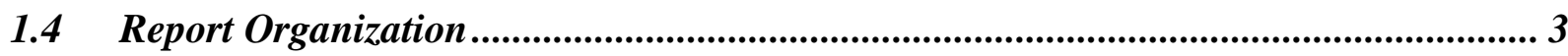

CHAPTER 2 LITERATURE REVIEW .......................................................................... 5

2.1 Pipeline Materials and Systems ................................................................................ 5

2.1.1 Gathering Lines......................................................................................... 5

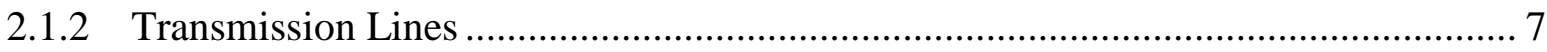

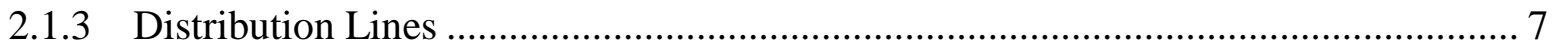

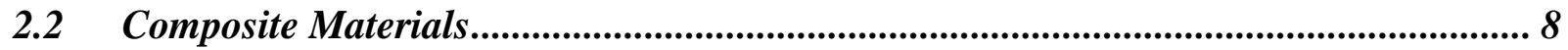

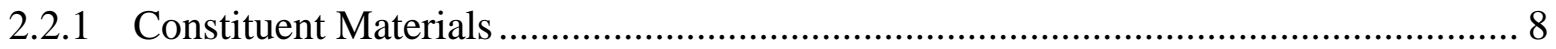

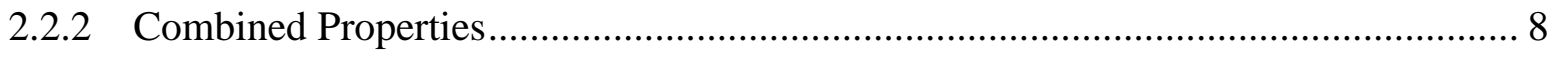




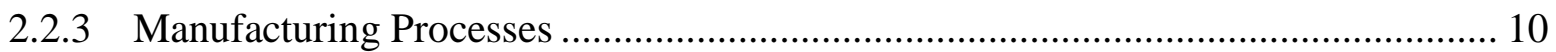

2.3 Composite Applications in Materials Transportation..................................................... 13

2.3.1 Composite Reinforced Line Pipe .................................................................... 13

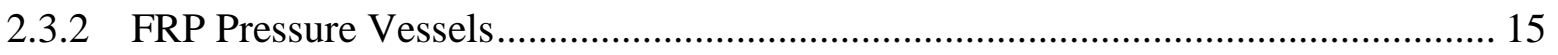

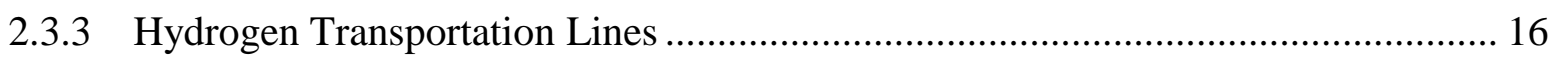

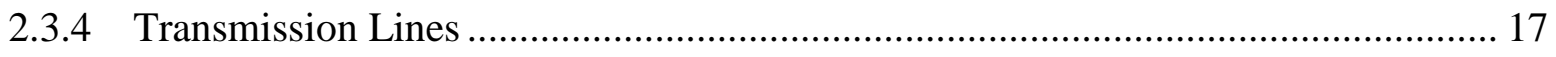

$2.4 \quad$ FRP Line Pipe Standards and Specifications ............................................................. 18

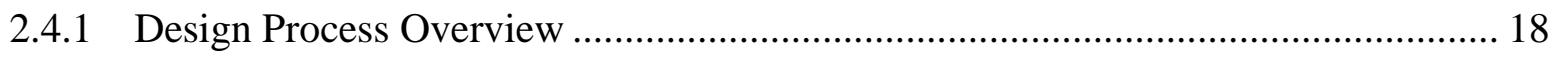

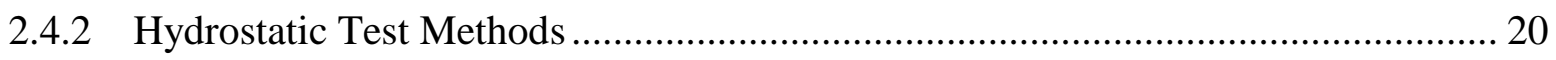

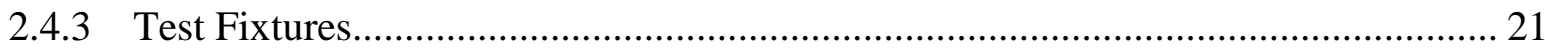

2.5 Conclusion ................................................................................................................ 22

CHAPTER 3 MECHANICAL BEHAVIOR OF THIN WALLED CYCLINDERS ...... 24

$3.1 \quad$ Thin Walled Isotropic Cylinders.................................................................................... 24

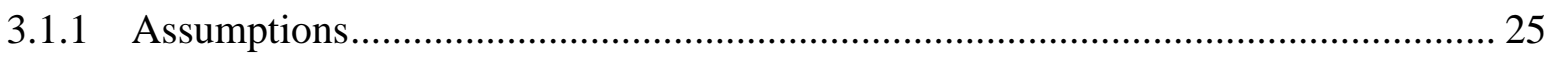

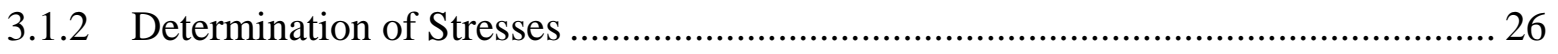

$3.2 \quad$ Thin Walled Composite Cylinders ................................................................................... 28

$3.3 \quad$ Elastic Behavior of Orthotropic Materials ........................................................................ 29

3.3.1 Classical Lamination Theory (CLT) …………................................................... 29

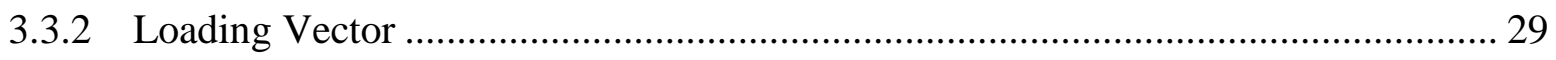

$3.4 \quad$ Failure Behavior of Composite Materials........................................................................ 31 
3.4.1 General Comments on Failure Progression ................................................ 32

3.4.2 Failure Progression through Ply Discount Methods ......................................... 32

3.4.3 Strain Energy Density Failure Theory …........................................................... 37

3.5 Conclusions on Pipe Mechanics......................................................................... 39

CHAPTER 4 ANALYSIS OF FILAMENT WOUND PIPES ........................................ 40

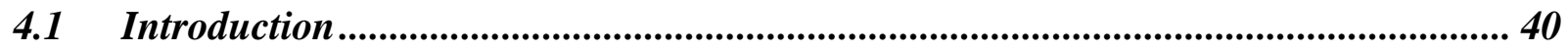

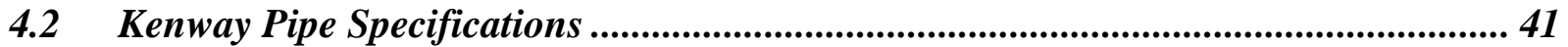

4.2.1 Filament Wound Pipes- $3 / 8$ Wall Samples ........................................................ 41

4.2.2 Filament Wound Pipes- 3/4 Wall Samples ...................................................... 43

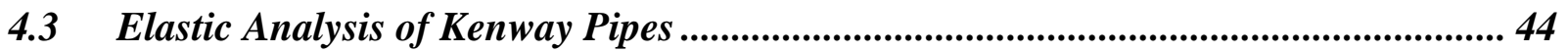

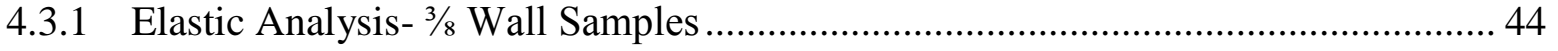

4.3.2 Commentary on Elastic Properties............................................................... 51

4.3.3 Elastic Analysis-3/4 Wall Samples............................................................... 53

4.3.4 Commentary on Elastic Properties................................................................. 57

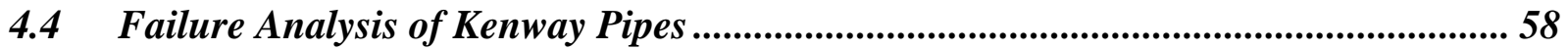

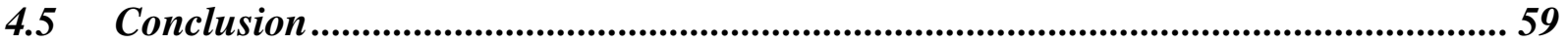

CHAPTER 5 EXPERIMENTATION AND RESULTS ........................................... 60

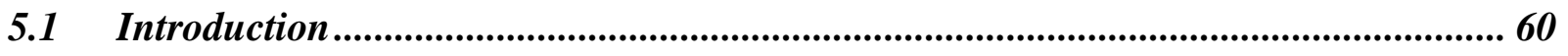

$5.2 \quad$ Hydrostatic Pressure Test Methodology ...................................................................60

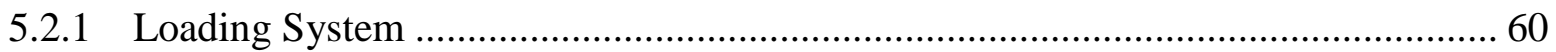


5.2.2 Samples and Testing.

5.3 Hydrostatic Pressure Test Results ....................................................................... 70

5.3.1 Pultruded Pipes .................................................................................. 70

5.3.2 Filament-Wound Pipes-3/8 Wall Samples....................................................... 72

5.3.3 Filament Wound Pipes -3/4 Wall Samples ................................................ 75

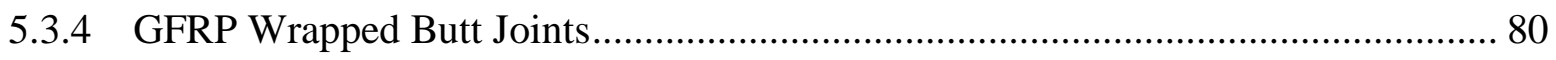

$5.4 \quad$ Split Ring Test Methodology ................................................................................... 82

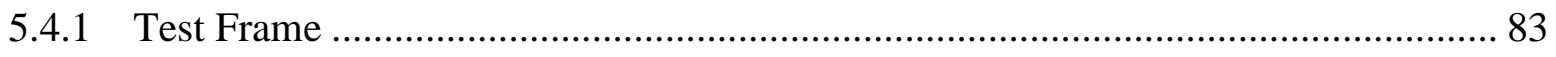

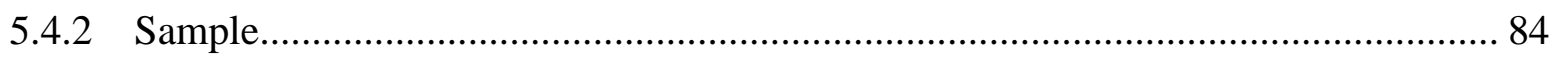

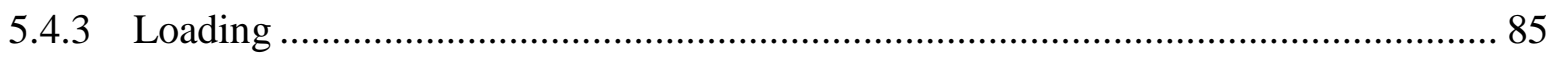

5.5 Split Ring Test Results ........................................................................................ 86

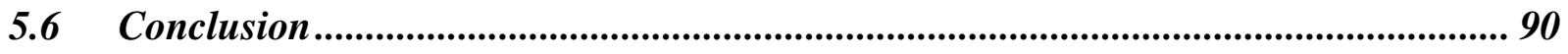

CHAPTER 6 BEHAVIOR ANALYSIS AND COMPARISON ..................................91

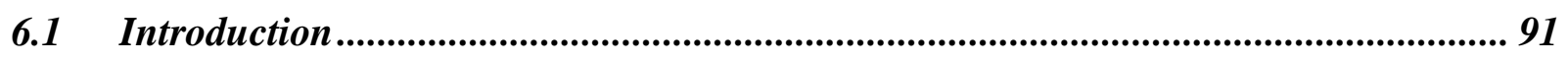

6.2 Analytical Prediction vs Hydrostatic Burst Pressure Results ................................. 91

6.2.1 Caveats Regarding Testing and Analysis .................................................. 91

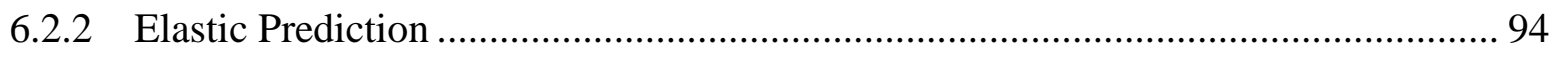

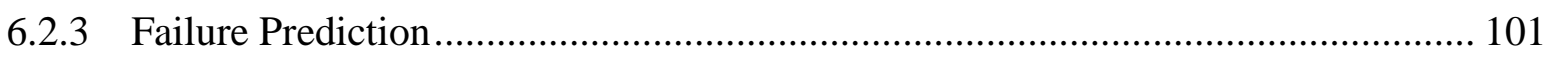

6.3 Split Ring Prediction vs Hydrostatic Burst Pressure Results ................................ 101

$6.4 \quad$ Summarizing Observations .......................................................................... 104 


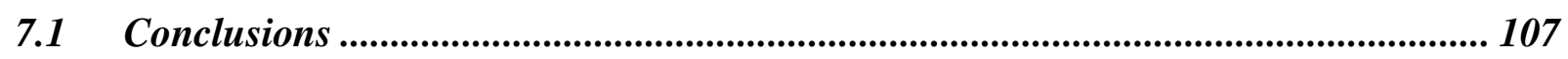

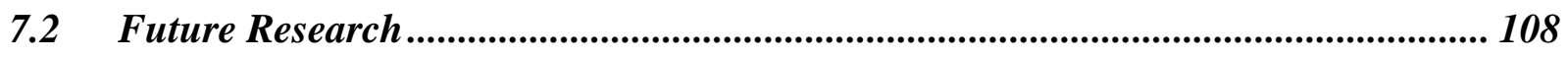

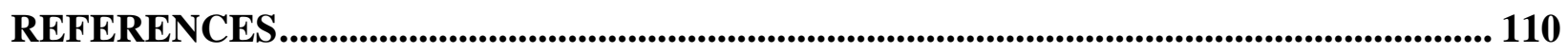

APPENDIX A - Classical Lamination Theory ................................................................................. 114

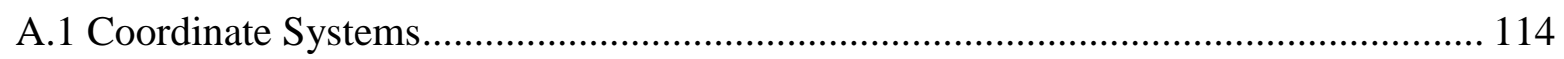

A.2 Stiffness Matrices ......................................................................................................... 115

A.2.1 Specially Orthotropic Lamina ............................................................................ 115

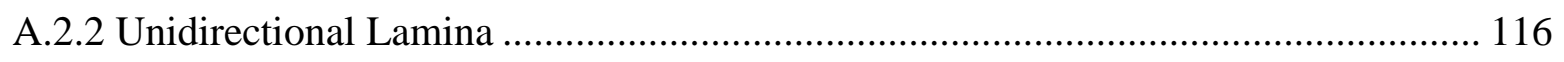

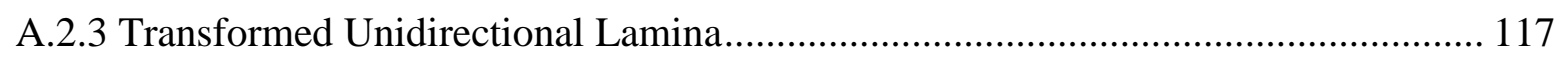

A.2.4 Stiffness Matrix of Chopped Strand Mats............................................................ 118

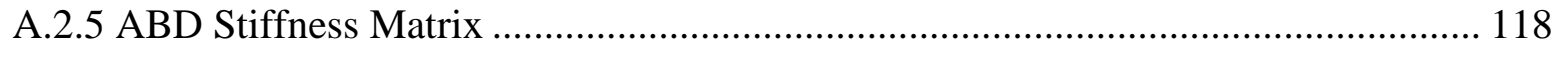

APPENDIX B - Pultruded Fabric Architectures ......................................................................... 120

APPENDIX C - Frame Drawing.......................................................................................................... 122

APPENDIX C - Frame Design Calculations........................................................................................... 123 


\section{LIST OF FIGURES}

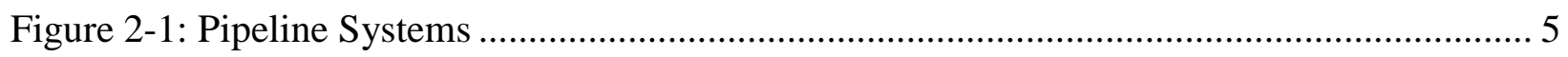

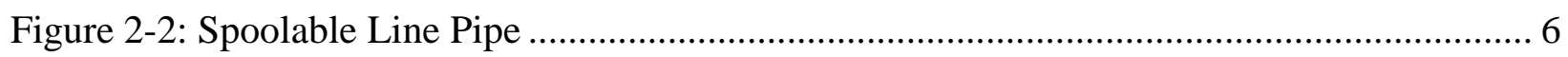

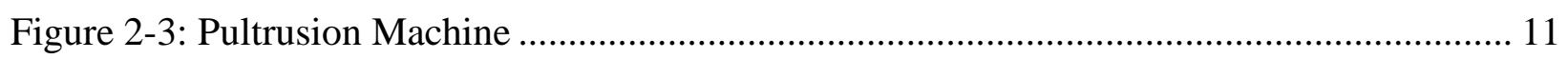

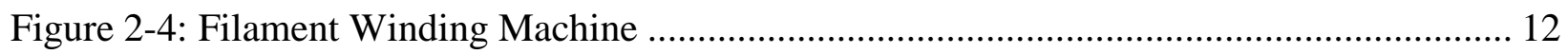

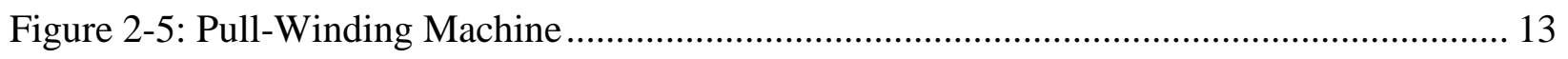

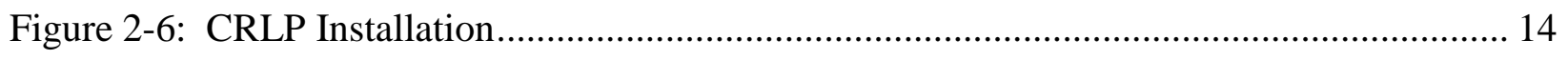

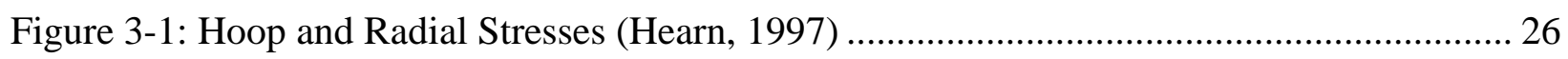

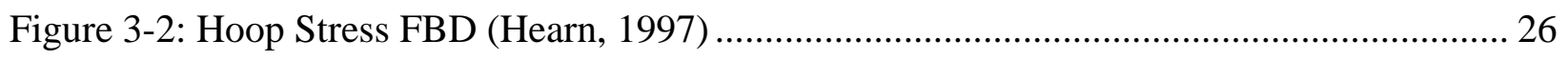

Figure 3-3: Strain Energy Density Diagram (Vadlamani, 2007) .................................................. 38

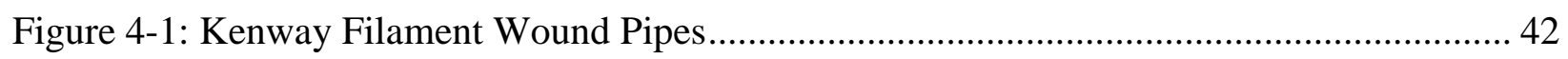

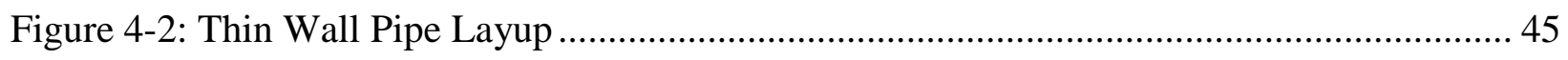

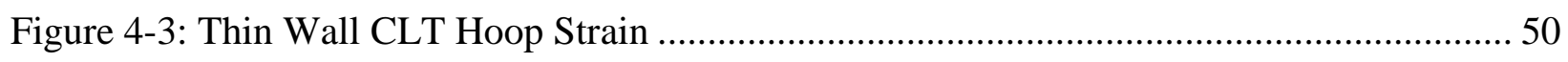

Figure 4-4: Thin Wall CLT Longitudinal Strain...................................................................... 50

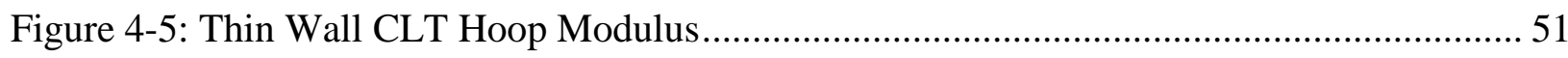

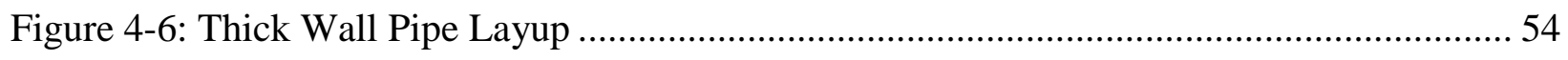

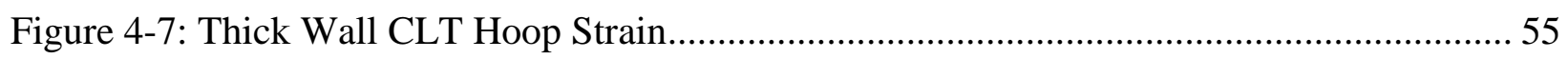

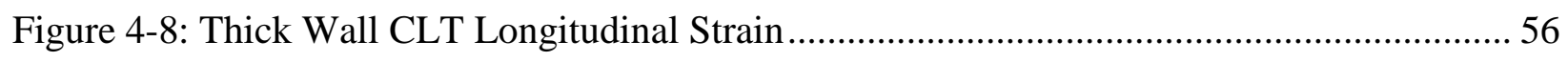

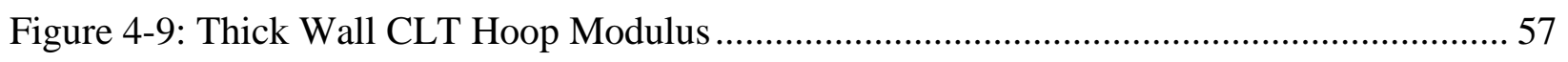

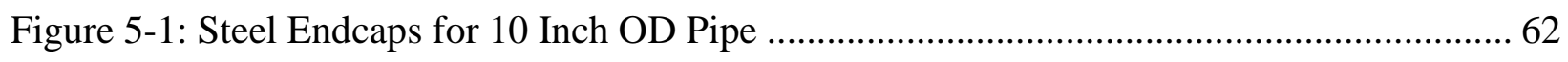

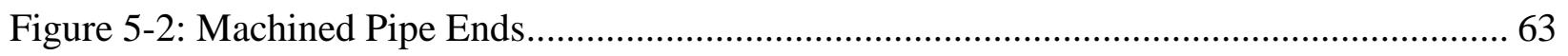

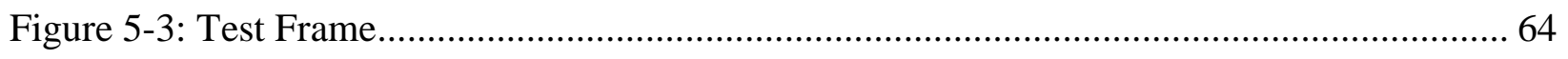

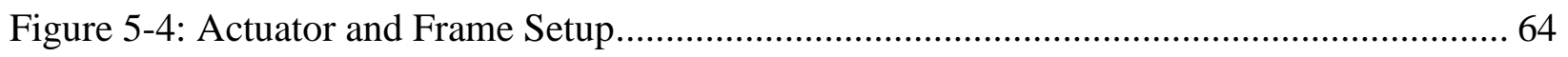




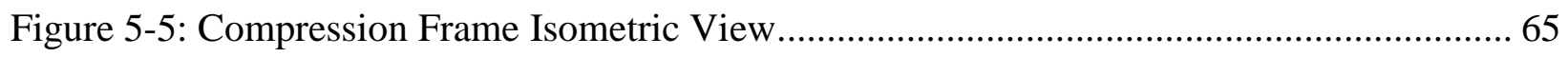

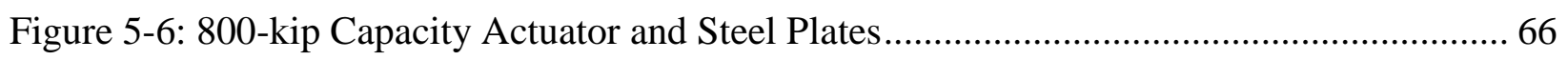

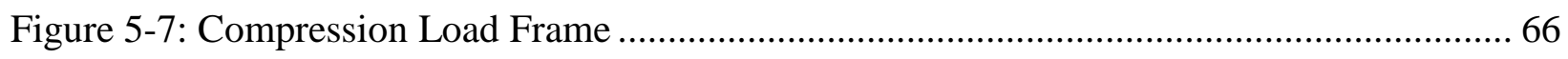

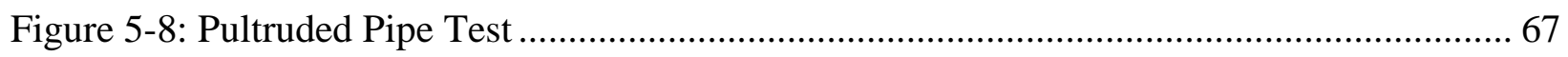

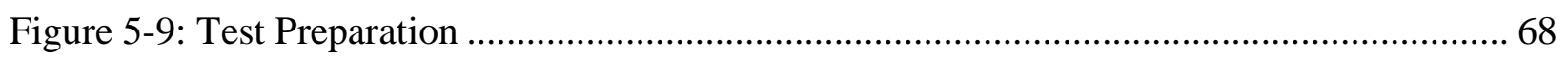

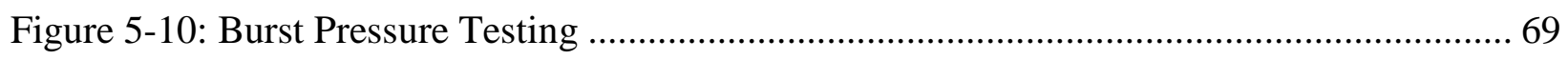

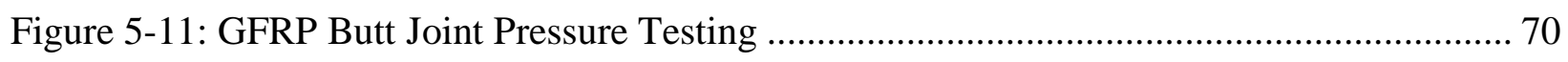

Figure 5-12: Pultruded Pipe Failure Modes.............................................................................. 71

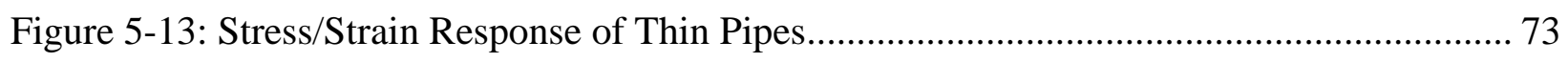

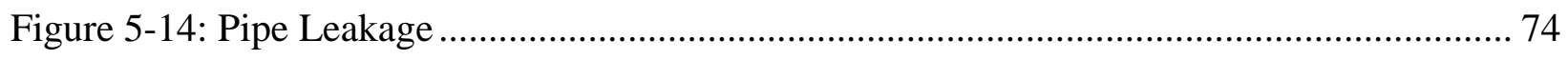

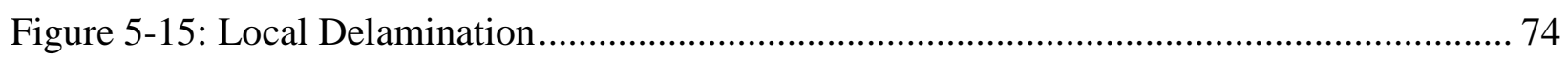

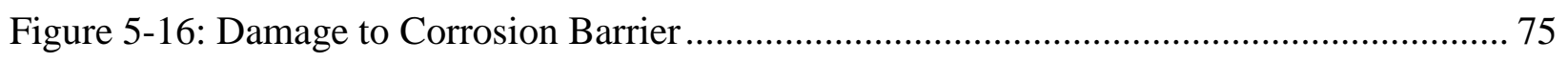

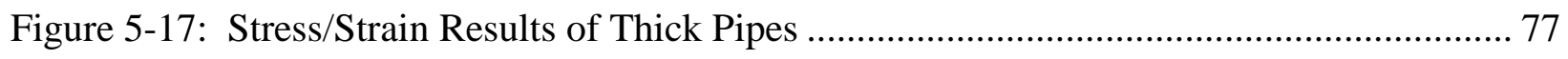

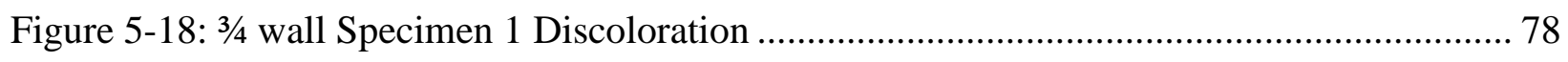

Figure 5-19: Exterior Damage of Thick Walled Pipes .............................................................. 78

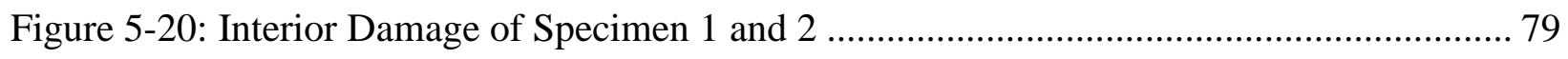

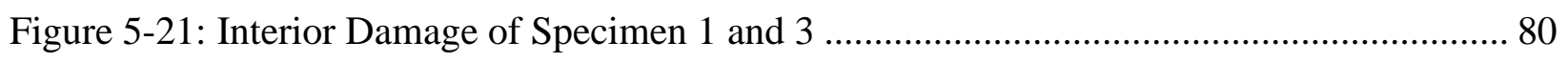

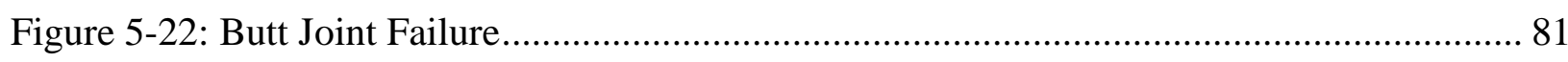

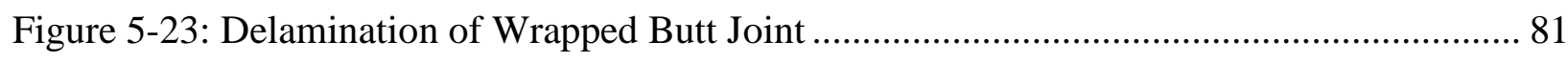

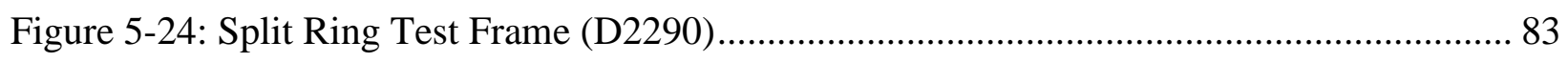

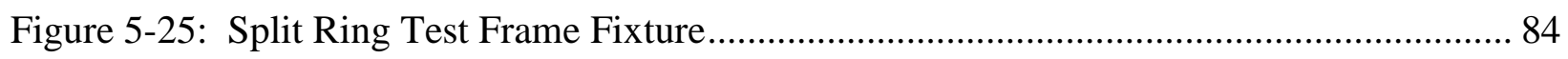

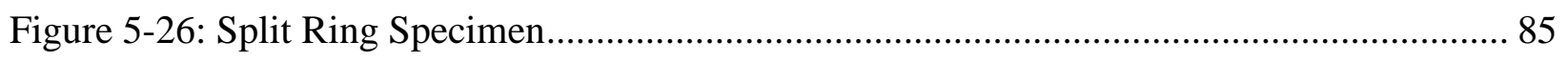

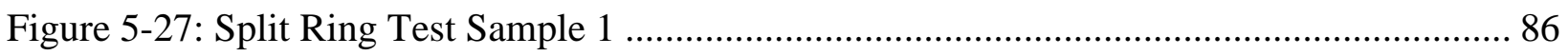


Figure 5-28: Split Ring Hoop Stress/Strain Response ................................................... 88

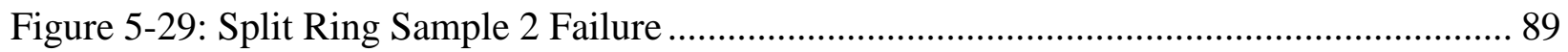

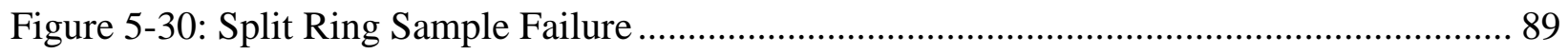

Figure 6-1: Thin Walled Stress/Strain Comparison........................................................... 96

Figure 6-2: Thick Wall Stress/Strain Comparison ............................................................. 99

Figure 6-3: Stress/Strain Comparison for HBP and Split Ring Tests ................................. 103

Figure 6-4: Hoop Stress/Strain Comparison .................................................................. 104

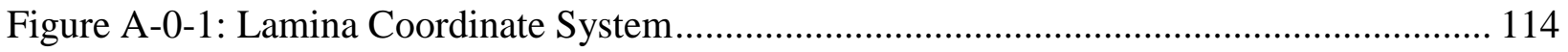

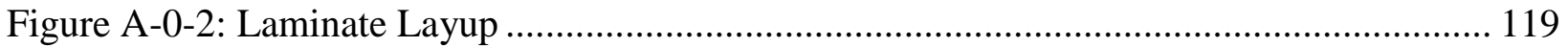




\section{LIST OF TABLES}

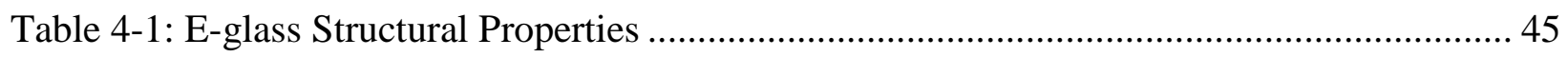

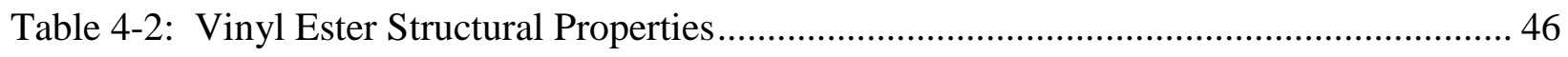

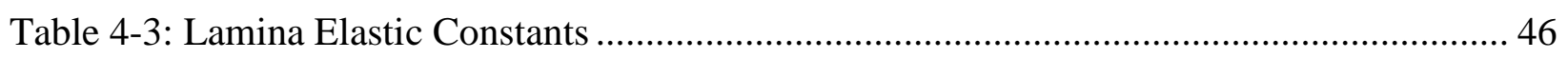

Table 5-1: Pultruded Specimen Results .................................................................................... 71

Table 5-2: Hydrostatic Pressure Test Results- FW Thin Wall ................................................... 72

Table 5-3: Hydrostatic Pressure Test Results-FW Thick Wall........................................................ 76

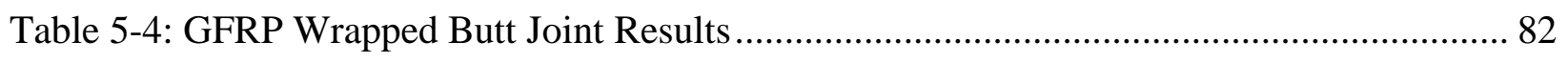

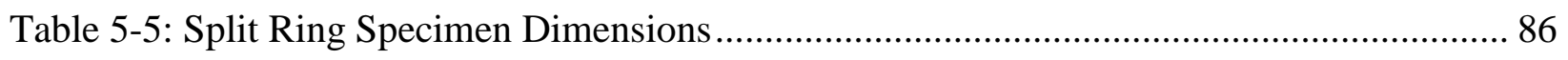

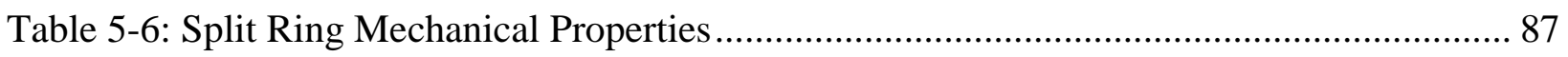

Table 6-1: Thin Wall vs Lame's Hoop Stresses ....................................................................... 92

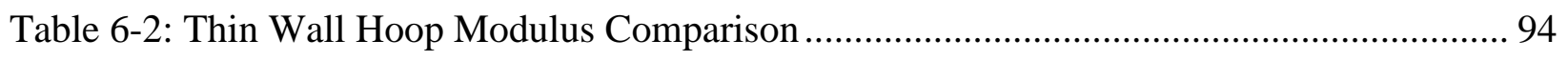

Table 6-3: Thin Wall Longitudinal Strain Comparison ................................................................. 97

Table 6-4: Thick-Walled Hoop Modulus Comparison ................................................................. 98

Table 6-5: Thick Wall Longitudinal Strain Comparison .......................................................... 100

Table 6-6: Elastic Modulus Comparison for Thin Wall Pipes.................................................... 102 


\section{CHAPTER 1 INTRODUCTION}

\subsection{Background}

The United States currently has 2.5 million miles of natural gas pipelines. These lines consist of nearly 2.15 million miles of small diameter distribution lines (less than 8 inches) and 300,000 miles of large diameter, transmission lines (up to 48 inches) (GangaRao, 2011). Distribution lines traditionally operate at pressures lower than 60 psi. Transmission lines traditionally operate at pressures lower than 1,000 psi, but can operate as pressures as high as 1,500 psi (Argonne National Laboratory, 2007). Operating pressures within pipelines are limited by material strengths, inner diameter, and wall thickness. Thus, lines operating at pressures between 1,000 and 1,500 must have small diameter (less than 24 inches) and have relatively thick walls (1 to 1.5 inches thick).

As demands for higher volumes of natural gas have increased over the last few years, so have the demands for pipelines with the capacity to support higher pressures within larger diameter lines. Future pipelines will need to withstand pressures (>3000 psi) for a service life of 50 years. While steel pipelines have performed admirably throughout the last century, the material has numerous limitations, which bring its effectiveness as a pipeline material of the future into question. Steel is currently an acceptable material for use in natural gas pipelines, but it is susceptible to corrosion, hydrogen embrittlement, and damage due to temperature, $\mathrm{pH}$, and moisture variations. (Laney, 2002) Furthermore, the material's yield strength, ranging from 36,000 to 50,000 psi depending on grade, suggests that steel pipelines cannot reasonably be expected to operate at pressures above 2,000 psi. Due to these concerns, steel pipe may not be the primary structural material employed in future pipelines. 
One such material that could meets these future needs is fiber reinforced polymer (FRP) composite. FRP is a broad term used to describe many unique subcategories. Two of the most common variants of FRP are carbon reinforced polymer composite (CFRP) and glass reinforced polymer composite (GFRP). GFRP is cheaper than CFRP and more flexible. In comparison to steel, GFRP is roughly the same cost per linear foot of pipe. Therefore, GFRP is the focus of this report and the focus of the testing conducted between fall of 2016 and summer 2018.

GFRP has many additional advantages over steel, but is not as well understood or characterized in terms of failure mechanisms and strengths. It has a higher strength to weight ratio, better resistance to corrosion and hydrogen embrittlement, better resistance to moisture variation, and better resistance to temperature variation between -50 and 140 degrees Fahrenheit. Furthermore, GFRP has nearly the same failure strength as steel, suggesting that it may be advantages in terms of strength, cost, and service life.

Significant barriers must be overcome if GFRP is ever to be implemented in natural gas transmission lines in a meaningful way. Most importantly, failure strengths and failure mechanisms must be determined. Since GFRP pipes could vary greatly in terms of constituent materials, structural properties, and cross section properties, generalized analytical models capable of predicting elastic and failure behaviors must be produced. Once failure strengths (i.e. burst pressures) are determined, allowable design pressures, service life, and design details of GFRP pipe can be determined and produced. Therefore, this report discusses several methods based on mechanics of materials, and experimental evaluations (GangaRao, 2016). 


\subsection{Objectives}

- To determine whether GFRP is a viable alternative/complementary material to steel for application in high pressure transmission lines

- To explore the current and future needs of the oil and gas industry as pertaining to high pressure transmission lines through literature review

- To review current applications of Glass Fiber Reinforced Polymer Composite in the oil and natural gas industries, as well as applications in piping, and pressure vessels through literature review

- To determine burst pressures of GFRP pipes through analytical and experimental methods

- To evaluate elastic behavior of filament wound pipes through classical lamination theory

- To pressure test GFRP pipes and joints

- To correlate experimental data with current FRP mechanics theories and to propose analytical methods through which composite pipe failure pressures may be predicted

\subsection{Scope}

- Hydrostatic Burst Pressure Testing of GFRP pipe and joints to 6,000 psi

- Analysis of GFRP pipe and joint behavior

- Prediction of mechanical behavior and failure mechanisms

- Characterization of GFRP pipes and joints

\subsection{Report Organization}

- Chapter 2 is a literature review 
- Chapter 3 examines thin and thick wall pipe analysis

- Chapter 4 discusses pressure vessel and pipe analysis through the ASME BPVC

- Chapter 5 explains the pressure testing experiments conducted

- Chapter 6 provides analysis of behavior prediction and evaluations methods

- Chapter 7 discusses conclusions and future work. 


\section{CHAPTER 2 LITERATURE REVIEW}

This chapter focuses on a review of composite materials and their implementation in the field of natural gas. Furthermore, this chapter provides background information pertaining to the natural gas industry and pipeline systems and materials.

\subsection{Pipeline Materials and Systems}

Pipelines can be constructed from numerous materials. They are primarily constructed from steel or high-density polyethylene (HDPE), but can also be constructed from cast iron, copper, and fiber reinforced composite. The material chosen for a given pipeline is determined primarily by the intended system of transportation. To explore these materials, the various pipeline systems first need to be understood. Natural gas is transported from the well to residential, commercial, or industrial consumers through three district pipeline systems. Figure 2-1 below provides a diagram detailing the various systems. The three main systems, gathering lines, transmission lines, and distribution lines, will each be discussed in depth (Laney, 2002).

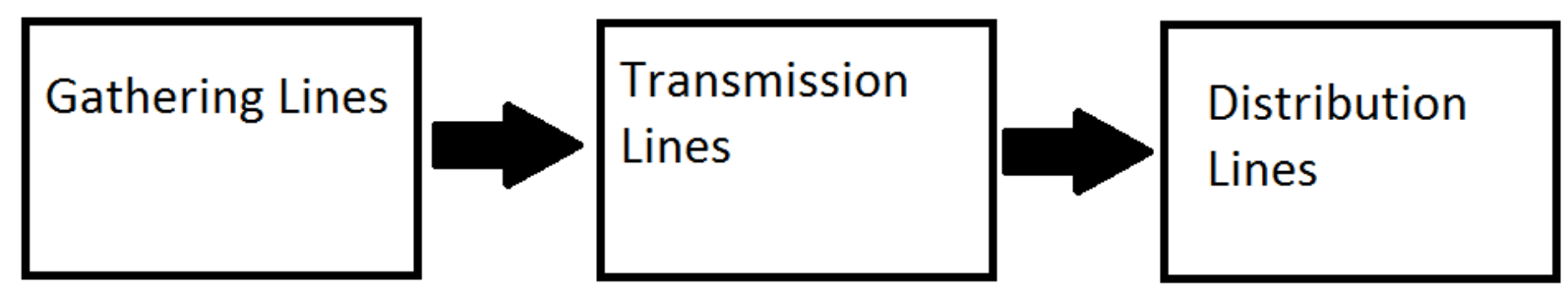

Figure 2-1: Pipeline Systems

\subsubsection{Gathering Lines}

Once natural gas is extracted from the ground through flowlines, it is transported to a processing plant through gathering lines. These lines are small in diameter (less than 9 inches) 
generally and operate under low pressures. These low pressures coupled with small diameters ensure that circumferential (hoop) and longitudinal stresses remain small. Since stresses are kept small, numerous materials provide adequate strength. Steel, HDPE, and FRP composite pipe are all used in this capacity (U.S. Energy Information Administration, n.d.). Over the last 20 years, 1200 miles of composite have been installed for this role. These lines range from 1.25 to 9 inches in diameter and can operate at pressures up to 2,500 psi. These pipes are known as spoolable composites, and produced in coils up to six miles in length (Walsh, 2017).

Many companies are starting to offer these small-diameter, high-pressure pipe products. Fiberspar, for example, supplies small diameter ( 2.5 to $6.5 \mathrm{inch}$ ), spoolable pipe for pressures as high as 2500 psi. These pipes (Figure 2-2) have an inner thermoplastic layer, a bonding layer, a glass fiber/epoxy structural layer, and thermoplastic wearing layers (Fiberspar, 2010).

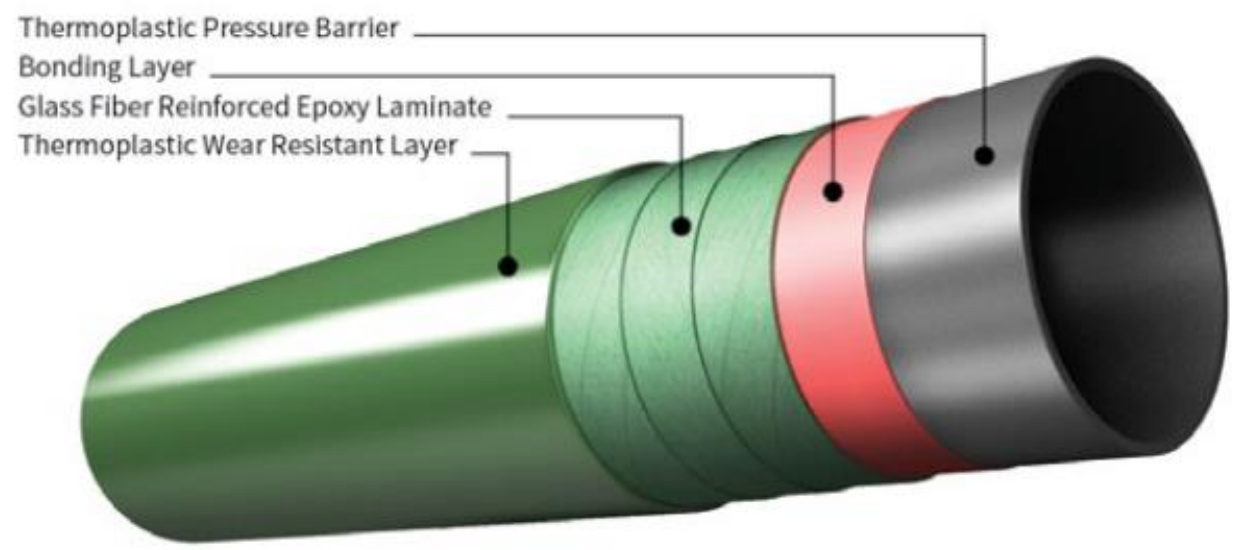

Figure 2-2: Spoolable Line Pipe 


\subsubsection{Transmission Lines}

Once the natural gas is processed, it is ready to be transported long distances to distribution plants all across the country. During this process, transmission lines, also known as trunk lines, transport the material. These lines are much larger and operate under much higher pressures (Guo \& Ghalambor, 2012). These lines can be as large as 48 inches in diameter and operate at pressures near 1,500 psi. However, the majority of transmission lines operate at 200 to 500 psi. The large diameters and high pressures create high hoop and longitudinal stresses; requiring that these lines be constructed from high strength materials. Traditionally, structural steel has been the only material used for transmission lines. Recently, FRP composite has been employed in this capacity. However, the implementation is still limited. For many reasons, composite pipe has not yet been widely adopted for this application (Laney, 2002). FRP application in transmission lines is covered in greater depth in section 2.3.4.

\subsubsection{Distribution Lines}

Once the material reaches the distribution plants, it is then transported to the customer through distribution lines. These lines are also small diameter and operate under pressures lower than 60 psi in general. Once again, the coupling of low pressure and small diameter means that stresses are very low. Since the stresses are low in these lines, they are primarily constructed of high density Polyethylene (HDPE) or other plastics. These lines are usually buried in the ground; a fact that makes steel impractical for this application, since it corrodes rapidly when interacting with moisture in soil. (U.S. Energy Information Administration, n.d.).

Together these gathering, transmission, and distribution systems account for the majority of pipeline mileage in the US. These lines are constructed primarily of steel (transmission) and HDPE (gathering and distribution). As has been seen, these materials do have disadvantages. Steel is 
susceptible to corrosion when in contact with water and soil. Plastic does not have sufficient strength to operate under high pressures. Furthermore, buried pipe is not intrinsically locatable. This has led to many accidents and challenges for contractors and others working near buried gas lines. As has been mentioned previously, fiber reinforced polymer composite materials may be provide advantages over these traditional steel and plastic materials.

\subsection{Composite Materials}

\subsubsection{Constituent Materials}

A composite is a material comprised of two or more components, a reinforcing material (fabric) and a binder material (organic polymer resins), which are bound together by chemical reaction to create specific material properties. After curing, these components act a one, bound together in a combination of fiber and matrix. The characteristics of the composite cannot be achieved by either of the components separately. Thus, composites refers to a wide range of fabric and resin combinations. Each combination offers different advantages and disadvantages. Two common fabrics are glass (grades Electrical (E) and Structural (S)) and carbon. These fabrics are combined with resins, such as Vinyl Ester, Polyurethane, polyester, Epoxy, and Phenolic, to create structural members such as WF shapes, angles, tubes and pipe. Due to advanced manufacturing processes, these materials are becoming cost effective, viable alternatives to wood, concrete, and steel in civil engineering infrastructure. (GangaRao, Taly, \& Vijay, 2007).

\subsubsection{Combined Properties}

Glass Fiber Reinforced Polymer (GFRP) and Carbon Fiber Reinforced Polymer (CFRP), common types of FRP, have many properties that make FRP a favorable material for use in natural 
gas and hazardous liquid pipeline industries. GFRP and CFRP differ in a few ways to steel individually; hence the two materials are compared to steel separately. CFRP has a higher strength to weight to ratio (60-300ksi rupture strength, specific gravity of 1.8$)$, higher stiffness, lower corrosiveness, lower thermal and electrical conductivity, and less susceptibility to hydrogen embrittlement. However, CFRP pipe costs far more per linear foot; so much so that CFRP has been mainly employed by the airline industry, where weight saving is more important than material cost saving.

In comparing GFRP with steel, GFRP is similar in cost per linear foot of pipe, but significantly lower in stiffness. However, GFRP is similar in failure strength to steel and has better resistance to thermal and electrical conductivity, better resistance to hydrogen embrittlement, and better resistance to variations of moisture and $\mathrm{pH}$. Apart from differences in strength and stiffness, GFRP and CFPR differ in that carbon is more electrically conductive (Mallick, 2007). Additionally, the two materials differ in underground detectability. While buried underground, CFRP and steel are detectable by ground penetrating radar. GFRP and plastic pipes are not, unless modified with resins or other detectable materials. Thus, inherent undetectability of GFRP is also under investigation by researchers at the WVU-CFC.

In summary, FRP pipe has the potential to be a replacement of steel as the primary structural material used in gas transmission lines. The key concern with FRP implementation in natural gas lines is cost. CFRP may have many advantages over steel, but is not as economically feasibility. Furthermore, GFRP has better corrosion resistance, and electrical resistance than CFRP. For these two reasons, GFRP is the primary material under consideration for implementation in natural gas lines. 


\subsubsection{Manufacturing Processes}

One key aspect pertaining to GFRP strength and stiffness is the fabrication process. The fabric process and consequent section architecture are crucial in determining the strength of a pipe. Carbon and Glass FRP members can be manufactured through a number of different manual and automated processes, such as hand lay-up, pultrusion, filament winding, resin transfer molding, injection molding, and compression molding (GangaRao, Taly, \& Vijay, 2007). Research during this phase of the project has primarily utilized the pultrusion and filament winding processes for the fabrication of GPFP and CFPR pipes. Additionally, the pull winding process, which is a combination of the pultrusion and filament winding processes, is being evaluated for this sort of application, because of the amenability to mass production of high-grade composite parts. While pipes have not yet been fabricated through the pull-winding process, the process is very promising for application in pressurized pipes. The polymer composite pipes have contained constituent materials such as glass or carbon fabrics and binders such as vinyl ester, polyurethane, and epoxy resins. At this point, the manufacturing has been done by Creative Pultrusion Inc. and Kenway Corporation, a recently acquired subsidiary of Creative Pultrusion Inc., Alum Bank, PA.

\subsubsection{Pultrusion}

The process of pultrusion involves the pulling of fiber fabrics or fiber rovings through a resin bath and heated die. The fibers are first pulled from creels and run through a resin bath, which could contain wetting agents, fillers, catalysts, accelerators, and pigments. These admixtures affect the curing time, cost, and structural properties of pultruded sections. The fibers are then shaped into a variety of sections by guides along the length of the machine. The fibers are then fed into the heated die, which initiates the cure. After passing through the die, the section is allowed to cool and then is cut to specified length. The output of a pultrusion machine is between 1 and 5 linear 
feet per minute; however, the throughput speed can be higher depending on the shape being pulled through the die. (GangaRao, Taly, \& Vijay, 2007). Figure 2-3 below shows a typical configuration of a pultrusion machine.

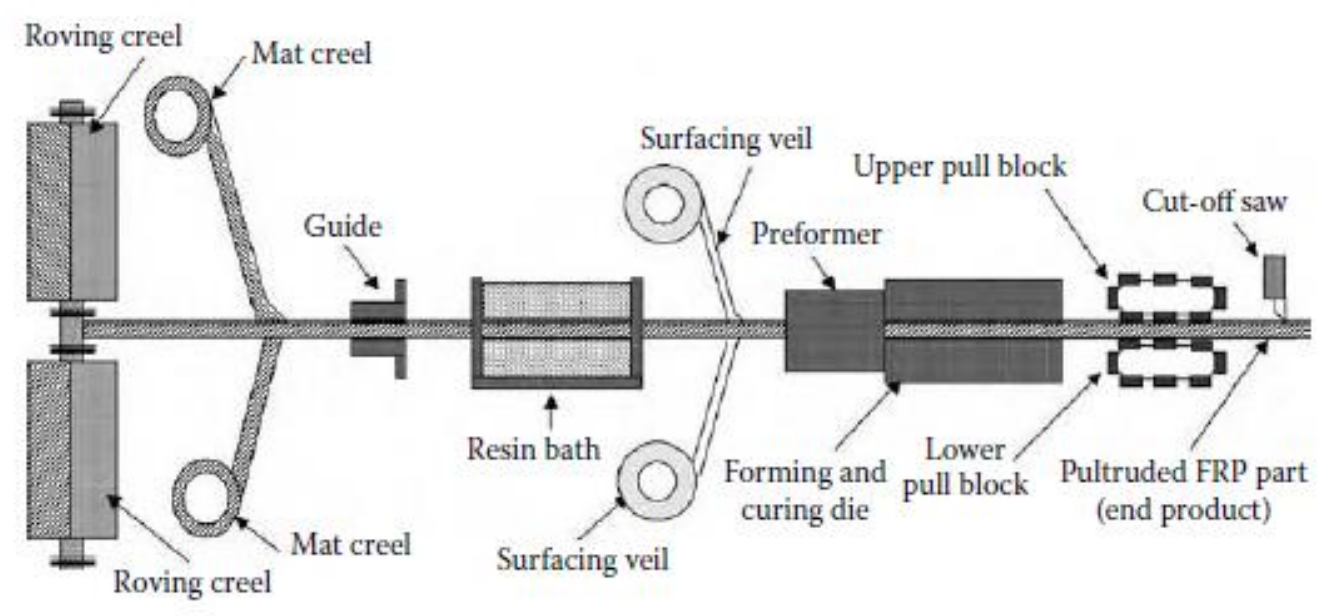

Figure 2-3: Pultrusion Machine

\subsubsection{Filament Winding}

The process of filament winding involves the wrapping of many continuous strands of fiber or continuous mats around a mandrel. The mandrel is made from one of several different materials, such as plywood, aluminum, and steel. Once again, the fibers are wetted by being run through a resin bath prior to wrapping around the mandrel. The member is then cured through the application of heat lamps or by being fed through an oven. Once curing is initiated, shrink-wraps are employed to minimize voids. Shrink-wrap is a flexible, thin plastic that is wrapped around the specimen to provide uniform pressure. The wrap is removed after the curing has finished (GangaRao, Taly, \& Vijay, 2007). A key advantage provided by filament winding is the ability of the process to produce a fabric architecture with fibers running in the magic angle. That is to say that fibers run at plus/minus 54 degrees. This angle is the optimum angle for pipes because the combination of hoop 
stress and longitudinal stress, created by internal pressures, act along this angle. Figure 2-4 below shows a typical filament-winding machine (GangaRao, Taly, \& Vijay, 2007).

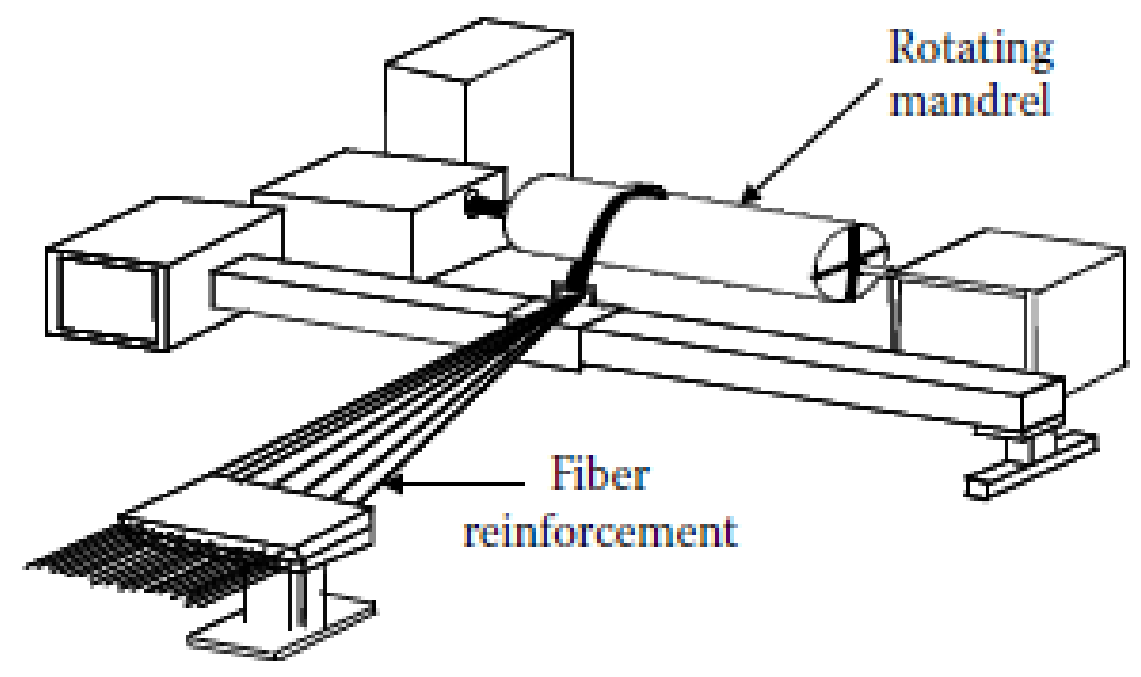

Figure 2-4: Filament Winding Machine

\subsubsection{Pull-Winding}

The process of pull winding is a combination of filament winding and pultrusion. A pull winding machine is essentially a pultrusion machine with an independent winding unit. This process allows for the manufacturing of high performance composite tubes. The technique intersperses longitudinal reinforcement layers with helically wound layers. As the longitudinal fibers are pulled through the resin bath towards the die, two winding heads, working in opposite directions, wrap the dry hoop fibers at the desired angle. Once the member is wrapped, it is pulled into the die. The pull-winding process is the best process for the fabrication of pipes designed to resists high internal pressures. It combines the advantages of the previously mentioned processes (Akovali, 2001). 


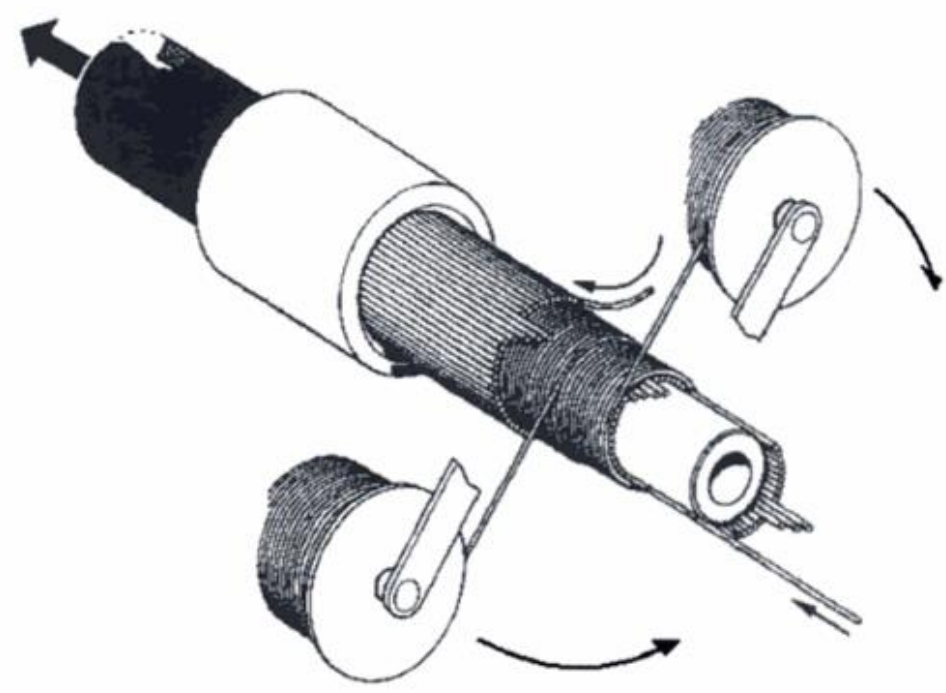

Figure 2-5: Pull-Winding Machine

\subsection{Composite Applications in Materials Transportation}

The many advantages associated with composites, mentioned in the previous sections, have allowed the material to be implemented in many aspects of materials transportation. Specifically, the fact composite can be fabricated through so many different processes means that it can be implemented in unique situations. Composite materials can be implemented in new construction projects, systems, and machines, as well as in rehabilitation projects. A few of the most common FRP applications in the field of materials transportation are discussed in the following sections. These applications demonstrate the potential of FRP composite systems, but also reveal significant knowledge gaps that must be overcome.

\subsubsection{Composite Reinforced Line Pipe}

One application involving the use of FRP in the rehabilitation is known as Composite Reinforced Line Pipe (CRLP). In this application, layers of glass fabric and resin are wrapped around the outside of steel pipe to add strength and corrosion resistance. The wrappings can be 
used to rehabilitate damaged line pipe, and can be used increase the strengths and operating pressures of an undamaged segment of pipe. Depending on the magnitudes of the principle stresses, wraps of unidirectional or bidirectional fabrics can be applied circumferentially or at an angle to add hoop and longitudinal strength (Deaton, 2015). Composite reinforced pipe is a practical alternative to high strength steels because it has thinner walls, strength similar to that of high strength steel, weighs less, and can be joined on-site more rapidly and affordably.

In 2002, TransCanada installed seven sections of 40 foot long CRLP in the Western Alberta. The line has is comprised of X-70 steel is wrapped with an outer layer of isopolyester resin/glass fiber composite. The total thickness of the wall is 0.461 inches. The line operates at 960 psi, but can operate at pressures as high as 1,260 psi. The figure below shows the installation of the pipe sections in the field.
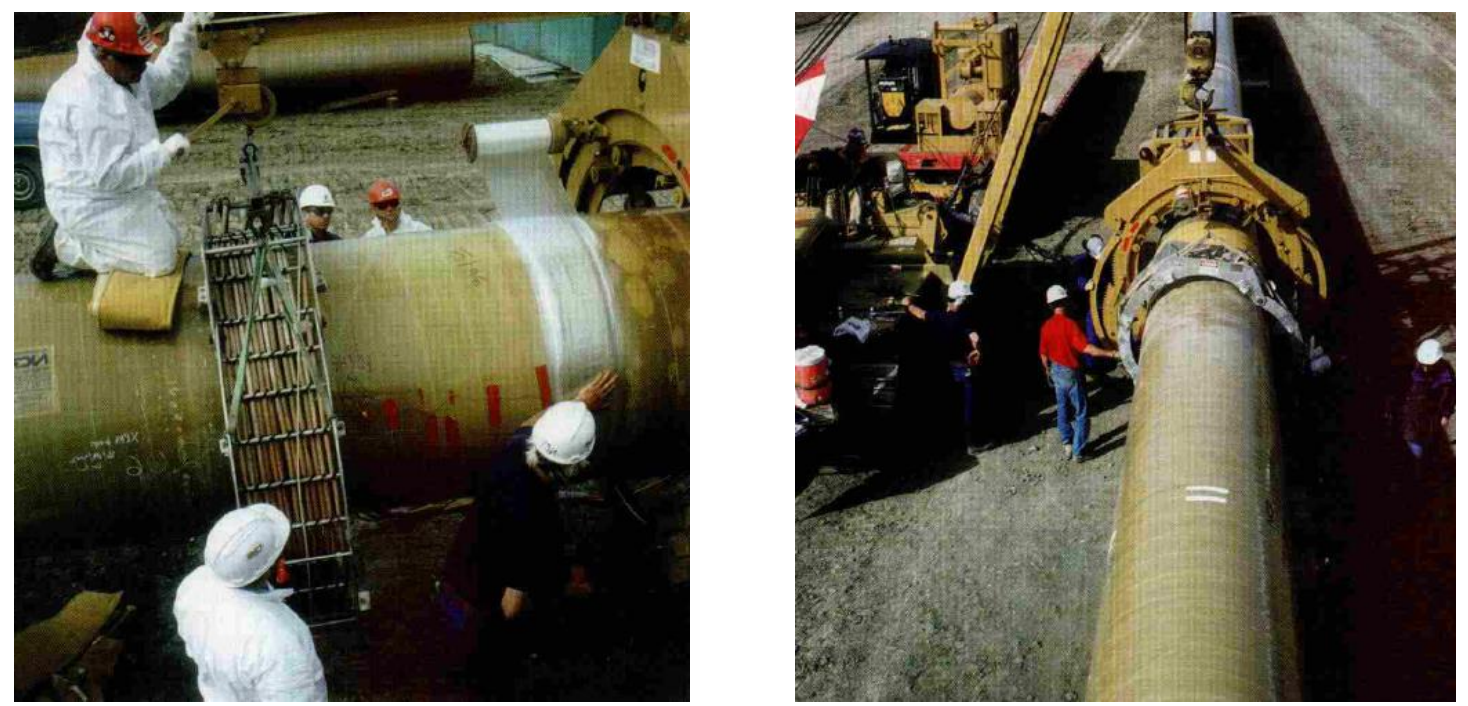

Figure 2-6: CRLP Installation

Pipe sections are wrapped in a manufacturing plant and shipped to the construction site with six inches exposed steel at each end. The pipes are welled similarly to traditional steel pipes, except that the welds are not required to have ultra - high strength. Technicians then use a portable field-wrapping machine to apply the pre-impregnated fibers around the joint. Once the wrap is 
placed, heat is applied, causing the resin to cure. The high tensile strength of the composite (120,000-140,000 psi) enables the composite to provide significant hoop strength at the joint as well as fracture resistance. Furthermore, the composite provides greater resistance to corrosion, crack propagation, and abrasion.

While CRLP does not necessarily result in increased maximum allowing operational pressure, these pipes are 30 to 40 percenter lighter, have 40 percent less weld time, 50 percent less weld area, and a total pipeline cost reduction between 4 and 12 percent (Oil and Gas Journal, 2003).

\subsubsection{FRP Pressure Vessels}

Another application of FRP is found in pressure vessels. FRP is a great material for storage tanks because of its high strength to weight ratio, high resistance to corrosion, and ability to be tailor- made for specific applications. Pressure vessel design and behavior are very similar to pipe design and behavior. Therefore, the study of FRP pressure vessels is a stepping-stone towards the study of FRP pipe. The key difference being that pressure vessels are significantly smaller. These pressure vessels fall into one of five categories, all including various proportions of steel, plastic, and composite. The vessels showing the most promise are type five. Type five vessels are fabricated purely from composite materials (Legault, 2012). The earliest of these vessels were made through hand layup as layers were applied to molds. More recently, these vessels have been manufactured through filament winding. This is largely due to the fact that filament winding provides for more accurate fabrication and results in better structural integrity (Helms, 2010). At this point, pressure vessels are being manufactured and certified for use under pressures as high as $35 \mathrm{MPa}$ (5000 psi). This means that the burst pressures are actually much higher. Because of this fact, the use of FRP in high-pressure pipes looks very promising. Pressure vessel design and 
fabrication are addressed in the ASME Boiler and Pressure Vessel Code (BPVC). Section X of this standard addressed the pure composite pressure vessels (type 5) (ASME, 2015).

\subsubsection{Hydrogen Transportation Lines}

In addition to the 2.15 million miles of natural gas lines, there are currently about 1,200 miles of hydrogen transportation lines in the United States. These lines are the most efficient way to transport large quantities of hydrogen. While hydrogen is not used for energy production as much as oil or natural gas, it is of interest because it is an ideal energy source. That is to say, it is available, clean, convenient, and free from foreign control. A major issue related to the use of hydrogen is pipeline degradation. When transported through steel pipes, hydrogen damages the steel through a process known as hydrogen embrittlement. This embrittlement can lead to leakage or failure of pipelines. Factors that influence embrittlement are pressure, concentration, purity, temperature, and metal composition. Therefore, transportation of hydrogen through steel pipeline is not practical on a large scale (Gupta, 2008).

Because of these issues related to hydrogen embrittlement, the Department of Energy has been evaluating FRP as a potential alternative material. At a glance, FRP is a feasible alternative in terms of cost, weight, strength, and resistance to hydrogen embrittlement. However, there is still much research, development, and implementation to be done in this field (Gupta, 2008). Researchers at Oak Ridge National Laboratory have identified several key knowledge gaps which must be addressed; evaluation of pipeline materials for hydrogen compatibility, development of plastic liners with low permeability, and enhancement of materials performance (Smith, Eberle, \& Frame, 2005). 


\subsubsection{Transmission Lines}

Although composite pipes, combined with corrosion resistant inner liners, have been widely implemented over the last 20 years for use in gathering lines, composite pipes have yet to be widely accepted for use in large diameter, high-pressure transmission lines. However, notable advancements towards that end have been made in the last few years. In addition to the spoolable composite pipes mentioned in section 2.1.1, rigid, larger diameter (8 to 18 inch), high strength composite pipes have recently been introduced for application in transmission lines. This material consists of a thermoplastic or thermoset liner, which is wrapped with continuous glass, carbon, or aramid fibers, and saturated with thermosetting resins. The inner liners have high corrosion resistance and range from 0.08 to 0.2 inches thick. The thickness of the reinforcing layer is based on required operating pressure. These larger diameter lines operate at pressures up to $450 \mathrm{psi}$ (Walsh, 2017).

A key issue associated with the application of these rigid FRP pipes in transmission lines is the determination of pipe strength, failure pressures, and pressure ratings. Currently, accurate numeric and analytical models for these properties do not exist. Thus, extensive laboratory testing is required for the determination of these properties. This is due to absence of tests for strength determination (section 2.4 expounds on these standards in more detail). While it is possible to extensively and affordably test small diameter composite pipe products under low pressures, composite materials cannot be commonly employed in high-pressure transmission lines until this sort of testing can be easily and affordably achieved for larger diameter pipes. This pressure testing is time consuming, expensive, and challenging to conduct. Alternative methods for the determination of pipe strength must be discovered so that the design process is not contingent upon pressure testing. 
This concept represents a critical knowledge gap and key research topic. Thus, in-depth composite pipe characterization must be accomplished through experimental, analytical, and numerical methods. Failure modes and failure progression in composite pipes must be identified and understood thoroughly, so that models for failure predictions can be created. Equations must be developed to account for a range of different fiber and resin types, fiber volume fractions, and fiber architectures. The effects of these aspects of composite pipes are not yet fully understood. Thus, predictive equations for elastic behavior and failure behavior are nothing more than approximations at this point. For these reasons and more, composite pipes have yet to be widely employed in transmission lines.

\subsection{FRP Line Pipe Standards and Specifications}

\subsubsection{Design Process Overview}

Natural gas pipelines are regulated by Title 49 of the Code of Federal Regulations (CFR) section 192, "Transportation of Natural or Other Gas by Pipeline: Minimum Federal Safety Standards." This standard references around 20 other standards, pulling from the American Society of Mechanical Engineers (ASME), the American Society for testing and Materials (ASTM) and the American Petroleum Institute (API). These 20 standards discuss, design, fabrication, construction, operation, and inspection of GFRP pipelines.

The standards of prime importance in section 192 are API 15HR "Specification for High Pressure Fiberglas Line Pipe," API 15LR "Specification for Low Pressure Fiberglass Line Pipe," and API 15S "Specification for Spoolable Reinforced Plastic Line Pipe. These standards apply to both oil and natural gas pipelines. The design chapters of these specifications refer heavily to ASTM D2992 "Standard Practice for Obtaining Hydrostatic or Pressure Design Basis for 
Fiberglass (Glass-Fiber-Reinforced Thermosetting-Resin) Pipe and Fittings (Title 49 CFR 192, 2018)." This standard discusses test methods used for the determination of the hydrostatic design basis (HDB) and the pressure design basis (PDB) which are employed in the determination of pressure rating for a pipeline.

The HDB and PDB are based on the long-term hydrostatic strength (LTHS). The LTHS is the stress at which a sample, will fail after a given amount of time or number of cycles. The determination of long-term strength of a pipe is critical because composite pipes exhibit time dependent creep behavior (due to sustained or cyclic loads). Thus, sustained low pressures (greater approximately 30 percent of the burst pressures) can still cause failure, given enough time. Once long term strength is determined, design engineers can determine safe operational pressures so that sustained and cyclic pressures do not cause creep or fatigue failures during the life of a pipeline.

The HDB and PDB are multiplied by a service factor(less than 1.0), which is determined by the design engineer, to determine the hydrostatic design stress (HDS) and pressure rating (PR). The hydrostatic design stress is defined as the "estimated max hoop tensile stress in the wall of the pipe due to internal hydrostatic pressure that can applied with a high degree of certainty that failure of the pipe will not occur." The pressure rating is defined as "The pressure which can be exerted continuously with a high degree of certainty that failure of the piping component will not occur." Therefore, a pipe operating under the pressure rating exhibits the hydrostatic design stress in the wall of the pipe in the hoop direction. Since pressure and hoop stress are linearly related, the two methods result in the same pressure rating. Therefore, it is simple to keep testing and design values in terms of pressures. Thus, ASTM D2992 provides an experimental method for the determination of pressure rating for composite pipes (ASTM, 2012). 


\subsubsection{Hydrostatic Test Methods}

Therefore, the first step in the composite pipeline design process is the determination of long-term strength of the pipes. ASTM D2992 describes two methods for the determination of long-term strength. The first test method (Procedure A) describes cyclic pressure testing (low pressure), and is outlined in ASTM D2143. The second test method (Procedure B) involves static testing (low pressure), and is outlined in ASTM D1598. Both of these tests rely on a significant numbers of time-consuming pressure tests and regression analyses to determine the long-term strength of a particular pipe size and fiber/resin architecture. Method A requires 18 samples to be cyclically tested with samples failing between 1,000 and 15,000,000 cycles. Method B requires 18 samples to be statically tested with samples failing within 10 to 10,000 hours. (ASTM, 2012).

By contrast, it is also possible to determine long-term behavior through hydrostatic burst pressure testing (HBP). Several researchers have noted that the creep threshold for composites is around 30 to 35 percent of the ultimate stress (Vadlamani, 2007). Since hydrostatic burst pressure testing yields a failure strength, the long-term creep failure strength can be approximated as 30 percent of the burst pressure. Based on approximated strengths, smaller numbers of cyclic or static tests can be conducted as proof tests.

Methods for burst pressure testing are established in ASTM D1599, "Standard Test Method for Resistance to Short-Time Hydraulic Pressure of Plastic Pipe, Tubing, and Fittings." The standard applies to reinforced thermoplastic and thermosetting resin pipes. The specification has two procedures. Procedure A is used for determination of failure mode, while produce B is used for minimum required burst pressure evaluation. Specimens with diameters greater than 6 inches shall be at least 30 inches in length. The tests should be conducted within 60 to 70 seconds. Any 
passage of water through the walls of the pipe, rapid loss of pressure, or pressure loss resulting in discontinuous loading shall constitute failure (ASTM, 2014).

\subsubsection{Test Fixtures}

While the hydrostatic test standards provide a helpful framework for testing, strength analysis, and regression of composite pipes, the standards say little about the details of the test methodology. Little is said in regards to frames and loading systems. One of the most important comments in the standard relates to end closures. Two types of end closures are discussed, freeend or restrained-end. End closures are also referred to as endcaps. Section 3.1 of ASTM D2992 defines these terms in more detail.

A. Free-End Closure- A sealing device fastened to the end of the pipe. Internal pressure in these systems produces hoop and longitudinal stresses. While a small magnitude of radial stress also exists within the walls of the pipe, these stresses are neglected for thin-walled pipes.

B. Restrained-End Closure-A sealing device or mechanism that relies on a rod through the specimen or an external frame to resist the end thrust exerted on the endcaps.

The different sealing mechanisms producing different loadings in the walls of the pipe. The free-end systems experience two-dimensional plane stress (hoop and longitudinal), while restrained-end closures experience one-dimensional stress (hoop). Thus, the type of end closure influences the elastic behavior in the walls of the pipe. ASTM D 1599 comments (Note 6) that hoop stresses at failure in the walls of thermoplastic pipes are 11 percent higher for restrained-end systems than free-end systems. This observation is critical because pipes in service (under internal pressure) may experience both longitudinal and hoop stresses (similar to the free-end test system). Therefore, a design based on the hoop failure strength of a restrained-end system would not 
necessarily be conservative for an actual pipe in service. The standard does not comment on the differences in effect for thermoset pipes, reinforced thermoplastic pipes, or reinforced thermoset pipes. However, the fact that testing method can heavily influence pressures should be accounted for in testing and analysis. At this point, standards have not addressed differences in effects of the end-closures for reinforced pipes.

\subsection{Conclusion}

This literature review has shown why investigation of GFRP composite pipe should be conducted and why GFRP could be a viable material for implementation in hydrogen and natural gas high-pressure transmission lines. Several barriers must be overcome if composites are to be widely accepted for this application. Furthermore, the research must demonstrate composite pipe to be superior to steel if it is to become the material of choice for transmission lines. The research must demonstrate that composite pipes and joints can withstand higher pressures, for longer periods, under the same forces of moisture and $\mathrm{pH}$ corrosion. The cost and complexity of the material suggests that there is very little to be gained by demonstrating that composite is comparable to steel. Research must demonstrate that composite pipes are superior (Laney, 2002). Specifically, research must produce models which can accurately predict elastic behavior and failure behavior.

The following chapters discuss the steps taken over the last months by the West Virginia University Constructed Facilities Center (WVU CFC), in partnership with the Department of Transportation (DOT) and the Pipeline Hazardous Materials Safety Administration (PHMSA), to contribute towards this needed research. Chapter 3 discusses the methods through which pipes are 
evaluated during elastic loading. Chapters 4 and 5 present different failure prediction models and lab tests through which pipe strengths can be predicted. 


\section{CHAPTER 3 MECHANICAL BEHAVIOR OF THIN WALLED}

\section{CYCLINDERS}

This chapter focuses on the review and development of the mechanics of materials based approach through which composite laminate pipes are evaluated in terms of elastic behavior. The in-plane and out-of-plane stresses and strains are evaluated in the layers of a laminate using the principles of the classical lamination theory (CLT). The secondary purpose is to discuss methods used to predict composite pipe burst pressures using CLT. These predictions are produced through stress/strain analysis, coupled with material failure strengths and failure criteria. Since steel pipes are predominately used in the natural gas industry, composite pipe behavior is developed in relation to steel pipe behavior. Furthermore, many of the mechanics principles employed in steel pipes can be used to approximate mechanics principles in composite pipes.

\subsection{Thin Walled Isotropic Cylinders}

The majority of pipes used in the natural gas industry have relatively thin walls in comparison to the inner diameter of the pipes. This is done for the sake of economy. The cost and weight of pipe are the two main factors employed in determination of a pipe's wall thickness and operational pressure. That is to say, design engineers must work within a pipeline project budget by determining the minimum required thickness of wall for a given operational pressure, for a specified service life. This steel pipeline design process requires the implementation of mechanics principles, which are well established and simplified in design codes (Guo \& Ghalambor, 2012). Unfortunately, mechanical evaluations of pipes are carried out differently for isotropic and orthotropic (composite) materials; the latter (composites) being the more computationally rigorous of the two. While composite pipe analysis differs significantly from steel pipe analysis, many of 
the distinctions, assumptions, and principles used for steel pipe can be applied to composites pipe. Therefore, the analysis of steel pipe is briefly addressed in the next sections, so that composite mechanics can then be discussed.

\subsubsection{Assumptions}

A key distinction is that the pipe is thin walled. A thin walled pipe is defined as having a radius to thickness ratio greater than 10 (although the number is disputed and may actually be 20) (Boresi \& Schmidt, 2005), (Hearn, 1997). In these circumstances, the relatively thin wall allows engineers to make simplified free body diagrams, which are used to determine the loads and stress that act within a pipe. This distinction of radius to wall thickness allows for the following assumptions.

The first assumption, for thin walled steel pipes, is that stresses and strains in the radial direction are neglected. The magnitude of the radial stress is very small in comparison to the high magnitudes of the longitudinal and circumferential stresses. This assumption is key because it allows designers to treat the state of stresses as plane stress, thus removing the third dimension of analysis (two dimensional stresses and strains).

The second assumption for thin-walled steel pipes is that the longitudinal and circumferential stresses are taken as an average constant across the thickness of the pipe. In reality, the circumferential stresses in isotropic pipes wall vary, with the highest magnitude of stress at the inside edge of the wall (for pipes under internal pressure) (Hearn, 1997). Furthermore, stresses in composite materials vary layer to layer, depending on the orientation of the fiber architecture. Figure 3-1 provides a visual representation of the actual radial and hoop distributions in the walls of a steel pipe. 


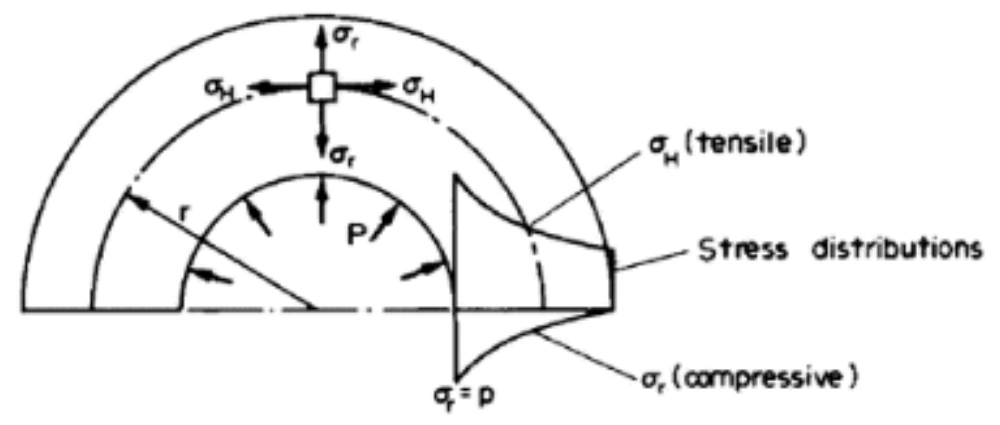

Figure 3-1: Hoop and Radial Stresses (Hearn, 1997)

\subsubsection{Determination of Stresses}

Based on these assumptions and appropriate free body diagrams, equations for both the longitudinal and hoop stresses can be determined. These equations are the basis of pipe strength evaluations. Figure 3-2 shows the free body diagram used in the determination of average circumferential (hoop) stresses and longitudinal stresses.

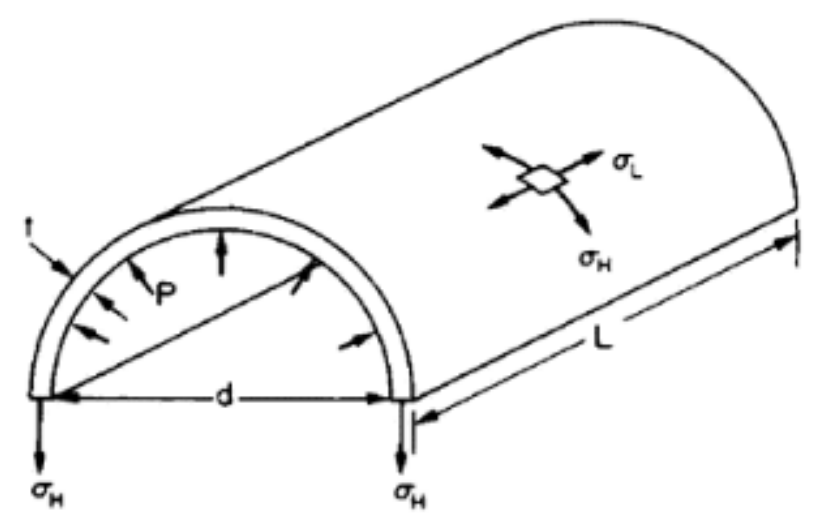

Figure 3-2: Hoop Stress FBD (Hearn, 1997)

Based on the free body diagram, the internal force on half of the pipe is a product of pressure, length, and inner diameter. The area resisting this force a product of thickness, and length. Thus, per laws of force equilibrium, the hoop (circumferential) stress is given by Equation 3-1. P is the internal pressure, $r$ is the radius, and $t$ is the wall thickness of the pipe. 


$$
\sigma_{\text {Hoop }}=\frac{(p * r)}{t}
$$

The longitudinal stresses are determined in similar fashion. Considering force equilibrium in the longitudinal direction, the longitudinal stress is given by Equation 3-2. Again, $\mathrm{p}$ is the internal pressure, $\mathrm{r}$ is the radius, and $\mathrm{t}$ is the thickness. As can be seen, the longitudinal stresses are half that of the hoop stresses.

$$
\sigma_{\text {Longitudinal }}=\frac{(p * r)}{2 * t}
$$

Based on the free body diagram, the principal stresses are then $\sigma_{H}=\sigma_{1}, \sigma_{L}=\sigma_{2}, \sigma_{r}=$ 0. Since these stresses are oriented in the principal directions, no shear stresses exist.

By contrast, general equations for stresses in thick-walled cylinders have also be produced. These equations were produced by Lamé, and can apply to thin-walled cylinders or thick-walled cylinders. In the general solutions, the effects of radial stress are not neglected. Furthermore, hoop stress are not assumed to be uniform. The equations for hoop, longitudinal, and radials stress are given by Equations 3-3 to 3-5, where $\mathrm{p}$ is the internal pressure, $\mathrm{r}_{\mathrm{i}}$ is the inner radius, $\mathrm{r}_{\mathrm{o}}$ is the outer radius, and $r$ is the location of the stress across the wall thickness. $r$ ranges from $r_{i}$ to $r_{o}$.

$$
\begin{gathered}
\sigma_{\text {Hoop }}=\frac{\left(p * r_{i}^{2}\right)}{\left(r_{o}^{2}-r_{i}^{2}\right)}+\frac{\left(r_{i}^{2} * r_{o}^{2} *(-p)\right)}{\left(r^{2} *\left(r_{o}^{2}-r_{i}^{2}\right)\right.} \\
\sigma_{\text {Longitduinal }}=\frac{p * r_{i}^{2}}{r_{o}^{2}-r_{i}^{2}}
\end{gathered}
$$




$$
\sigma_{\text {Radial }}=\frac{\left(p * r_{i}^{2}\right)}{\left(r_{o}^{2}-r_{i}^{2}\right)}-\frac{\left(r_{i}^{2} * r_{o}^{2} *(-p)\right)}{\left(r^{2} *\left(r_{o}^{2}-r_{i}^{2}\right)\right.}
$$

Once principal stresses are determined by either the thin wall equations or Lamé's equations, the principles of Hooke's law can be applied to determine strains. From there, failure theories/criterion can be applied to predict failure pressures (Hearn, 1997). Since, isotropic and orthotropic materials differ greatly in elastic behavior and failure behavior; the two materials are henceforth addressed separately. Focus is placed on orthotropic materials.

\subsection{Thin Walled Composite Cylinders}

As has been discussed above, the mechanics principles, distinctions, and assumptions that apply to isotropic materials can also be applied orthotropic (quasi-isotropic) materials. Based on Equations 3-1 and 3-2, pipes under internal pressure experience a magnitude of hoop stress that is twice that of the longitudinal stress. Therefore, isotropic materials are twice as strong as necessary in the longitudinal direction. By contrast, composite pipes can be manufactured in a way that allows fibers to be wound at an angle (cross ply architecture), satisfying the strength requirements of the hoop and longitudinal stresses and reducing the required material and wall thickness.

Many researchers have sought to determine the optimal winding angle analytical and experimentally. The value has been found to be 54.7 degrees. This is known as the "magic angle." Since filament winding allows for tremendous precision in fiber placement, composite pipes, intended for pressurized applications, are commonly fabricated through this process. These pipes include corrosion barriers (resin rich zones with veils, and quasi-isotropic chopped-strand mats), 
and layers of unidirectional fibers wound at \pm 55 degrees. The winding angle may differ slightly depending on a manufacturer's capabilities (Xia, Takayangagi, \& Kemmochi, 2001).

\subsection{Elastic Behavior of Orthotropic Materials}

\subsubsection{Classical Lamination Theory (CLT)}

Composite materials are a nonhomogeneous combination of constituent materials and fall into the category of orthotropic materials. In contrast to isotropic materials, orthotropic materials have three planes of symmetry; meaning the material has nine independent elastic constants. The elastic constants are E11, E22, E33, G12, G13, G23, v12, v13, and v23. However, unidirectional fiber composites fall into a category known as special orthotropic/transversely isotropic. For this special case, reinforcing fibers run in either the $0^{\circ}$ or $90^{\circ}$ directions. In this case, there are only

five elastic constants. The constants are E11, E22, v12, v21, and G12. Therefore, the endeavor of design engineers is to evaluate laminated composites as a stacked sequence of unidirectional laminae. This analysis process, known as classical lamination theory (CLT), is key to understanding the behavior of composite pipes under pressure. This process is detailed in appendix A. This section discusses the loading vector and the elastic analysis for pipes under internal pressure.

\subsubsection{Loading Vector}

The classical lamination theory (for plane stress) does not account for strains in the $\mathrm{Z}$ direction. The theory can be employed to consider radial effects; however, the process is complex. Therefore, the thin-walled pipe assumption of negligible radial stresses is crucial in this elastic analysis. This assumption allows design engineers to make the critical simplification that the wall 
of a pipe behaves like a laminated plate under plane stress. Therefore, the hoop stress is related to the force resultant in the $\mathrm{Y}$ direction and the longitudinal stress is related to the force resultant in the $\mathrm{X}$ direction. These force resultants (force per unit width) are not the same as the longitudinal and hoop stresses (force per area) because the force resultants are taken per unit width. That is to say, stresses are integrated over the area so that the units match. Therefore, the thickness $(\mathrm{t})$ of the wall is neglected in the force resultants. The loading vector for composite pipes under pressure only has two non-zero terms $\left(\mathrm{N}_{\mathrm{x}}\right.$ and $\mathrm{N}_{\mathrm{y}}$ ), given in equations 3-6 and 3-7 (ASME, 2015).

$$
\begin{aligned}
& N_{X}=\frac{P * r}{2} \\
& N_{y}=p * r
\end{aligned}
$$

The relationship between in-plane forces $\left(N_{x}, N_{y}, N_{y x}\right)$ moments $\left(M_{x}, M_{y}, M_{y x}\right)$, and midplane strains $\left(\epsilon_{\mathrm{x}}{ }^{0}, \epsilon_{\mathrm{y}}{ }^{0}, \epsilon_{\mathrm{xy}}{ }^{0}\right)$ mid-plane curvatures $\left(\mathrm{k}_{\mathrm{x}}, \mathrm{k}_{\mathrm{y}}, \mathrm{k}_{\mathrm{xy}}\right)$ is given by Equation 3-8. This equation is the key equation employed in the determination of strains within a laminate. Stresses and strains in the fiber directions and global can all be determined from this base equation. Thus, this equation is the basis for elastic analysis for stresses and strains in the walls of thin walled pipes. More details for this theory is provided in appendix A.

$$
\left[\begin{array}{c}
\epsilon_{x}^{0} \\
\epsilon_{y}^{0} \\
\epsilon_{x y}^{0} \\
k_{x} \\
k_{y} \\
k_{x y}
\end{array}\right]=\left[\begin{array}{llllll}
A_{11} & A_{12} & A_{16} & B_{11} & B_{12} & B_{16} \\
A_{12} & A_{22} & A_{26} & B_{12} & B_{22} & B_{26} \\
A_{16} & A_{26} & A_{66} & B_{16} & B_{26} & B_{66} \\
B_{11} & B_{12} & B_{16} & D_{11} & D_{12} & D_{16} \\
B_{12} & B_{22} & B_{26} & D_{12} & D_{22} & D_{26} \\
B_{16} & B_{26} & B_{66} & D_{16} & D_{26} & D_{66}
\end{array}\right]^{-1} \quad *\left[\begin{array}{c}
N_{x} \\
N_{y} \\
N_{x y} \\
M_{x} \\
M_{y} \\
M_{x y}
\end{array}\right]
$$


Equation 3-8 only holds true for elastic zone of composite materials. Once failure progression is initiated, non-linear behavior is initiated, the extent of which is based on a number of factors.

\subsection{Failure Behavior of Composite Materials}

Failure behavior of composites materials is very challenging to predict. The issue arises from the fact that damage onset does not necessarily coincide with final failure. Laminate failure is a result of progressive failure of the fibers, matrix, and laminae. The usual progression initiates with matrix micro-cracking and then moves to matrix cracking, fiber pull-out, layer delamination, and finally fiber breakages. However, failure does not necessarily include all of these various modes. Some of the factors that complicate the analysis are fabric architecture, fiber volume fraction, voids, manufacturing process, material types and properties, and loading type, and nonhomogenous stresses within a laminate. (Barbero, 1998).

There are many equations, criteria, and analysis methods for the prediction of laminate failure. These methods rely on mechanics principles, empirical equations, and experimental data. In the literature, several different methods have been proposed for the failure predictions of composite pipes under internal pressure. Two specific methods were explored in this research. The first is known as the ply-discount failure progression. Researchers have applied this process to predict failure pressures of composites pipes with varying degrees of success. The second method evaluated is known as the strain energy density failure theory. This theory was proposed by Vadlamani and GangaRao. This theory has shown reliability in predicting failure of coupons of varying fabric architecture under tension and bending up to 90 percent of ultimate stress. However, this theory has not yet been evaluated for reliability in predicting burst pressures of GFRP pipes. 


\subsubsection{General Comments on Failure Progression}

Failure prediction methods involve two major processes, in addition to the process of classical lamination theory. The first process employed in failure prediction is the process through which stress distributions, failure modes, and failure strengths are evaluated. This can be done through the study of micromechanics, in which the individual constituents within a lamina are evaluated for stress distribution and failure modes. However, most researchers simplify the analysis by viewing each ply as a homogenous material. Therefore, the details of damage initiation and propagation are captured by the overall failure strengths of the laminae. In this simplified method, failure stresses are then viewed as the ultimate stresses of the individual laminae (Barbero, 1998).

The second process employed in failure progression analysis is a stiffness degradation method. Stiffness degradation refers to process through which the properties of a failed lamina are accounted for in terms of the effect on the other laminae. Therefore, the degradation rules determine the redistribution of stresses in a laminate once a lamina has failed. There are currently two popular degradation methods, the continuum discount method and the ply discount method (Knight, 2008).

\subsubsection{Failure Progression through Ply Discount Methods}

As has been discussed previously, classical lamination theory is employed to determine stresses and strains within the layers of a laminate within the elastic loading zone. This theory does not apply once failure is initiated. Therefore, the first step in failure prediction to determine the load (internal pressure within pipes) at which the first lamina fails. This point is known as first ply failure (FPF). Since most laminates have complex fabric architectures (usually of unidirectional 
fabrics oriented at various angles), failure criteria and strength properties of unidirectional laminae are employed in this task (Kassapoglou, 2010).

\subsubsection{Unidirectional Strength Properties}

Since the onset and progression of damage for the constituent materials is accounted for in the failure strength of a homogenous (assumed) lamina, failure strengths for various failure modes must be determined for a given lamina. Failure criteria for plane stress conditions require

five strength values to be determined. The five values are mentioned below (Kassapoglou, 2010).

1. Longitudinal Tensile Strength(Xt)

2. Transverse Tensile Strength(Yt)

3. Longitudinal Compressive Strength(Xc)

4. Transverse Compressive Strength(Yc)

5. In-Plane Shear Strength(S)

These strength properties are determined through ASTM coupon tests of unidirectional laminates. The primary standards for these tests are D3039, D3410, and D5379. Since empirical relationships are not reliably accurate, these test methods are the most accurate way to determine failure strengths of these unidirectional laminates.

\subsubsection{Failure Criteria}

Many failure criteria for plane stress conditions have been proposed for orthotropic materials. Failure criteria are empirical equations with parameters that are fitted to experimental data. The criteria are applied to determine whether individual laminae have failed. These criteria are used because it is very challenging to produce accurate models for the complex failure modes 
of micro-cracking, cracking, and delamination. These criteria do not capture the actual failure modes. A few of the most commonly used criteria are mentioned below (Barbero, 1998).

\section{Maximum Stress Criterion}

2. Maximum Strain Criterion

\section{Tsai-Hill Criterion}

\section{Tsai-Wu Criterion}

The maximum stress and strain criteria differentiate between fiber failure modes and matrix failure modes. However, neither considers the interaction of the various stress components. The methods evaluate stresses and strains for failure examination one at a time. Since there is no interaction of stress or strain components, the two methods are not conservative if several components of stress are near the failure strengths in those directions.

To account for this issue, quadratic failure criteria were developed. These criteria provide failure envelopes for failure evaluation. The Tsai-Hill and the Tsai-Wu theories fall into this category. A general 2-D representation of the quadratic criterion is provided in Equation 3-9.

$$
\begin{gathered}
F_{11} * \sigma_{1}^{2}+F_{22} * \sigma_{2}^{2}+F_{66} * \tau_{12}^{2}+F_{1} * \sigma_{1}+F_{2} * \sigma_{2}+2 * F_{12} * \sigma_{1} \\
* \sigma_{2}
\end{gathered}
$$

The Tsai-Hill theory works well for situations where the tensile and compressive strengths are the same, but provides poor results when the values differ from one another. The Tsai-Wu criteria was developed to overcome this insufficiency. Furthermore, the Tsai-Wu failure criteria has been proven to result in relatively accurate burst pressure failure predictions. For these reasons, the Tsai-Wu was the primary failure criteria investigated in this research. The major shortcoming of the Tsai-Hill and Tsai-Wu criteria is that no differentiation of fiber failure and 
matrix failure is made (Barbero, 1998). It has yet to be seen whether this shortcoming significantly effects burst pressure predictions for composite pipes.

\subsubsection{Tsai-Wu Failure Criteria}

Substitution of specific terms for the Tsai-Wu criteria, the general quadratic criterion becomes Equation 3-10.

$$
\begin{aligned}
\left(\frac{1}{X_{t} * X_{C}}\right) * & \sigma_{1}^{2}+\left(\frac{1}{Y_{t} * Y_{C}}\right) * \sigma_{2}^{2}+\frac{1}{S^{2}} * \tau_{12}^{2}+\left(\frac{1}{X_{t}}-\frac{1}{X_{c}}\right) * \sigma_{1} \\
& +\left(\frac{1}{Y_{t}}-\frac{1}{Y_{c}}\right) * \sigma_{2}+\frac{\left(\sigma_{1} * \sigma_{2}\right)}{2 * \sqrt{\left(X_{t} * X_{C}\right) *\left(Y_{t} * Y_{C}\right)}}=1
\end{aligned}
$$

Where:

$\sigma_{1}=$ Stress in the fiber direction

$\sigma_{2}=$ Stress Transverse to the fiber direction

$\tau_{12}=$ In plane shear stress

Therefore, when the left side of the equation is equal to one, the lamina has failed. The positive root of the quadratic equation is known as the strength ratio(R). The strength ratio is a measure of the remaining strength in a lamina under stress; meaning that the strength ratio is similar to a factor of safety. When $\mathrm{R}=1$ the lamina has failed. Therefore, the failure load of a lamina is a product of the applied load and the strength ratio. The quadratic equation with $\mathrm{R}$ substituted is given by Equation 3-11 and the strength ratio is given by Equation 3-13 (Kuo-Shih \& Tsai, 1996).

$$
\mathrm{R}=-\left(\frac{\mathrm{b}}{2 * \mathrm{a}}\right)+\sqrt{\left(\frac{\mathrm{b}}{2 * \mathrm{a}}\right)^{2}+\left(\frac{1}{\mathrm{a}}\right)}
$$




$$
\begin{gathered}
a * R^{2}+b * R-1=0 \\
R=-\left(\frac{b}{2 * a}\right)+\sqrt{\left(\frac{b}{2 * a}\right)^{2}+\left(\frac{1}{a}\right)}
\end{gathered}
$$

Where:

$$
\begin{aligned}
& \mathrm{a}=\left(\frac{1}{X_{t} * X_{C}}\right) * \sigma_{1}^{2}+\left(\frac{1}{Y_{t} * Y_{C}}\right) * \sigma_{2}^{2}+\frac{\left(\sigma_{1} * \sigma_{2}\right)}{2 * \sqrt{\left(X_{t} * X_{C}\right) *\left(Y_{t} * Y_{C}\right)}}+\frac{1}{S^{2}} * \tau_{12}^{2} \\
& \mathrm{~b}=\left(\frac{1}{\mathrm{X}_{\mathrm{t}}}-\frac{1}{\mathrm{X}_{\mathrm{c}}}\right) * \sigma_{1}+\left(\frac{1}{\mathrm{Y}_{\mathrm{t}}}-\frac{1}{\mathrm{Y}_{\mathrm{c}}}\right) * \sigma_{2}
\end{aligned}
$$

\subsubsection{Ply Degradation}

Once first ply failure has occurred, the stiffness properties of the failed ply must be reduced, and the analysis must be iterated a second time. This must be done because stresses redistribute to other plies, causing further failure. When the strength ratio of the last ply equals one, catastrophic failure of the laminate occurs. The final failure of a pipe under internal pressure occurs at the last ply failure. Thus, the progression of damage is simulated by the progressive reduction of the stiffness of each of the laminae until all the laminae have reached failure stresses (Roy \& Tsai, 1988)).

Ply degradation methodology is still an active area of research. Several different authors have proposed methods to reduce specific elements of the transformed stiffness matrices. The challenge is to reduce the stiffness matrices in a way that matches the actual failure mode. Since the Tsai-Wu criteria does not differentiate between failure modes, it is challenging to identify an accurate method of degradation. 


\subsubsection{Failure Progression Steps}

In conclusion, failure prediction is an analytical process involving several steps. The process involves several strength properties, empirical equations, and mechanics principles. The process is outlined by the following steps (Kassapoglou, 2010):

1. Apply lamination theory to determine strains and stresses within each of the laminae

2. Determine strength properties of unidirectional composite coupons

3. Apply a failure criterion to determine strength factors and the load at first ply failure

4. Apply rules of degradation to failed plies

5. Iterated lamination theory to determine stress redistribution and further ply failure

6. Iterate until last ply failure (burst Pressure prediction) is reached.

\subsubsection{Strain Energy Density Failure Theory}

It is apparent that failure prediction through lamination theory and failure criteria involves rigorous manufacturing, testing, and computation. Therefore, a second theory, known as the Strain Energy density theory was investigated. This theory was proposed by Vadlamani, Skehar, and GangaRao in 2007. The theory applies to vinyl ester/glass coupons of varying fiber architectures, loaded under tension or bending. The purpose of this investigation was to determine if the strain energy density failure model could be applied to predict elastic behavior and failure predictions for pipes under internal pressure.

\subsubsection{Strain Energy Density Model}

The strain energy density is a common principle discussed in structural mechanics. The strain energy density is defined as the stored energy in a material that has deformed under load. Strain energy density is indicative of material behavior because it is stored energy per unit volume. 
Thus, strain energy density is not related to specimen dimensions. Strain energy density is taken as the area under the stress strain curve. Therefore, strain energy density can be determined from mechanical testing of coupons, where $\mathrm{E}$, the points of slope change $\left(\mathrm{K}_{1}\right.$ and $\left.\mathrm{K}_{2}\right)$, and the slope ratio can be determined. Figure 3-3 shows a bi-linear strain energy density diagram (Vadlamani, 2007).

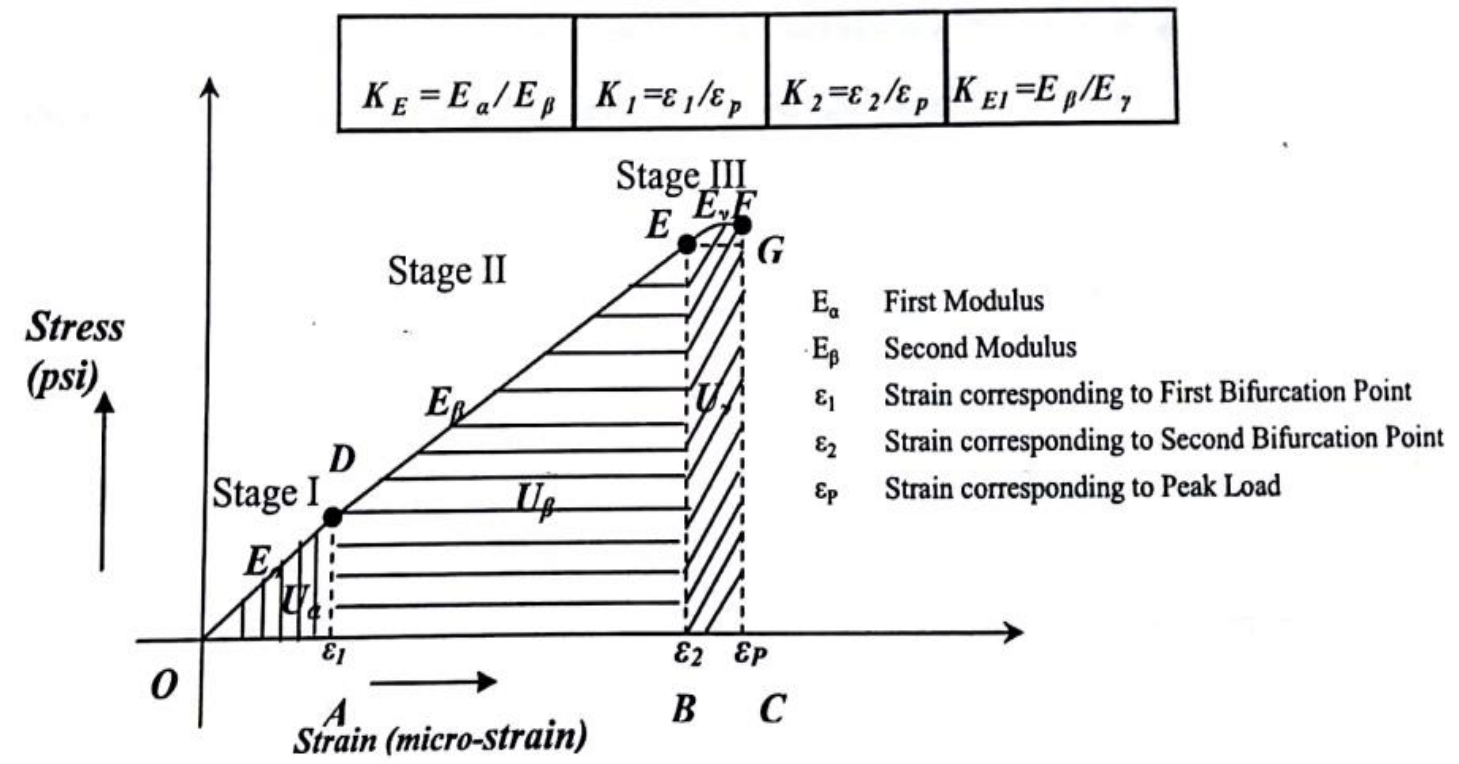

Figure 3-3: Strain Energy Density Diagram (Vadlamani, 2007)

Based on the stress/strain curve, the axial for a member under tension strain energy is given by Equation 3-13. However, as can be seen, the model must be slightly altered to account for changes in modulus as load increases. Therefore, the strain energy density of a composite coupon is considered the be the sum of $\mathrm{U}_{\alpha}, \mathrm{U}_{\beta}, \mathrm{U}_{\gamma}$, the three areas shown in Figure 3-3.

$$
U_{T}=\frac{P^{2} * L}{2 * A * E}
$$

Where:

P=Applied Load

L=length

$A=$ Area of the specimen 
$\mathrm{E}=$ Elastic Modulus in the direction of loading.

The research conducted by Vadlamani evaluated five different symmetric laminates (unidirectional, bidirectional, tri-directional with CSM, quadri-directional with CSM, and quadridirectional without CSM), manufactured using compression molding, tested under tension and bending. The results of the study showed the laminates to exhibit bi-linear stress strain response, up to 90 percent of the ultimate stress. The points of slope change $\left(K_{1}\right.$ and $\left.K_{2}\right)$ were found to be .34 and .87 . The slope ratio $\left(\mathrm{K}_{\mathrm{E} 1}\right)$ between the two linear portions of the stress strain curve was found to be 1.2 (Vadlamani, 2007).

Therefore, investigation during this research project sought to determine whether the stress strain curve of a composite pipe, under internal pressure would fit this model. This evaluation was based on the principle that the hoop stress in the wall of the pipe exhibits similar to that of a coupon under tensile loading. This evaluation was done through an evaluation known as split ring testing. The testing methodology, results, and comparisons are presented in the next chapters.

\subsection{Conclusions on Pipe Mechanics}

This chapter has discussed the methods through which steel and composite pipes can be evaluated. These models are used to predict stresses, strains, and failure pressures for pipes under internal pressure. The purpose in discussing these models was to provide a framework through which pipe properties can be determined outside of the laboratory. The next chapter discusses the specific analysis of filament wound glass/vinyl ester pipes under internal pressure. These pipes were tested in the lab under internal pressure, and were evaluated through the theories presented in this chapter. The results are comparisons are provided in chapter 6 . 


\section{CHAPTER 4 ANALYSIS OF FILAMENT WOUND PIPES}

\subsection{Introduction}

Over the last 18 months, Kenway Corporation, a subsidiary of Creative Pultrusion Inc, has provided two batches of GFRP pipes and two batches of GFRP pipe joints for researchers at WVUCFC to test and analyze. In addition to the pipes, Kenway also provided a report, prepared by the Advance Engineering Wood Center (AEWC) at the University of Maine, detailing the constituent properties, fiber contents, and longitudinal and hoop strengths. Furthermore, Kenway provided the fabric architectures for the two batches of pipes. This data was used throughout this research project for modelling and for comparison with experimental and analytical results.

The pipes and joints were subjected to burst pressure testing and split ring testing. The testing methodology and results for these tests are discussed in chapter 5. In tandem with pressure testing, analytical processes to evaluate elastic properties and failure properties were explored. Since the beginning of the project, the endeavor has been to, not only test and characterize pipes, but also to produce simple methods to predict these failure pressures. The principles of the CLT were applied to the pipes, so that these predictions could be produced. As was discussed in the previous chapter, the CLT only applies to the elastic zone of a given stress strain curve. Therefore, complex failure modelling processes must be coupled with this elastic theory if accurate failure predictions (burst pressure) are ever to be produced. 


\subsection{Kenway Pipe Specifications}

Throughout this chapter, the two batches of filament wound (FW) pipes are considered separately. The pipes are discussed in terms of specifications and geometry, elastic properties, and failure properties. The joints were tested to failure under internal pressure, but have not been evaluated from this mechanics based perspective.

\subsubsection{Filament Wound Pipes- $3 / 8$ Wall Samples}

\subsubsection{Dimensions}

During the first round of pressure tests, Kenway generously provided three 36-inch long filament wound pipes, and two 48-long jointed pipes for pressure testing. The three pipes and joints have average inner diameters of 9.30 inches and average wall thicknesses of 0.45 inches. By a slim margin, these pipes fall into the category or thin-walled pipes. The D/t ratio is 20.66 , slightly over the lower limit value of 20. Therefore, the thin-walled approximation was employed in both analytical and experimental analyses for the first batch of pipes. Since the thin-walled approximation is met, the wall is viewed as a laminated plate, subjected to only longitudinal and hoop stress. 


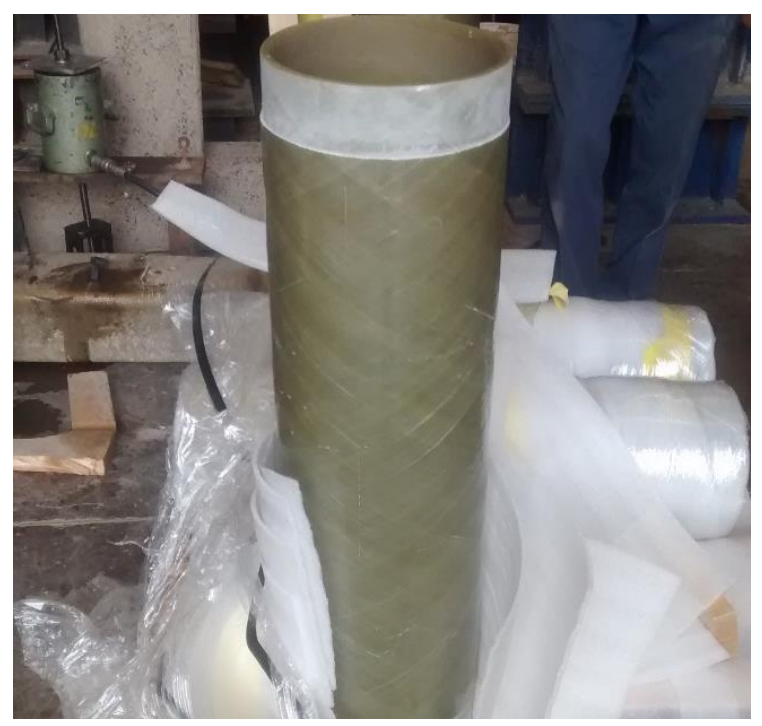

Figure 4-1: Kenway Filament Wound Pipes

The main constituent materials in the pipes are E-glass and vinyl ester resin. The fiber content by weight was determined to be 66 percent. Thus, dividing by densities of the constituents, the fiber volume fraction was found to be 47.8 percent. The resin volume content is 52.2 percent. Fiber content was determined in accordance with ASTM D2584, "Standard Test Method for Ignition Loss of Cured Reinforced Resins".

\subsubsection{Fiber Architecture}

The fabric architecture of the first batch of pipes consists of two primary layers, the corrosion barrier layer (which is not assumed to contribute significant strength or stiffness) and the structural layer. The corrosion barrier layer is around 0.1 inches thick and is primarily provided to offer corrosion resistance against materials within the pipe, although it does offer some strength. The majority of the strength and stiffness comes from the structural layer, which is 0.35 inches thick. These three pipes are henceforth referred to as $3 / 8$ wall pipes, for the approximate thickness of the structural layer. The details of the layup are mentioned below, to the extent Kenway provided.

1. Resin Rich Corrosion Barrier Layer(0.1" to 0.128 " thick) 
a. One layer of Nexus Surfacing Veil

b. Two layers pf $1.5 \mathrm{oz} / \mathrm{ft}^{2}$ chopped strand mat

2. Structural Layer( 0.33 " to 0.35 " thick)

a. One layer of $0.75 \mathrm{oz} / \mathrm{ft}^{2}$ chopped strand mat

b. Nine layers of \pm 55 degree filament winding

\subsubsection{Filament Wound Pipes- 3/4 Wall Samples}

\subsubsection{Dimensions}

The second round of tests, also involved three 36-inch long specimens. The pipes has an inner diameter of 9.625 " inches and an average wall thickness of 0.8 inches. The second set of pipes was manufactured so that the effective thickness could be doubled between the two batches. The effective thickness was considered to be the thickness of the structural layer. Therefore, the resin rich zone remained 0.1 inches thick, while the structural layer thickness was doubled from 0.35 inches to 0.7 inches. These pipes are henceforth referred to as $3 / 4$ wall pipes. This second set of pipes was tested to investigate the possibility of a law of diminishing return. Researchers wanted to determine whether doubling the thickness of the structural layer would result in doubled pressure capacity.

\subsubsection{Fiber Architecture}

The fabric architecture of the second batch of pipes consists of three primary layers, the corrosion barrier layer and two structural layers.

1. Resin Rich Corrosion Barrier Layer(0.1" to $0.128 "$ thick)

a. One layer of Nexus Surfacing Veil

b. Two layers pf $1.5 \mathrm{oz} / \mathrm{ft}^{2}$ chopped strand mat 
2. Structural Layer One (.33" to $.35 "$ thick)

a. One layer of $0.75 \mathrm{oz} / \mathrm{ft}^{2}$ chopped strand mat

b. Nine layers of \pm 55 degree filament winding

3. Structural Layer Two (0.33" to 0.35 " thick)

a. One layer of $0.75 \mathrm{oz} / \mathrm{ft}^{2}$ chopped strand mat

b. Nine layers of \pm 55 degree filament winding

\subsection{Elastic Analysis of Kenway Pipes}

Once the properties and fiber architectures were determined, the pipes were modelled through the classical lamination theory. The purpose of the analysis was to determine both the modulus of elasticity in the hoop and the longitudinal directions, and to provide the base from which failure progression and failure predictions could be produced.

\subsubsection{Elastic Analysis- $3 / 8$ Wall Samples}

Based on the known constituents and fiber volume fraction, structural properties of the fibers and resin were determined (commonly available in the literature). The five independent elastic constants for orthotropic material laminae were then determined, as well as the stiffness and transformed stiffness matrices. Finally, the ABD matrix, and stress/strain relationships were established. Units throughout this section are considered in inches, and lbf.

For the analysis, excel files and mat lab programs were used, The excel file was generic, but demonstrated good agreement with the mat lab file, which was built specifically for the 11 layer Kenway pipes (nine FW layers and two CSM layers). The small $0.75 \mathrm{oz} / \mathrm{ft}^{2}$ mat in the structural layer was neglected. The resin rich zone was modelled as two 0.05-inch thick layers of CSM. The structural layer was modelled at nine 0.039 -inch layers of \pm 57 filament winding. The total laminate 
thickness of the model was 0.45 inches. Therefore, the layup of the batch one pipes is given by Figure 4-2, where layer one is the outer surface and layer 11 is the inner surface of the pipe. The $\mathrm{Z}$ values are provided to the left of the figure. It should be noted that the layup is not symmetric, nor does the neutral axis of the laminate run through the center of a ply.

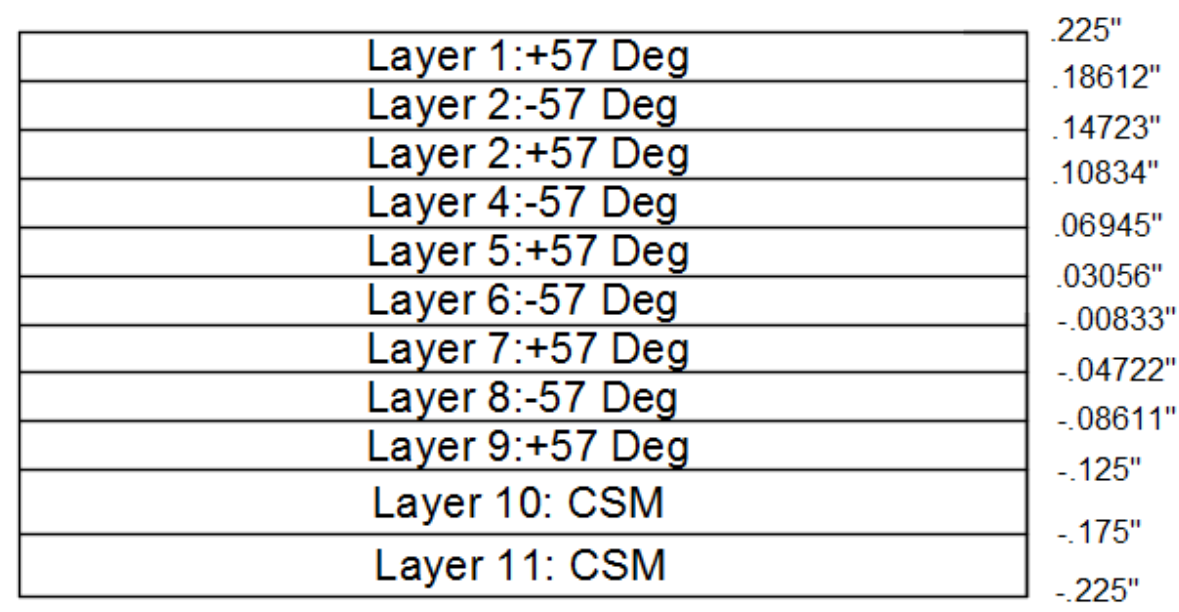

Figure 4-2: Thin Wall Pipe Layup

\subsubsection{Constituent Properties}

Table 4-1 and Table 4-2 provide the structural properties for the constituent materials that were used. These properties vary slightly in the literature. Therefore, there is a possibility that a small degree of error exists between these values on those of the actual materials used. Values were rounded for ease of computation.

Table 4-1: E-glass Structural Properties

\begin{tabular}{|l|l|l|}
\hline E-Glass Property & Calculated Value & Rounded Value \\
\hline Tensile Modulus & $10,500,000 \mathrm{psi}$ & $10,500,000 \mathrm{psi}$ \\
\hline Poisson Ratio & .21 & .21 \\
\hline Shear Modulus & $4,338,843 \mathrm{psi}$ & $4,339,000$ \\
\hline FVF & .478 & .48 \\
\hline
\end{tabular}




\begin{tabular}{|l|l|l|}
\hline Density & $2.5 \mathrm{~g} / \mathrm{cm}^{3}$ & $2.5 \mathrm{~g} / \mathrm{cm}^{3}$ \\
\hline
\end{tabular}

Table 4-2: Vinyl Ester Structural Properties

\begin{tabular}{|l|l|l|}
\hline Vinyl Ester Property & Calculated Value & Rounded Value \\
\hline Tensile Modulus & $500,000 \mathrm{psi}$ & $500,000 \mathrm{psi}$ \\
\hline Poisson Ratio & .38 & .38 \\
\hline Shear Modulus & $181,159 \mathrm{psi}$ & $181,000 \mathrm{psi}$ \\
\hline FVF & .525 & .52 \\
\hline Density & $1.3 \mathrm{~g} / \mathrm{cm}^{3}$ & $1.3 \mathrm{~g} / \mathrm{cm}^{3}$ \\
\hline
\end{tabular}

\subsubsection{Lamina Properties}

The independent elastic constants for the unidirectional were determined based on equations A-1A-5.

Table 4-3: Lamina Elastic Constants

\begin{tabular}{|l|l|l|}
\hline Unidirectional Lamina Stiffness Terms & Calculated Value & Rounded Value \\
\hline Longitudinal Modulus $\left(\mathrm{E}_{11}\right)$ & $5,280,000 \mathrm{psi}$ & $5,280,000 \mathrm{psi}$ \\
\hline Transverse Modulus( $\left.\mathrm{E}_{22}\right)$ & $1,567,946 \mathrm{psi}$ & $1,568,000$ \\
\hline Major Poisson Ratio $\left(v_{12}\right)$ & .2987 & .30 \\
\hline Minor Poisson Ratio $\left(v_{21}\right)$ & .0887 & .09 \\
\hline Shear Modulus $\left(\mathrm{G}_{12}\right)$ & $451,945 \mathrm{psi}$ & $452,000 \mathrm{psi}$ \\
\hline
\end{tabular}

\subsubsection{Stiffness Matrices}

Based on these elastic constants, the stiffness matrix of the mat, and transformed stiffness matrices of the 57 degree filament winding and -57 degree filament wound layers are provided in Equations 4-2 and 4-3. These equations provide stiffness properties in terms of the global coordinate system. While unidirectional fibers offer greater longitudinal stiffness than a mat, the 
mat provides greater stiffness when compared against fiber wound at a cross ply angle. Therefore, CSM plays an important role in laminate strength. Equation 4-1 provides the stiffness matrix of a CSM. These equations are explained more thoroughly in appendix A.

$$
\begin{aligned}
Q_{C S M}= & {\left[\begin{array}{ccc}
1 / E & -v / E & 0 \\
-v / E & 1 / E & 0 \\
0 & 0 & 1 / G
\end{array}\right]=\left[\begin{array}{ccc}
3,546,486 & 1,443,004 & 0 \\
1,443,004 & 3,546,486 & 0 \\
0 & 0 & 2,103,482
\end{array}\right] } \\
\overline{Q_{57}}= & {\left[\begin{array}{lll}
\bar{Q}_{11} & \bar{Q}_{12} & \bar{Q}_{16} \\
\bar{Q}_{12} & \bar{Q}_{22} & \bar{Q}_{26} \\
\bar{Q}_{16} & \bar{Q}_{26} & \bar{Q}_{66}
\end{array}\right]=\left[\begin{array}{ccc}
1,862,658 & 1,359,157 & 480,030 \\
1,359,157 & 3,413,973 & 1,262,125 \\
480,030 & 1,262,125 & 1,343,780
\end{array}\right] } \\
\overline{Q_{-57}}= & {\left[\begin{array}{llll}
\bar{Q}_{11} & \bar{Q}_{12} & \bar{Q}_{16} \\
\bar{Q}_{12} & \bar{Q}_{22} & \bar{Q}_{26} \\
\bar{Q}_{16} & \bar{Q}_{26} & \bar{Q}_{66}
\end{array}\right]=\left[\begin{array}{ccc}
1,862,658 & 1,359,157 & -480,030 \\
1,359,157 & 3,413,973 & -1,262,125 \\
-480,030 & -1,262,125 & 1,343,780
\end{array}\right] }
\end{aligned}
$$

\subsubsection{ABD Stiffness Matrix}

The ABD global stiffness was then compiled based on the stiffness matrices of the layers (Equations 4-1 to 4-3) and the laminate layup of Figure 4-2. Two different versions of this matrix were produced. One version was produced for a symmetric 9 layer FW laminate. In this laminate the B coupling matrix (lower left and upper right) included only zero terms. The second model produced (Equation 4-4 ) includes contribution of mats and lack of symmetry. The B matrix is full of significant, non-zero, terms. As will be discussed in the next chapters, this second model was found to be more accurate. 


$$
Q_{A B D}=\left[\begin{array}{cccccc}
1,006,579 & 620,005 & 18,664 & -29,467 & -1467 & 932 \\
620,005 & 1,549,539 & 49,071 & -1,467 & -2,319 & 2,452 \\
18,664 & 49,071 & 680,671 & 932 & 2,452 & -13,295 \\
-29,467 & -1467 & 932 & 19,442 & 10,585 & 613 \\
-1,467 & -2,319 & 2,452 & 10,585 & 26,342 & 1,613 \\
932 & 2,452 & -13,295 & 613 & 1,613 & 12,594
\end{array}\right]
$$

\subsubsection{Elastic Analysis}

The loading vector is the key in an accurate stress/strain prediction. As was noted in Chapter 3, the loading vector contains only two non-zero terms $\left(\mathrm{N}_{\mathrm{x}}\right.$ and $\left.\mathrm{N}_{\mathrm{y}}\right)$ for pressure vessels and pipes under longitudinal and hoop stress. However, it is conceivable that the longitudinal stresses $\left(\mathrm{N}_{\mathrm{x}}\right)$ may not always be present, or that $\mathrm{Nx}$ may be a compression stress. Therefore, models were produced including, and excluding the longitudinal stress resultant. The global stress/strain equations for the three loading conditions are then given by Equations 4-5 to 4-7. Equation 4-5 considers the effect of longitudinal tensile and hoop tensile stresses and simulates the plane stress effects of a free-end closure testing system (referred to as CLT-PST in figures). Equation 4-6 considers the effects of hoop tensile stress only, and simulates the theoretical restrained-end closure (referred to as CLT-NPS). In reality, the restrained-end closure testing system actually exerts hoop tensile stress and longitudinal compression stress. This is simulated by Equation 4-7 (referred to as CLT-PSC in figures and tables). More discussion on the differences is provided in Chapters 5 and 6.

$$
\left[\begin{array}{c}
\epsilon_{x}^{0} \\
\epsilon_{y}^{0} \\
\epsilon_{x y}^{0} \\
k_{x} \\
k_{y} \\
k_{x y}
\end{array}\right]=\left[\begin{array}{cccccc}
1,006,579 & 620,005 & 18,664 & -29,467 & -1467 & 932 \\
620,005 & 1,549,539 & 49,071 & -1,467 & -2,319 & 2,452 \\
18,664 & 49,071 & 680,671 & 932 & 2,452 & -13,295 \\
-29,467 & -1467 & 932 & 19,442 & 10,585 & 613 \\
-1,467 & -2,319 & 2,452 & 10,585 & 26,342 & 1,613 \\
932 & 2,452 & -13,295 & 613 & 1,613 & 12,594
\end{array}\right]^{-1} *\left[\begin{array}{c}
p * r \\
2 \\
p * r \\
0 \\
0 \\
0 \\
0
\end{array}\right]
$$




$$
\left[\begin{array}{c}
\epsilon_{x}^{0} \\
\epsilon_{y}^{0} \\
\epsilon_{x y}^{0} \\
k_{x} \\
k_{y} \\
k_{x y}
\end{array}\right]=\left[\begin{array}{cccccc}
1,006,579 & 620,005 & 18,664 & -29,467 & -1467 & 932 \\
620,005 & 1,549,539 & 49,071 & -1,467 & -2,319 & 2,452 \\
18,664 & 49,071 & 680,671 & 932 & 2,452 & -13,295 \\
-29,467 & -1467 & 932 & 19,442 & 10,585 & 613 \\
-1,467 & -2,319 & 2,452 & 10,585 & 26,342 & 1,613 \\
932 & 2,452 & -13,295 & 613 & 1,613 & 12,594
\end{array}\right]^{-1} *\left[\begin{array}{c}
0 \\
p * r \\
0 \\
0 \\
0 \\
0
\end{array}\right]
$$

$$
\left[\begin{array}{c}
\epsilon_{x}^{0} \\
\epsilon_{y}^{0} \\
\epsilon_{x y}^{0} \\
k_{x} \\
k_{y} \\
k_{x y}
\end{array}\right]=\left[\begin{array}{cccccc}
1,006,579 & 620,005 & 18,664 & -29,467 & -1467 & 932 \\
620,005 & 1,549,539 & 49,071 & -1,467 & -2,319 & 2,452 \\
18,664 & 49,071 & 680,671 & 932 & 2,452 & -13,295 \\
-29,467 & -1467 & 932 & 19,442 & 10,585 & 613 \\
-1,467 & -2,319 & 2,452 & 10,585 & 26,342 & 1,613 \\
932 & 2,452 & -13,295 & 613 & 1,613 & 12,594
\end{array}\right]^{-1} *\left[\begin{array}{c}
-t * p \\
p * r \\
0 \\
0 \\
0 \\
0
\end{array}\right]
$$

Since the above equations for stress and strain are valid for a particular pressure $p$, MatLab was employed to iterate strain analysis for pressures between 0 and 1500 psi. 1500 psi was chosen because this pressure marks the high end of operational pressures for transmission lines. Additionally the stress/strain curves were generated. Based on the predicted curves, moduli of elasticity were determined for both the hoop and longitudinal directions. Additional details are provided in appendix A.
A. Hoop Strain Comparison 


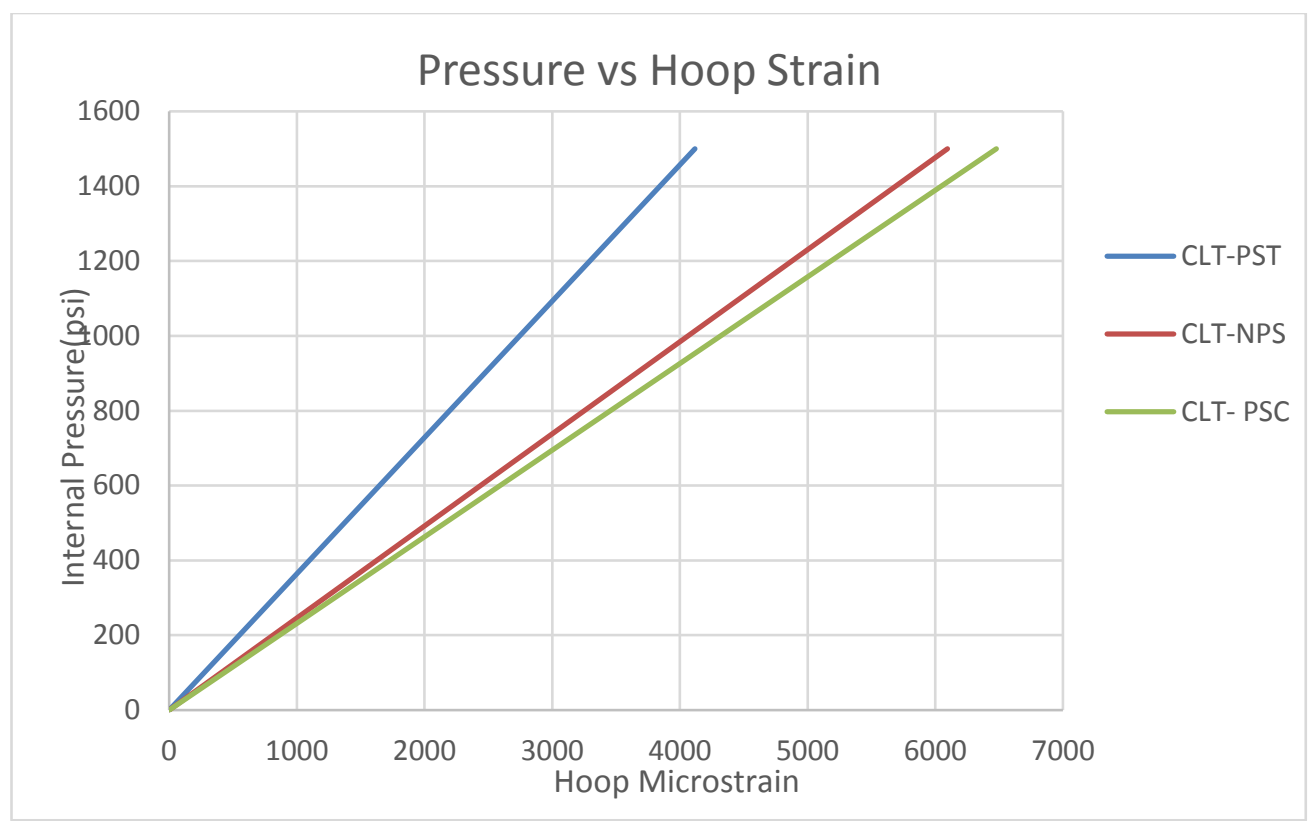

Figure 4-3: Thin Wall CLT Hoop Strain

B. Longitudinal Strain Comparison

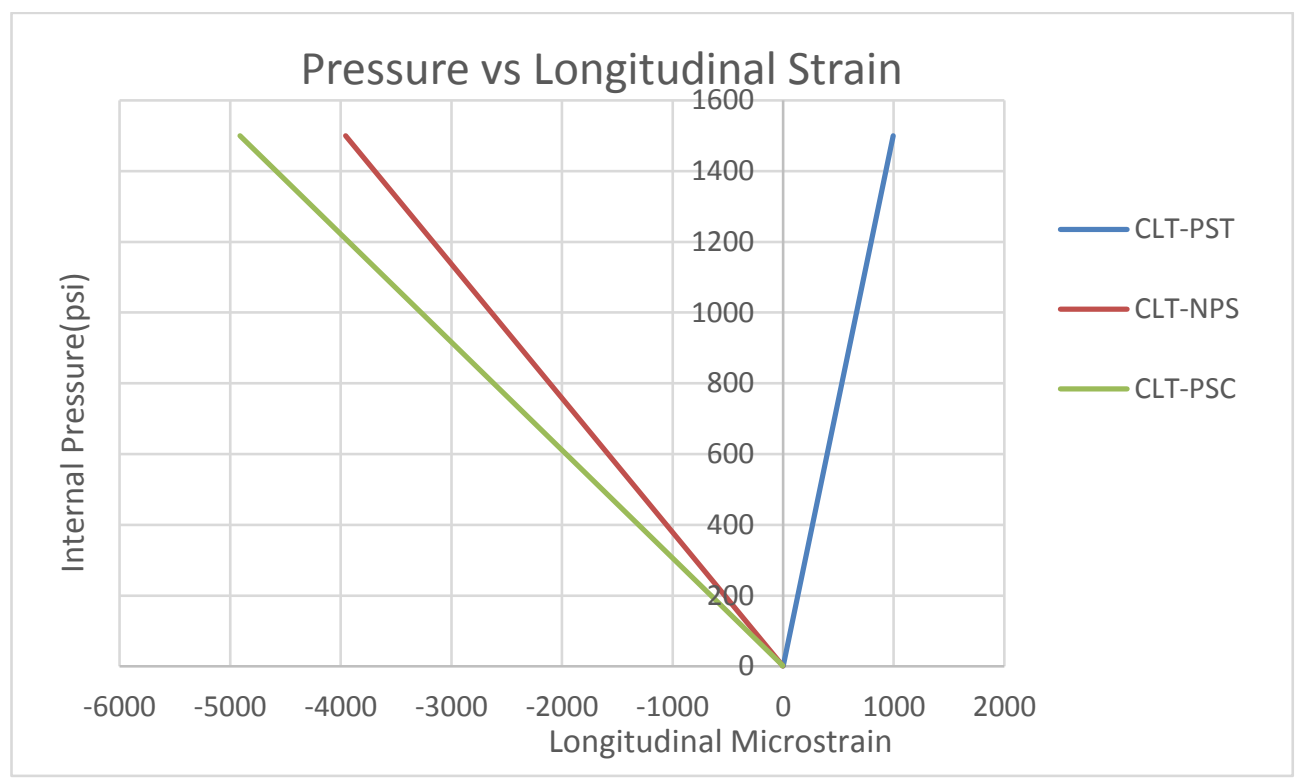

Figure 4-4: Thin Wall CLT Longitudinal Strain

C. Hoop Modulus Comparison 


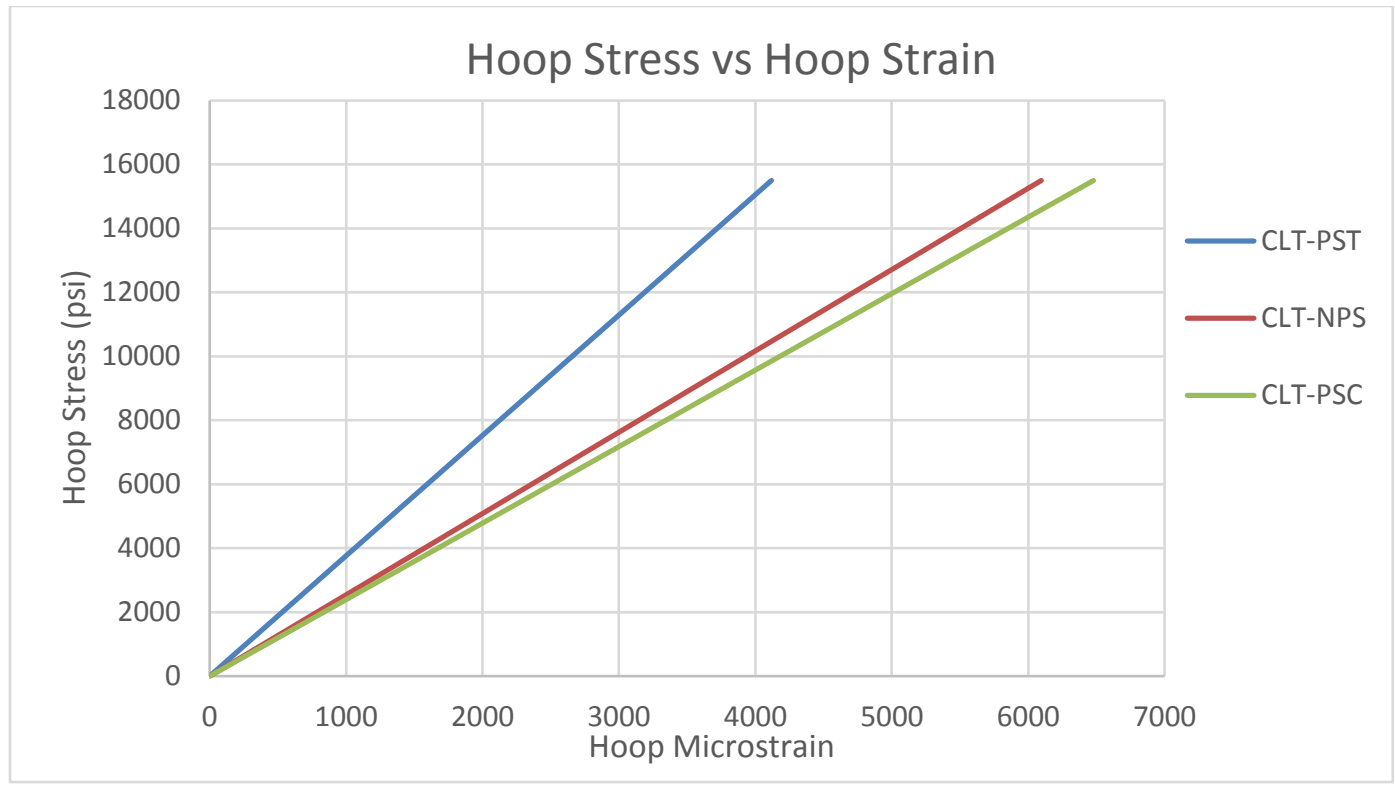

Figure 4-5: Thin Wall CLT Hoop Modulus

\subsubsection{Commentary on Elastic Properties}

The elastic properties were determined based on the data for predictions above. The hoop modulus of the CLT-PST prediction was found to be $3.76 \mathrm{Msi}$, the hoop modulus of the CLT-NPS was found to be $2.54 \mathrm{Msi}$, and the hoop modulus of the CLT-PSC prediction was found to be 2.39 Msi. In reality, the moduli do not change. However, the differing states of stresses produce different strains in the hope directions, giving the appearance of differing hoop modulus. Therefore, the predicted modulus is more of an apparent modulus.

Figure 4-3 to 4-5 to offer comparisons between the different types of loading. CLT-PST models behavior under both hoop and longitudinal tensile stress. This would be the case in situations where resultant forces on the endcaps produce longitudinal stresses in the walls of the pipe. CLT only models the effects of hoop stress. This would be the case in situations where the endcaps do not exert longitudinal stress. CLT-PSC models effects of hoop tension and longitudinal compression. 
The three figures demonstrate a key principle for pipes under internal pressure, the effects of fabric architecture and Poison's ratio. In CLT-PST, longitudinal stresses produced axial tension, causing the pipe to elongate and "neck down" in diameter. This means that longitudinal stress counteracts the effect of hoop stress. In CLT-NPS prediction, longitudinal stresses do not exist (i.e. there is no plane stress, abbreviated NPS). Therefore, the effects of hoop stress, the pipe architecture, and Poisson's ratio produce compression strains. As the hoop stress causes the pipe to bulge in dimeter, the length is forced to contract. It can be seen that the two models result in hoop strains differing by nearly 2000 micro strain and the result in longitudinal strains differing by 5,000 psi. In the case of the CLT-PSC, the effects of longitudinal compression stress are observed to increase hoop strains.

\subsubsection{Observations}

- It is critical to model fabric architecture as accurately as possible if meaningful CLT stress strain curves are to be produced. Initially, contribution of chopped strand mat was neglected. However, the contribution of CSM can increase hoop and elastic stiffness. Additionally, small variations in winding angle and fiber volume fraction can affect the results.

- An accurate loading vector is critical. The predicted hoop moduli differ by 37 percent. It was not possible to determine difference in longitudinal moduli since CLT-NPS assumes no longitudinal load exists, except load due to Poisson effect. However, the longitudinal strain vs pressure results reveal that CLT-PST produces axial tension, while CLT-NPS produces axial compression. Strains predicted by CLT-PSC are even larger in terms of tension and compression. Thus, strains in the fiber directions differ significantly, for the two types of loading. 
- Lack of symmetry in the laminate layup results in a non-zero bending matrix(B), but makes little difference in stresses because the curvatures remain small. Therefore, strains within each layer vary little from layer to layer.

- The effect of different loadings ultimately results in differing stresses within the fibers. In situations where both the hoop and longitudinal forces are in tension, fiber stresses are much higher than in situations where longitudinal stresses are in compression and hoop stresses are in tension. Therefore, comparison with experimental results and accurate failure predictions are contingent upon a theoretical loading that matches real world situations.

- Comparisons in chapter 6 are based on the CLT-PSC prediction. This is because CLT-PSC most accurately models the loading of the hydrostatic burst pressure test.

\subsubsection{Elastic Analysis-3/4 Wall Samples}

The elastic analysis of the $3 / 4$ wall samples was addressed differently than the first set. Since this set of pipes has an inner diameter of 9.625 inches and a thickness of 0.8 inches (D/t=12.03), this batch falls into the thick-walled pipes category. Therefore, radial stresses cannot be neglected. Furthermore, the magnitudes of the longitudinal and hoop stresses are impacted by the radial stress component. Several equations have been developed to address this behavior in isotropic (Lame's equations) and orthotropic materials. In the end, the stress resultants differ by around 10 percent. For the sake of simplicity, the thin walled approximation and CLT theory were employed in the analysis.

The major difference between the two batches is the fabric architecture. Figure 4-6 below shows structural layer 1 (layers 1-9), structural layer 2 (layers 10-18), and the corrosion resistance layers (layers 19 and 20). The $\mathrm{z}$ values of each surface in a layer are provided to the left of the 
figure. The elastic constants for orthotropic materials, stiffness, and transformed stiffness matrices remained the same. Therefore, the major change between the two sets of pipes is addressed in the ABD stiffness matrix.

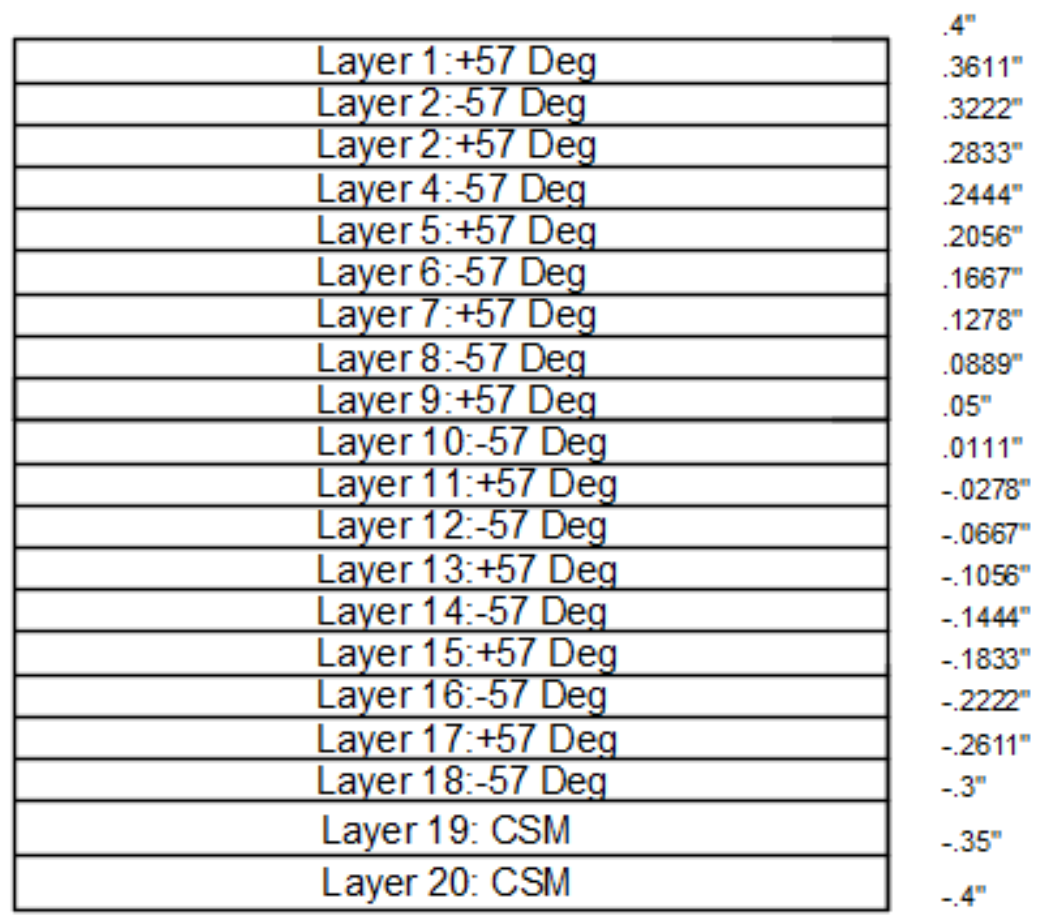

Figure 4-6: Thick Wall Pipe Layup

\subsubsection{Elastic Analysis}

As would be expected, the ABD matrix of batch two was found to be much stiffer in terms of load per unit thickness. Loading vectors were kept the same for the CLT-PST, CLT-NPS, and CLT-PSC predictions.

$\left[\begin{array}{c}\epsilon_{x}^{0} \\ \epsilon_{y}^{0} \\ \epsilon_{x y}^{0} \\ k_{x} \\ k_{y} \\ k_{x y}\end{array}\right]=\left[\begin{array}{cccccc}1,658,509 & 1,095,711 & -28 & -58,934 & -2,935 & 6,524 \\ 1,095,711 & 2,744,430 & -73 & -2,935 & -4,638 & 17,155 \\ -28 & -73 & 1,150,995 & 6,524 & 17,155 & -26,590 \\ -58,934 & -2,935 & 6,524 & 100,241 & 59,025 & 651 \\ -2,935 & -4,638 & 17,155 & 59,025 & 147,297 & 1,712 \\ 6,524 & 17,155 & -26,590 & 651 & 1,712 & 66,704\end{array}\right]^{-1} \quad *\left[\begin{array}{c}p * r \\ p * r \\ p \\ 0 \\ 0 \\ 0 \\ 0\end{array}\right]$ 


$$
\left[\begin{array}{c}
\epsilon_{x}^{0} \\
\epsilon_{y}^{0} \\
\epsilon_{x y}^{0} \\
k_{x} \\
k_{y} \\
k_{x y}
\end{array}\right]=\left[\begin{array}{cccccc}
1,658,509 & 1,095,711 & -28 & -58,934 & -2,935 & 6,524 \\
1,095,711 & 2,744,430 & -73 & -2,935 & -4,638 & 17,155 \\
-28 & -73 & 1,150,995 & 6,524 & 17,155 & -26,590 \\
-58,934 & -2,935 & 6,524 & 100,241 & 59,025 & 651 \\
-2,935 & -4,638 & 17,155 & 59,025 & 147,297 & 1,712 \\
6,524 & 17,155 & -26,590 & 651 & 1,712 & 66,704
\end{array}\right]^{-1} *\left[\begin{array}{c}
0 \\
p * r \\
0 \\
0 \\
0 \\
0
\end{array}\right]
$$

$$
\left[\begin{array}{c}
\epsilon_{x}^{0} \\
\epsilon_{y}^{0} \\
\epsilon_{x y}^{0} \\
k_{x} \\
k_{y} \\
k_{x y}
\end{array}\right]=\left[\begin{array}{cccccc}
1,658,509 & 1,095,711 & -28 & -58,934 & -2,935 & 6,524 \\
1,095,711 & 2,744,430 & -73 & -2,935 & -4,638 & 17,155 \\
-28 & -73 & 1,150,995 & 6,524 & 17,155 & -26,590 \\
-58,934 & -2,935 & 6,524 & 100,241 & 59,025 & 651 \\
-2,935 & -4,638 & 17,155 & 59,025 & 147,297 & 1,712 \\
6,524 & 17,155 & -26,590 & 651 & 1,712 & 66,704
\end{array}\right]^{-1} \quad *\left[\begin{array}{c}
-t * p \\
p * r \\
0 \\
0 \\
0 \\
0
\end{array}\right]
$$

Again, stress/strain analysis was iterated between 1 and 1500 psi. Strain vs Pressure and approximate stress/strain curves very produced.

A. Hoop Strain Comparison

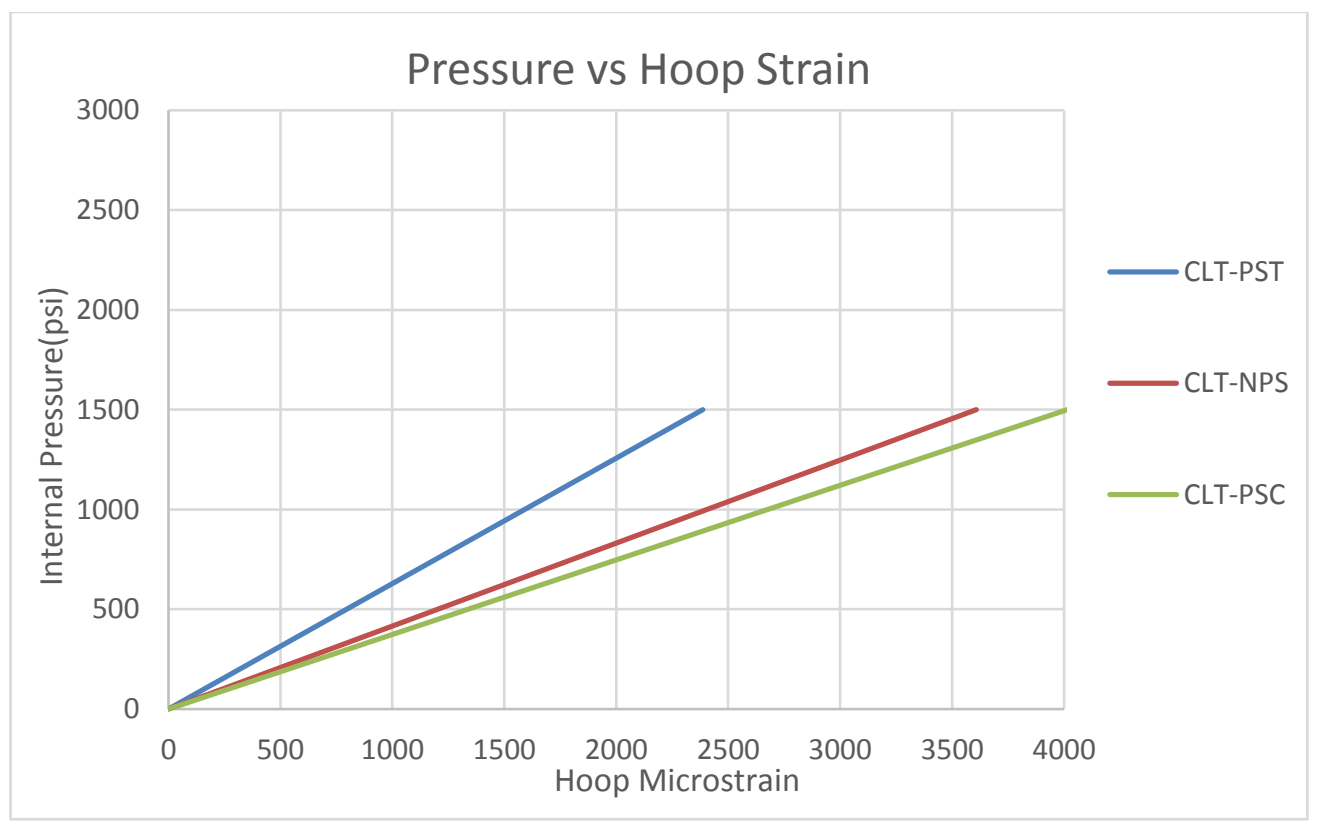

Figure 4-7: Thick Wall CLT Hoop Strain 
B. Axial Strain Comparison

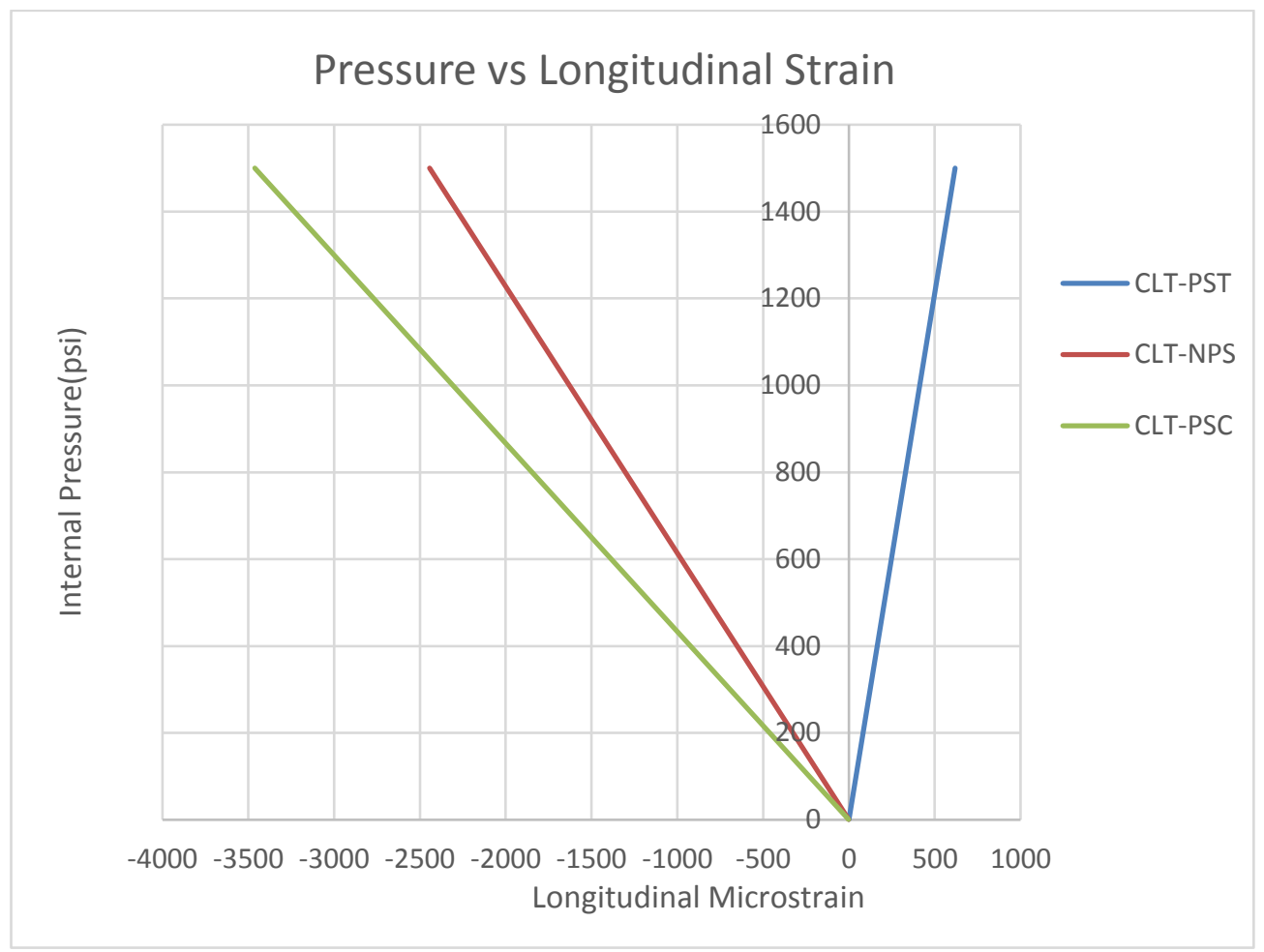

Figure 4-8: Thick Wall CLT Longitudinal Strain 


\section{Hoop Modulus Comparison}

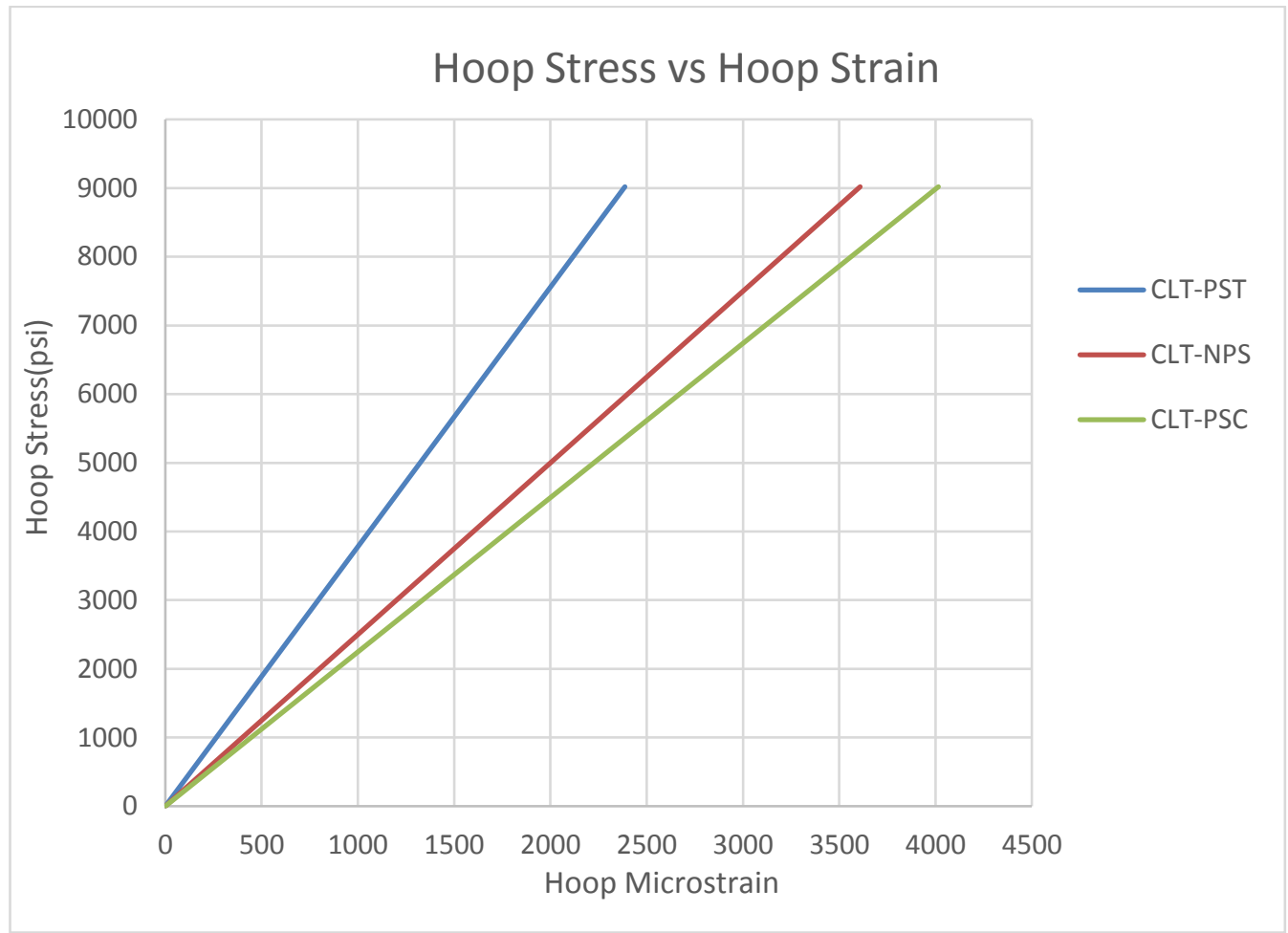

Figure 4-9: Thick Wall CLT Hoop Modulus

\subsubsection{Commentary on Elastic Properties}

The elastic properties were determined based on the data for Figure 4-7 to 4-9. The hoop modulus of the CLT-PST prediction was found to be $3.78 \mathrm{Msi}$, the hoop modulus of the CLT-NPS was found to be $2.50 \mathrm{Msi}$, and the hoop modulus of the CLT-PSC prediction was found to be 2.24 Msi. The graphs above and subsequent elastic moduli are only approximate, since the pipes do not truly follow thin-wall mechanics relationship. However, the elastic moduli of the two batches of pipes are very similar. Furthermore, the Poisson effect and loading produce similar differences in mechanical behavior. Therefore, it is crucial to accurately represent the state of plane stresses, or lack thereof. 


\subsubsection{Observations}

- Modelling of multilayered laminates is tedious and time consuming. Mistakes are difficult to catch and can significantly alter results

- To a small degree, it is possible to reduce the mathematical computation for a model by reducing the number of layers and increasing layer thickness, so that the laminate thickness remains constant.

- The method of loading alters hoop strain by 40 percent at 1500 psi.

- The method of loading alters approximated hoop moduli by 41 percent

- The two batches provided good agreement on the effect of axial stress on the overall mechanical behavior

- Again, the CLT-PSC prediction is used in chapter 6, for comparison with experimental methods.

\subsection{Failure Analysis of Kenway Pipes}

Failure analysis through classical lamination theory and failure criteria is only possible if an accurate elastic model exists. As will be discussed in the next chapter, this model seems to perform reasonably well for both the thin walled pipes and thick-walled pipes. The challenge arises at the onset of failure in the resin or fibers. The failure initiation and propagation result in lower hoop and longitudinal moduli, and increased strains. In this situation, the ABD stiffness matrix must be adjusted and the analysis rerun. Thus, failure analysis models nonlinear behavior through a series of small linear segments of degreasing stiffness. The result is in an approximated nonlinear curve.

During evaluations, it was not possible to model this failure because accurate unidirectional lamina strength values could not be determined. It was not possible to produce tensile coupons and 
conduct tests in the available time. Furthermore, it remains to be seen if the filament winding process can produce a unidirectional coupon similar in strength to the pipe specimens. Additionally, mechanics based and empirical equations do not provide accurate predictions of lamina failure strengths. Therefore, failure prediction using the Tsai-Wu failure criteria and ply degradation models remains a topic for future work. However, the methods proposed in Chapters 3 and 4 indicate that such research could yield fruitful results.

\subsection{Conclusion}

The CLT can be used to produce predictions of elastic behavior for thin-walled and thickwalled pipes. In order for these predictions to be produced, engineers must have a strong grasp of the theoretical background material and composite mechanics. Several assumptions and approximations must be made. Samples must be produced, so that constituent properties and mechanical properties can be determined. Details of the fabric architecture and specimen dimensions must be known. Therefore, the theory leaves a great deal to be desired in terms of ease of use. The theory may provide accurate results, but also requires a great deal of technical competence, attention to detail, and time. However, as the next section will demonstrate, CLT proves to be a reliable method for determining mechanical behavior for pipes under internal pressure, in the elastic zone. 


\section{CHAPTER 5 EXPERIMENTATION AND RESULTS}

\subsection{Introduction}

The previous two chapters have explained the methods through which composite pipe behavior can be analytically evaluated. This chapter explains two methods through which composite pipes and joints were experimentally evaluated and presents the results, with Chapter 6 comparing and discussing the two methods. Since the relevant standards and test methods were addressed in Chapter 2, this chapter explains the details of the test frames, enclosures fixtures, and results, with an emphasis on the unique test conditions that had to be dealt with to obtain quality experimental data.

\subsection{Hydrostatic Pressure Test Methodology}

The main goal of this research is testing of FRP pipe under internal hydrostatic pressures until burst or other failure, thus this section includes a description of the end-closures, the test frames, the testing process, and the types of specimens used in this testing.

\subsubsection{Loading System}

\subsubsection{Endcaps}

Burst pressure testing introduces a unique challenge that static and fatigue testing do not encounter, i.e.; high magnitudes of hoop and longitudinal forces. The resultant force on each endcap is the product of internal pressure and internal area of the endcap. Thus, large diameter (>10 inch) pipes (large endcap surface area) under high pressures experience high magnitudes of longitudinal forces (200-600 kips). Since cyclic and static tests are conducted under operation 
pressures, the test pressures are 10 to 20 percent of the burst pressures. Therefore, the longitudinal forces on the endcaps are 5 to 10 times higher during burst pressure tests than for static and cyclic tests, for pipes of a given diameter. The initial project goal was to produce a pipe with a burst pressure of 30,000 psi, which for a 10 inch diameter pipe results in an endcap force of 2.3 million pounds. While end-closures of this type may exist, the closures would likely only be used for one test each, since chemical bonding would be required. The more economical expense of reusable endcaps was preferred. Therefore, burst pressure testing of free-end systems was determined to be unreasonable for this project.

For each of the pipes tested during this project, a restrained-end closure was used using steel to resist the loads and nitrile O-rings to seal. For initial evaluation, endcaps were designed based on the hoop stress equation for an internal pressure of 10,000 psi (factor of safety of 2 based on initial designs of 5,000 psi pipes). The endcaps (Figure 5-1) were fabricated from 2.5-inch thick Grade 50 steel. The inner diameter of endcap was machined to 10.000 inches, corresponding to a pipe with an outer diameter of 10.000 inches to match the dimensions of commercially available O-rings. The outer diameter of the endcaps is 14 inches, thereby creating a steel pipe with 2 inch wall thickness to fit around the end of the FRP pipe. The left cap in Figure 5-1 shows the outer surface of one of the caps, where two fittings are located. These fittings were only installed in one end cap, and were used to fill the pipes and apply pressure during testing. 


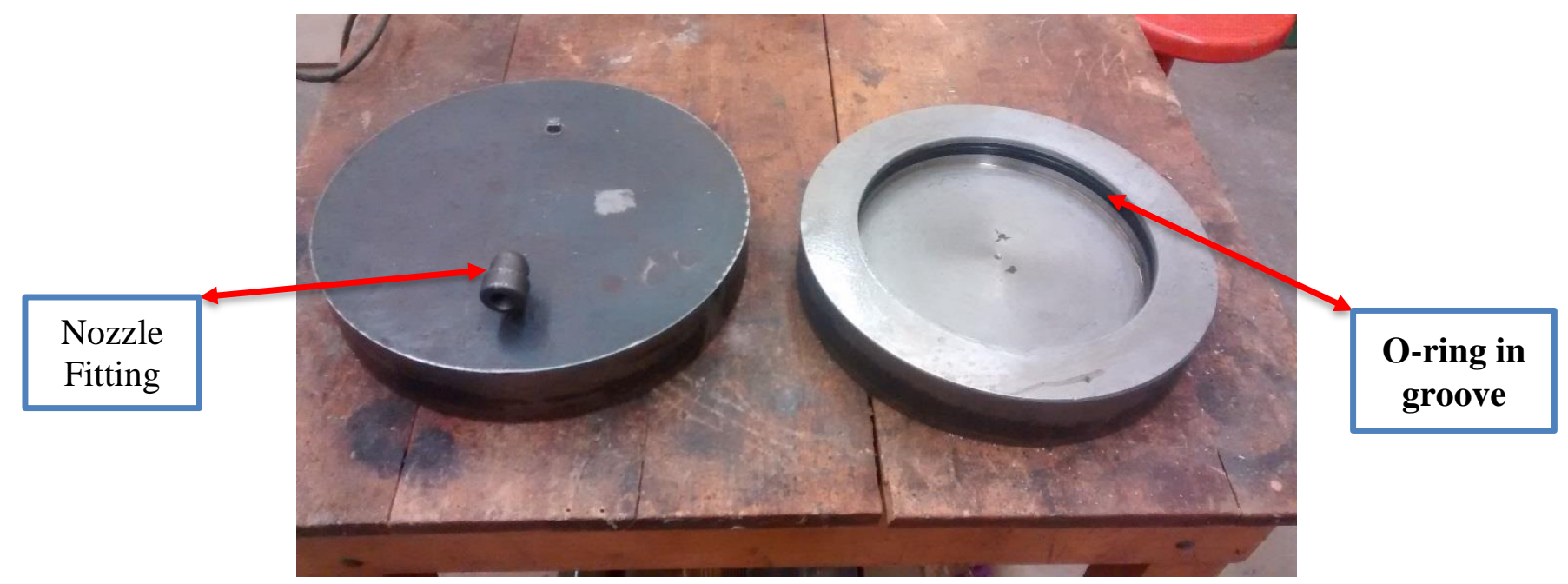

Figure 5-1: Steel Endcaps for 10 Inch OD Pipe

The cap was machined so that 1.25 inches of steel endcap would overlap the ends of the pipe. Furthermore, grooves were cut into the inner surface of the walls of the endcaps so that $\mathrm{O}$ rings, for pressure sealing, could be inserted and compressed. The machining, grooves, and Orings can be seen on the right cap in Figure 5-1.

Narrow tolerances were discovered to be a challenge during testing. Although steel can be machined to tolerances of 0.001 inches and 0.0001 inches, the outer diameter of filament wound pipes cannot be fabricated as precisely as the steel end caps. This issue arises because filament wound pipe thickness can only be increased by whole layers of fiber and resin. Furthermore, the filament-winding process does not always result in a perfectly round pipe. Therefore, the pipes were wound to be bigger than 10 inches, and then machined down to 9.995 inches up to 1.25 inches from the end of the each pipe. The smaller OD of the pipe was chosen based on the recommendations for the O-rings, as provided by the Parker O-ring handbook (Parker Hannaflin Corporation, 2007)) for the Parker 2-449 N552-90 O-rings used in the end caps. The endcaps were also machined to accept two backup rings (Parker 8-449 N1444-90) as recommended by Parker as the pressure was over 1500 psi. Full dimensions for the O-rings and backup rings is given in the 
Parker O-ring Handbook (Parker Hannaflin Corporation, 2007). The substantial wall thickness of the end caps over the pipe is much stiffer than the pipe, thus the steel reinforces the end of the pipe preventing a premature failure due to the machining. The FRP would also push into the steel with a greater and greater force as the internal pressure increased, thereby enhancing the seal and preventing leaks at high pressure. A machined pipe is seen in Figure 5-2. Prior to testing, a 1/4 inch "round-over" was machined on the OD of the pipe to provide a smooth surface for endcap and Oring placement.

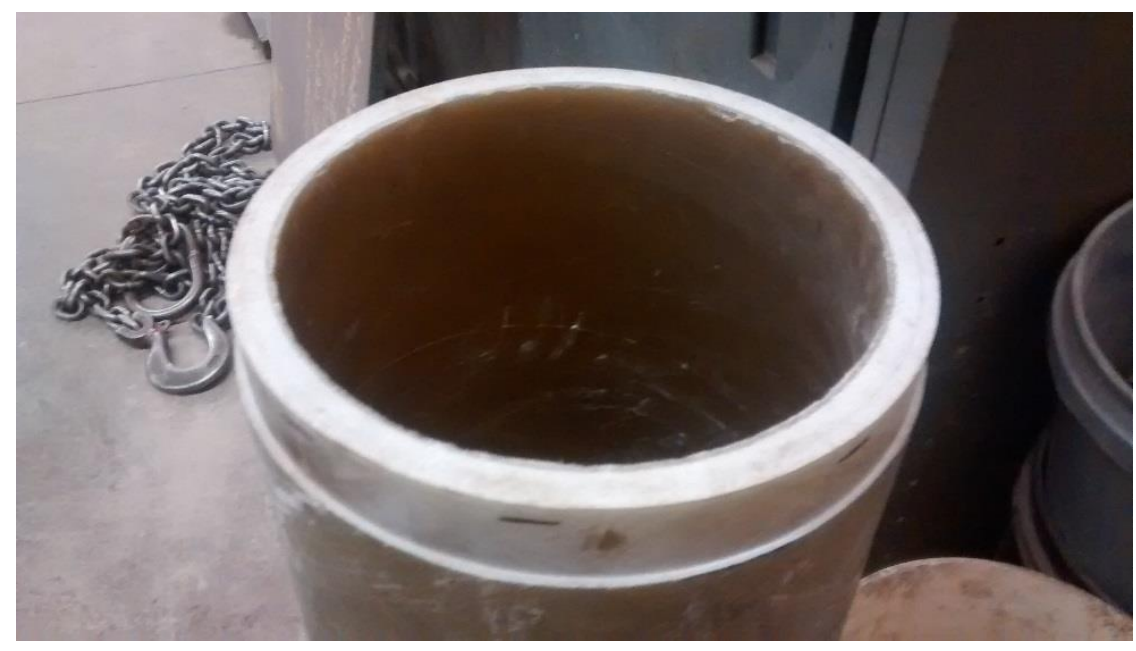

Figure 5-2: Machined Pipe Ends

\subsubsection{Load Frame}

As shown in Figure 5-3, the test method used an oil-based hydraulic hand pump to load a ram which in turn pressurized water in a 5-inch diameter steel cylinder. The pressurized water was transmitted to the GFRP pipe through a high strength hydraulic line, entering the pipe through an end cap. Pressure was measured by a pressure transducer (rated for 50,000 psi). Thrust on the endcaps was resisted by a load frame holding a second 800-kip actuator, which held the endcaps secure on the pipe. 


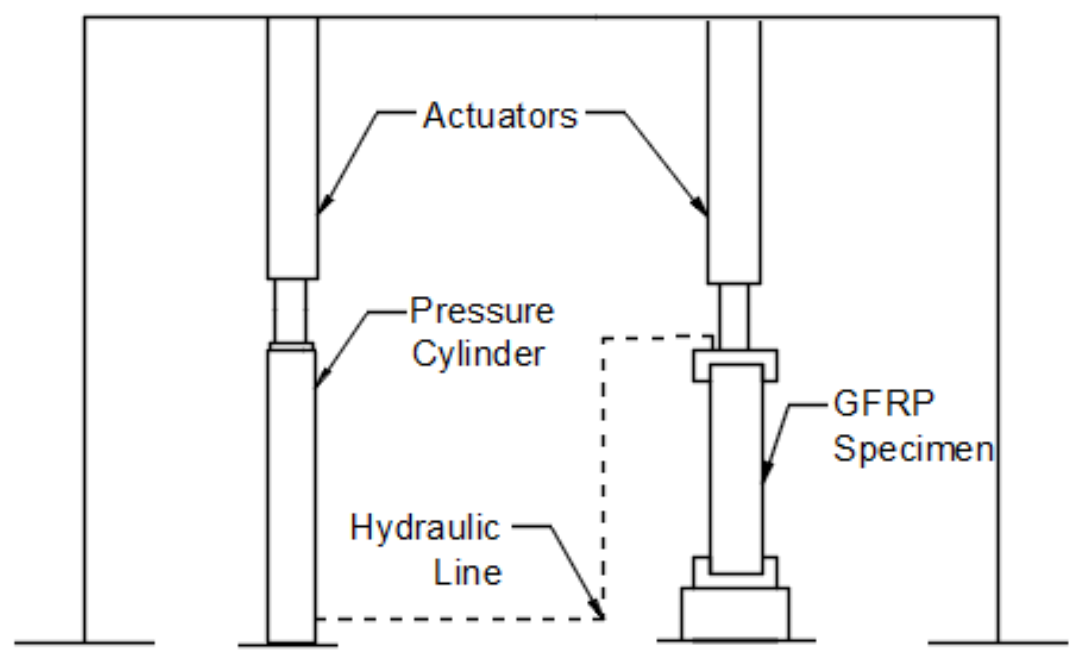

Figure 5-3: Test Frame

Initial testing took place using existing load frames in the CFC Major Units Laboratory.

Due to previous alterations on the existing frames, testing on the 10 -inch pipes was limited to a maximum internal pressure of 2,300 psi. Testing was completed on the existing frames for the Creative Pultrusion (CP) samples and the butt joint samples, as they failed well below the frame capacity. Figure 5-4 shows two early iterations of the frame and actuator setup.

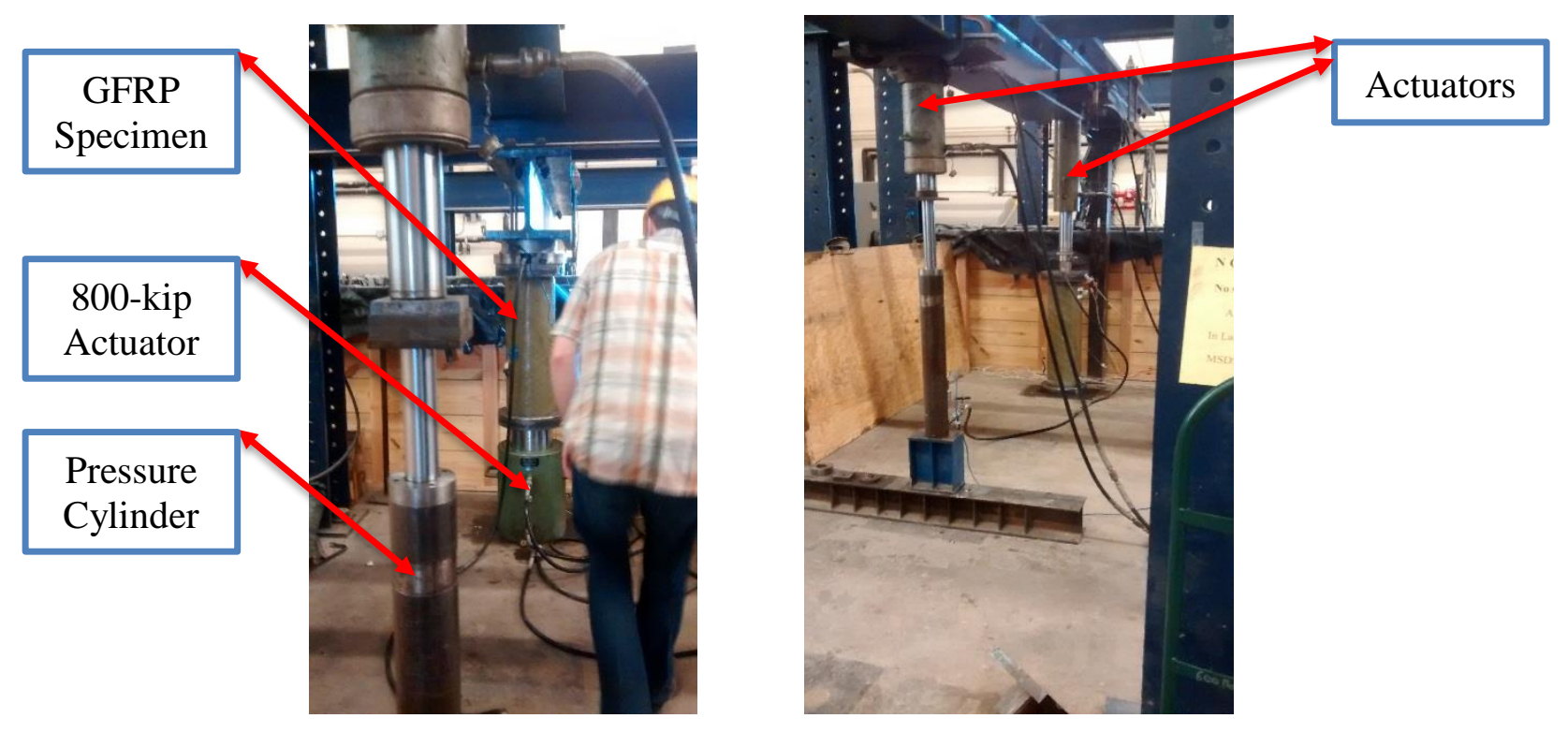

Figure 5-4: Actuator and Frame Setup 
Due to the capacity limitations of the existing load frames, a new compression frame (Figure 5-5) was designed. The frame was designed to have minimal deformations under high loads, as the existing frames allowed significant deflection (up to 0.625 inches) under load. This deflection allowed the endcaps to come off the ends of the pipes, eventually resulting in the Orings coming off the end of the pipe and the water to leak out.

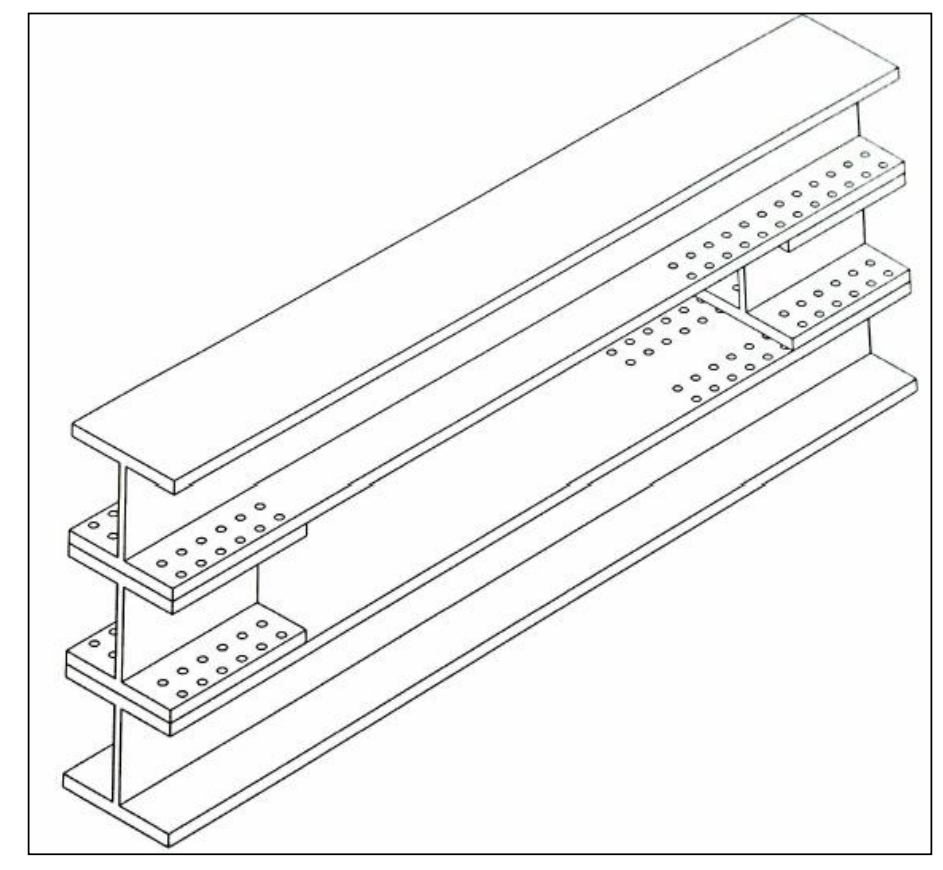

Figure 5-5: Compression Frame Isometric View

The compression frame was fabricated of four, W14 X 233, grade 50 steel beams, fastened together by 1-inch diameter, A490 bolts. Additional bolt holes were provided to allow the frame to be adjusted for lengths of pipe ranging from 30 to 72 inches. The pipe to be tested rests between 2 inch thick steel plates, which bear against a 800-kip actuator and then on the shorter beams. The actuator is used to make fine adjustments to the length of the sample between bolt holes and to push the end caps back onto the sample while it shrinks in length during testing. The actuator and steel plates are seen in Figure 5-6. 


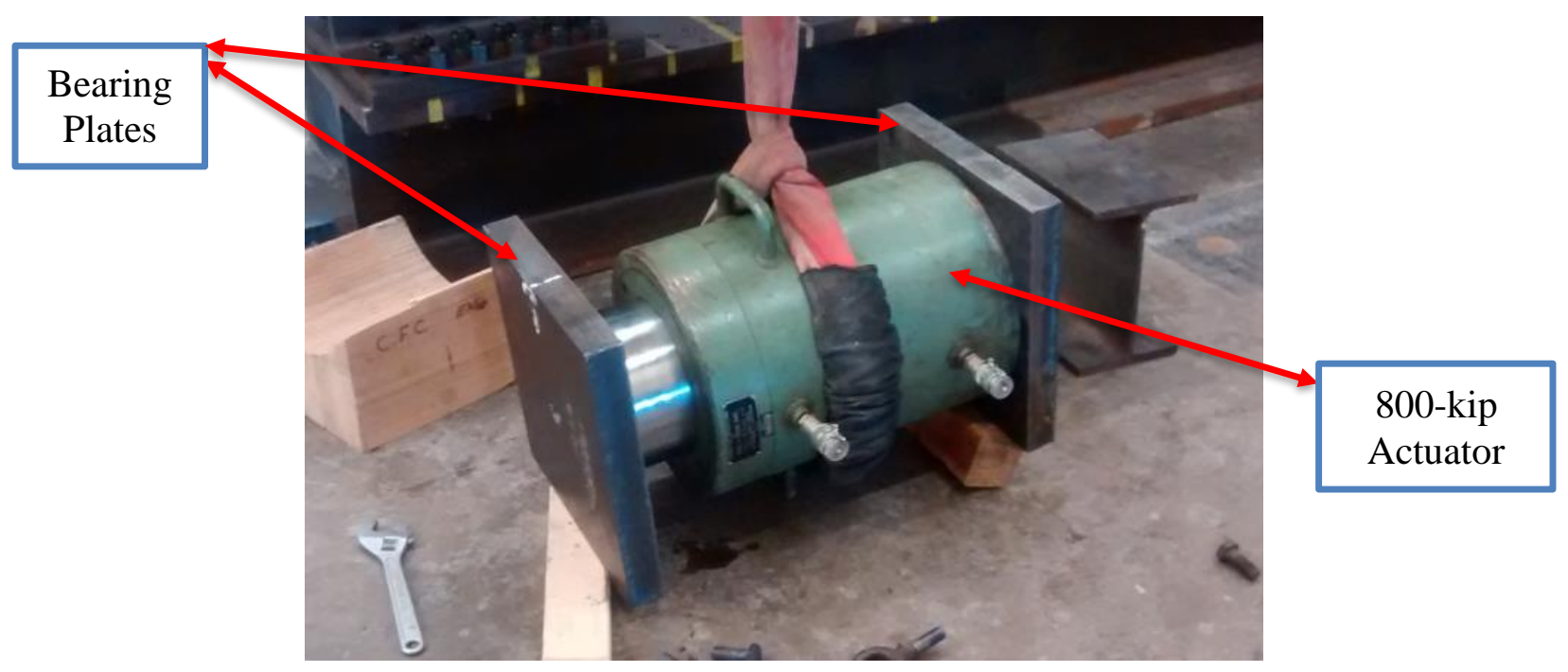

Figure 5-6: 800-kip Capacity Actuator and Steel Plates

The two smaller beams experience compression stresses. Load is transferred to the two larger beams (120 inches long) through bolted connections of 24 bolts per flange. Therefore, the longer beams experience tensile stress and bending stress (due to the eccentricity of the bolted connections). This compression/tension frame provides high resistance to longitudinal deflection and endcap rotation. Details of the frame design and capacity are provided in the appendix. Figure 5-7 shows the fabricated frame, the hydraulic actuator, and two of the three bearing plates.

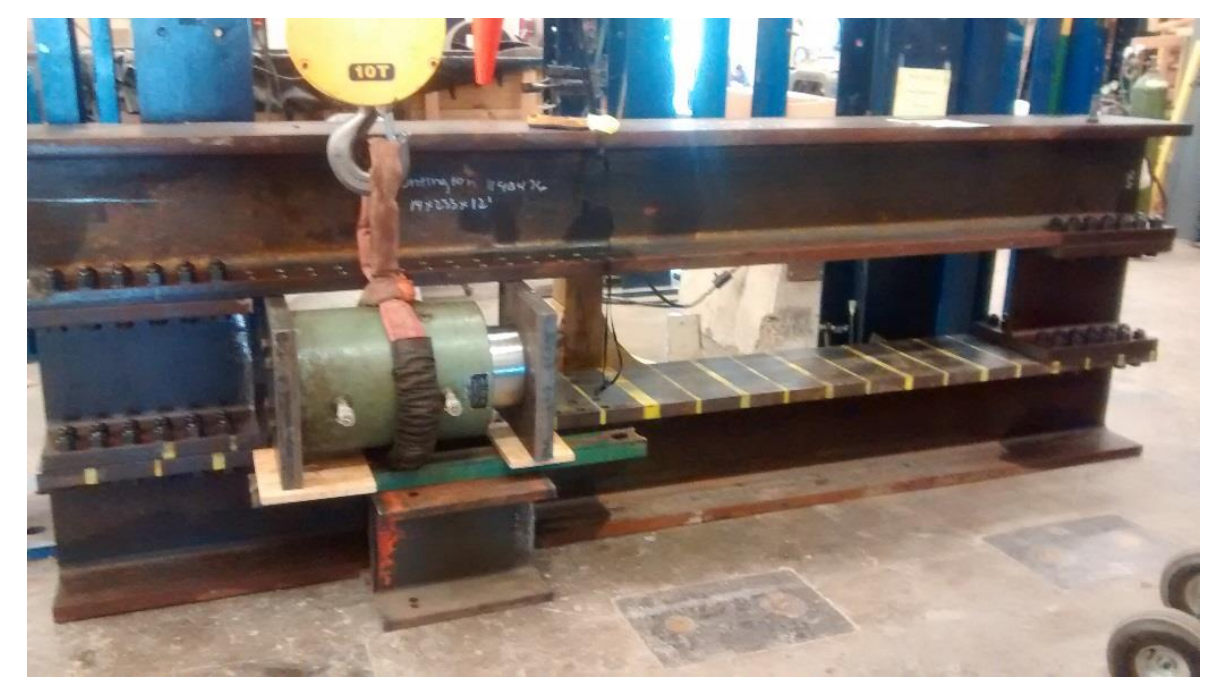

Figure 5-7: Compression Load Frame 


\subsubsection{Samples and Testing}

\subsubsection{Pultruded Pipes}

The initial batch of samples tested was a 6-inch diameter pultruded pipe and four 10-inch diameter pipes. The pipes were pultruded using several layers of glass mats. The details of the fabric architectures are provided in the appendices. These samples were prepped with 4 strain gauges; two hoop, two longitudinal. Figure 5-8 shows the test setup for the 6-inch diameter pultruded pipe. A similar setup was used for the 10-inch diameter pultruded pipes.

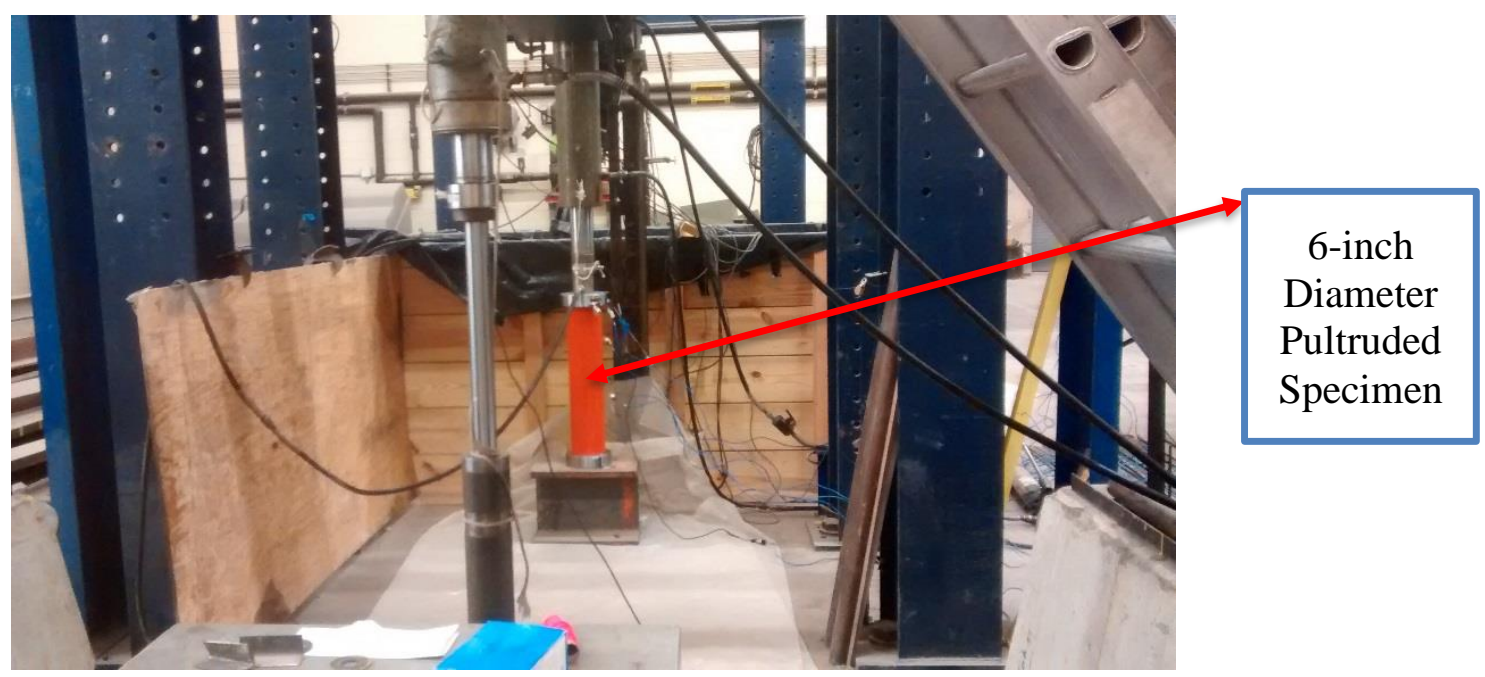

Figure 5-8: Pultruded Pipe Test

\subsubsection{Filament Wound Pipes}

Two batches (3 specimens each) of 10-inch diameter, filament wound (FW) GFRP pipes were also tested. The dimensions and architectures for these pipes are detailed in Chapter 4. Figure 5-9 shows a pipe ready for testing; i.e. the end caps have been installed, it has been filled with water and connected to the hydraulic line. The pipe was placed horizontally into a timber cradle to hold the pipe in the frame without it rolling out. 


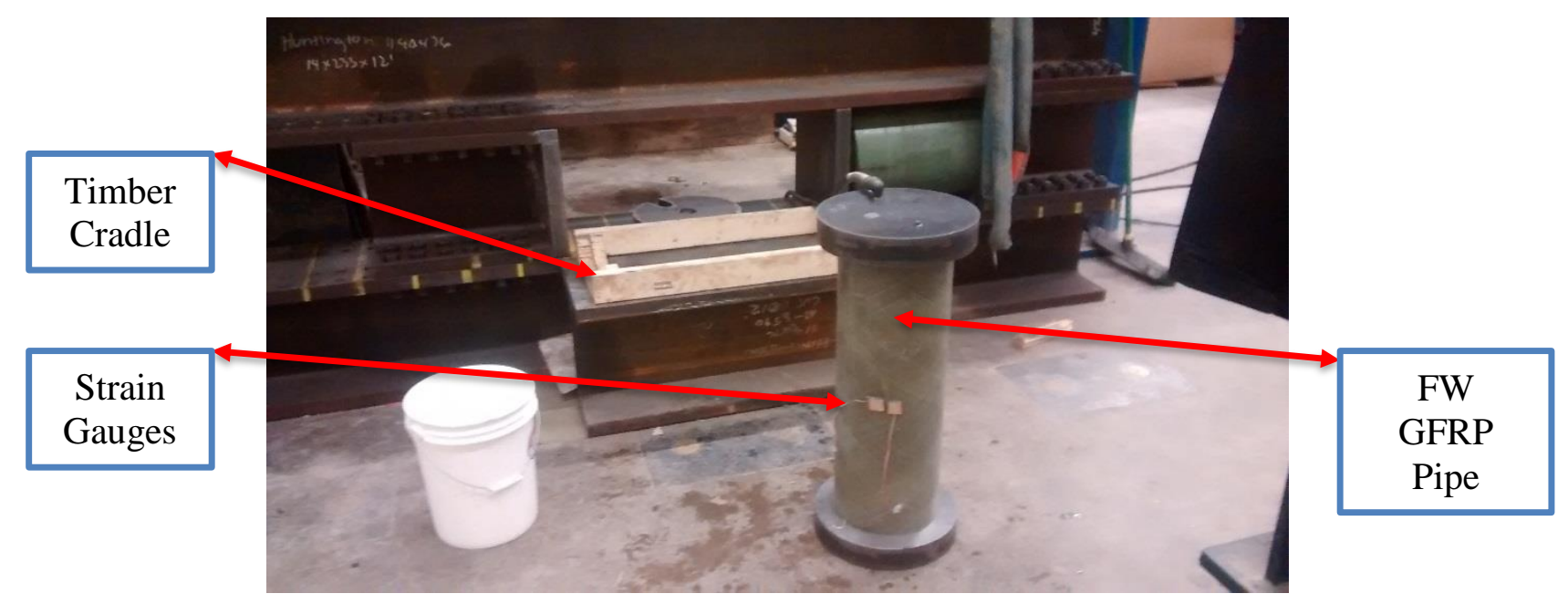

Figure 5-9: Test Preparation

Four strain gauges were placed on each pipe, near the midpoint along the length; two in the hoop directions, one in the longitudinal direction, and one in the fiber angle direction. The gauges and water pressure were monitored using a Vishay System 7000 Data Acquisition System collected data on all channels at 10 scans per second. The pressure was monitored using a Honeywell Pressure Transducer (Model 060-1108-13ZG-01) with a maximum pressure rating of 50,000 psi and an accuracy of $+/-50$ psi.

As load was applied (through the hand pump), strain versus pressure data were collected. During testing, the pipes contracted and were coming out of the endcaps. As has been mentioned, this is because the hoop stress (in the absence of longitudinal stress) produces compression strain in the longitudinal direction (due to Poisson effect and fabric architecture). As the pipe contracted away from the endcaps, the water also caused a longitudinal compression force on the pipe, further causing it to shrink. Therefore, the 800- kip capacity actuator was periodically employed to push the endcaps back onto the pipe, which also served to increase the longitudinal force and internal pressure on the pipe. Therefore, the loading process was often a dynamic process of pumping on both actuators. This process ensured that the O-rings in the endcaps were able to seal to the pipe. 
Load was applied until leakage was observed in the walls of the pipe. Based on the data, stresses and loads were calculated. Figure 5-10 shows a pipe in the frame during testing.

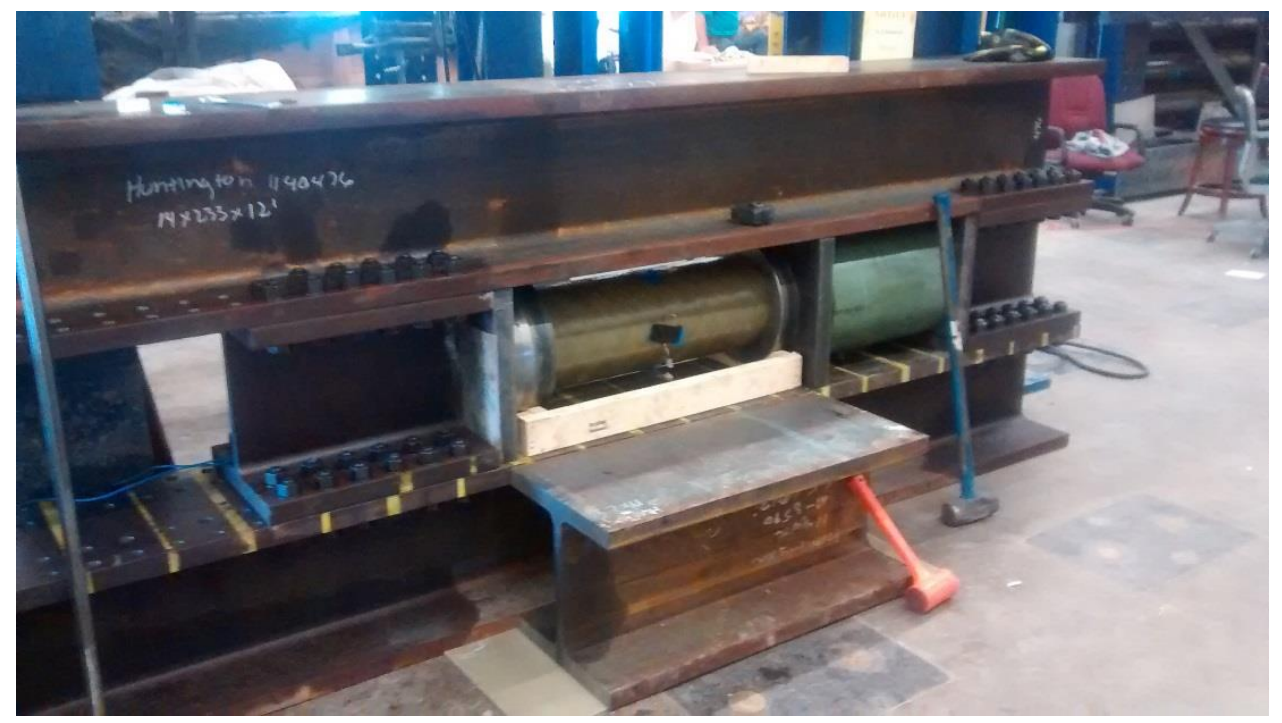

Figure 5-10: Burst Pressure Testing

\subsubsection{Joints}

In addition to the three sets of pipes, two GFRP butt joints and two CFRP scarf joints were tested. The GFRP butt joints were tested in an earlier configuration of the load frame. The butt joints were constructed of two thin-walled pipes (thickness 0.45 inches, ID 9.30 inches), butted together and wrapped with several layers of glass composite (0.375 inches thick). The CFRP scarf joints were fabricated from thin-walled pipes, with male/female type fittings, and several layers of carbon composite. The scarf joints were wrapped in carbon with the hope that the increased hoop stiffness, contributed by the carbon fiber, would contain the joint more successfully than the glass and allow for higher burst pressures. In addition to the four strain gauges placed on the pipes, four gauges were placed on the wrapped joint. Figure 5-11 shows the pressure testing of the GFRP butt joints, in the early iterations of the load frame. 

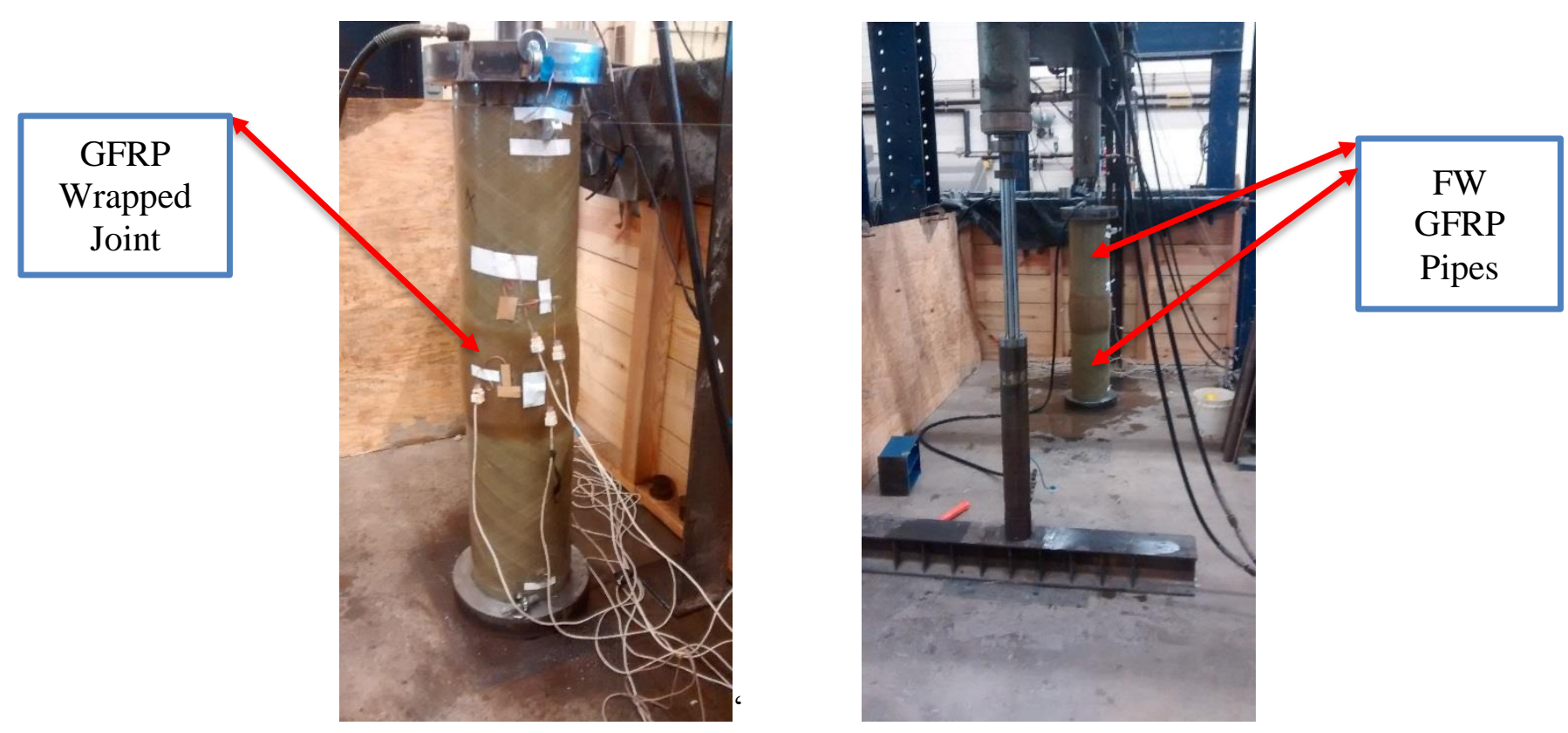

Figure 5-11: GFRP Butt Joint Pressure Testing

\subsection{Hydrostatic Pressure Test Results}

The pipe properties and test results, including strain, pressure and time, are presented in the following sections. The time to failure for each of the pipes was between 5 and 35 minutes. While this time exceeds the 60 to 70 seconds of ASTM 1599, creep effects are not believed to have been a significant factor in the results, as the previous testing up to 2300 psi was left for 100 minutes with no signs of failure.

\subsubsection{Pultruded Pipes}

The results from the 6-inch diameter pultruded pipe and the four 10-inch diameter pultruded pipes are presented in Table 5-1. Since the failure pressures were well below the expected values, little analysis was conducted on these pipes. 
Table 5-1: Pultruded Specimen Results

\begin{tabular}{|l|c|c|c|c|}
\hline \multicolumn{1}{|c|}{ Specimen } & $\begin{array}{c}\text { Inner } \\
\text { Diameter } \\
\text { (in) }\end{array}$ & Thickness(in) & $\begin{array}{c}\text { Burst } \\
\text { Pressure } \\
\text { (psi) }\end{array}$ & $\begin{array}{c}\text { Time to } \\
\text { Failure } \\
\text { (min) }\end{array}$ \\
\hline 6" Pipe & 5.50 & .250 & 1,224 & 6.0 \\
\hline 10" Pipe 1 & 9.25 & .375 & 323 & 5.0 \\
\hline 10" Pipe 2 & 9.25 & .375 & 319 & 2.2 \\
\hline 10" Pipe 3 & 9.25 & .375 & 324 & 1.8 \\
\hline 10" Pipe 4 & 9.25 & .375 & 332 & 2.6 \\
\hline
\end{tabular}

The 6-inch diameter pipe failed via a longitudinal crack running the entire length, i.e. it unzipped, along a seam. This is believed to have occurred at a location where the mats overlapped (discontinuity). The failure was sudden and loud. It was the most violent failure of all the pipes and joints tested. The 10-inch diameter pipes failed through weeping of water through the outer surface of the pipe. In this mode of failure, water was observed to seep through the walls of the pipe. Although pressure loss was observed for the 10-inch diameter pipes, the fibers were not observed to have broken, i.e; potential failure of resin bonding the fibers together.
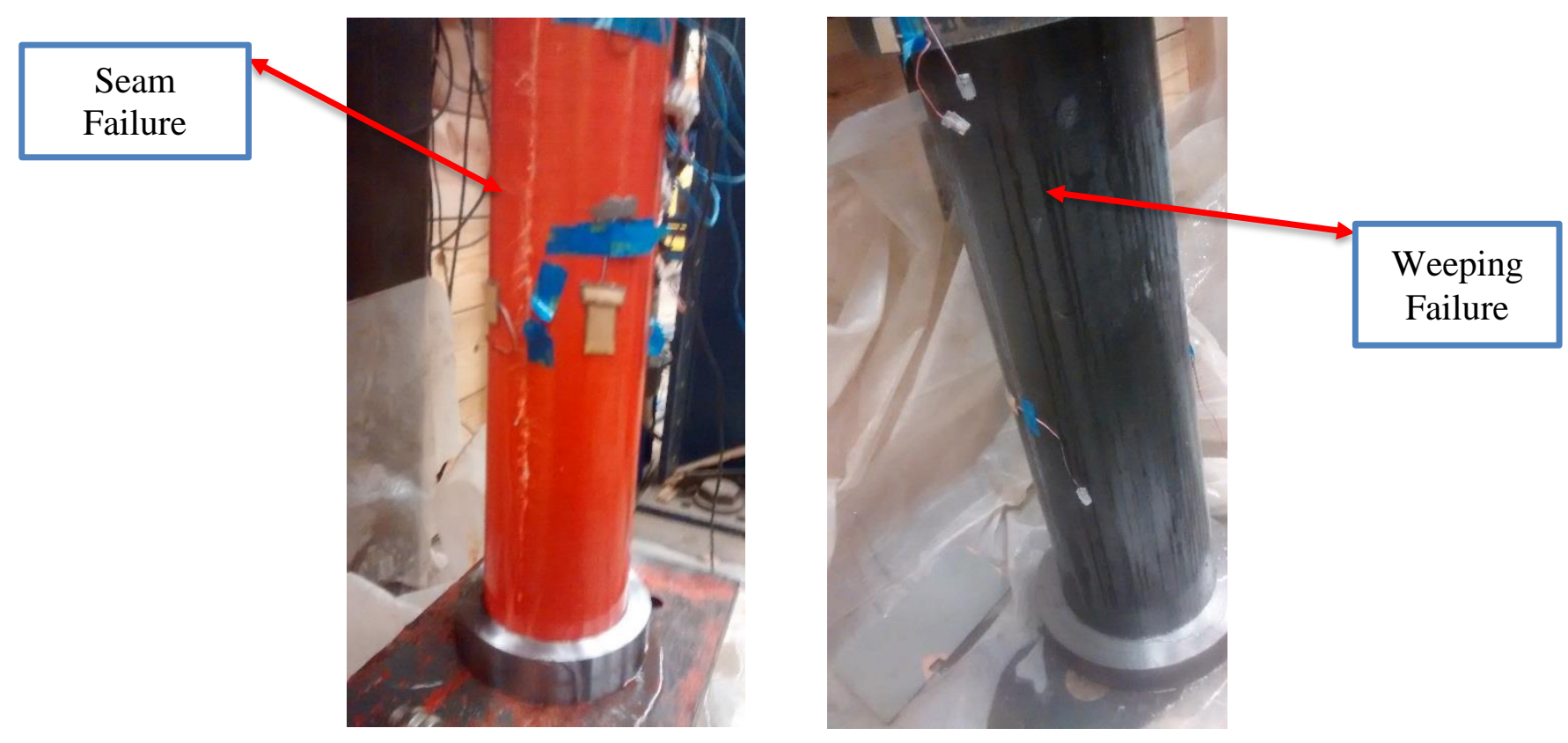

Figure 5-12: Pultruded Pipe Failure Modes 


\subsubsection{Filament-Wound Pipes-3/8 Wall Samples}

Three thin-walled pipes (referred to henceforth as $3 / 8$ wall) were tested under hydrostatic pressure until failure was observed. The pipes failed at an average pressure of 2,957 psi as evident via water spraying out of the walls (as opposed to weeping). Once water began to leak, rapid pressure loss was observed via the pressure transducer. The results from $3 / 8$ wall pipe hydrostatic testing are provided in Table 5-2. It should be noted that hoop strains between the two gauges on a given pipe always measured different, albeit, slightly different. This difference would likely also be seen if additional gauges had been placed in the longitudinal and fiber angle directions. The failure pressures for the three pipes differed by 12 percent, average hoop strains for the three pipes at failure differ by 10 percent, longitudinal strains at failure differ by 31 percent, and fiber angle strains at failure differed by 43 percent. The time to failure for each of the pipes only differ by 8 minutes, suggesting that test time is most likely not responsible for differences in results.

Table 5-2: Hydrostatic Pressure Test Results- FW Thin Wall

\begin{tabular}{|l|c|c|c|c|c|c|c|}
\hline Specimen & $\begin{array}{c}\text { Burst } \\
\text { Pressure } \\
(\mathrm{psi})\end{array}$ & $\begin{array}{c}\text { Hoop A } \\
\text { Failure } \\
\text { Strain } \\
(\mu \epsilon)\end{array}$ & $\begin{array}{c}\text { Hoop B } \\
\text { Failure } \\
\text { strain } \\
(\mu \epsilon)\end{array}$ & $\begin{array}{c}\text { Average } \\
\text { Hoop } \\
\text { Failure } \\
\text { Strain }(\mu \epsilon)\end{array}$ & $\begin{array}{c}\text { Longitudinal } \\
\text { Failure } \\
\text { Strain }(\mu \epsilon)\end{array}$ & $\begin{array}{c}\text { Fiber } \\
\text { Angle } \\
\text { Failure } \\
\text { Strain }(\mu \epsilon)\end{array}$ & $\begin{array}{c}\text { Time to } \\
\text { Failure } \\
(\mathrm{min})\end{array}$ \\
\hline 1 & 2,761 & 15,800 & 15,179 & 15,490 & $-13,425$ & 7,219 & 12.8 \\
\hline 2 & 2,969 & 16,622 & 17,919 & 17,270 & $-12,975$ & 4,855 & 14.0 \\
\hline 3 & 3,142 & 15,415 & 17,411 & 16,278 & $-19,475$ & 4,085 & 20.9 \\
\hline
\end{tabular}

The hoop stress equation (for thin walled pipes) was used to determine hoop stresses. Hoop stresses at failure were $28,711,30,571$, and 32,067 psi for pipes 1-3 respectively. Figure 5-13 shows the stress/strain response until failure. The figure shows consistent hoop stress/strain response up to failure across the three pipes. This fact demonstrates that the test method produces consistent results, for the $3 / 8$ wall specimens. 


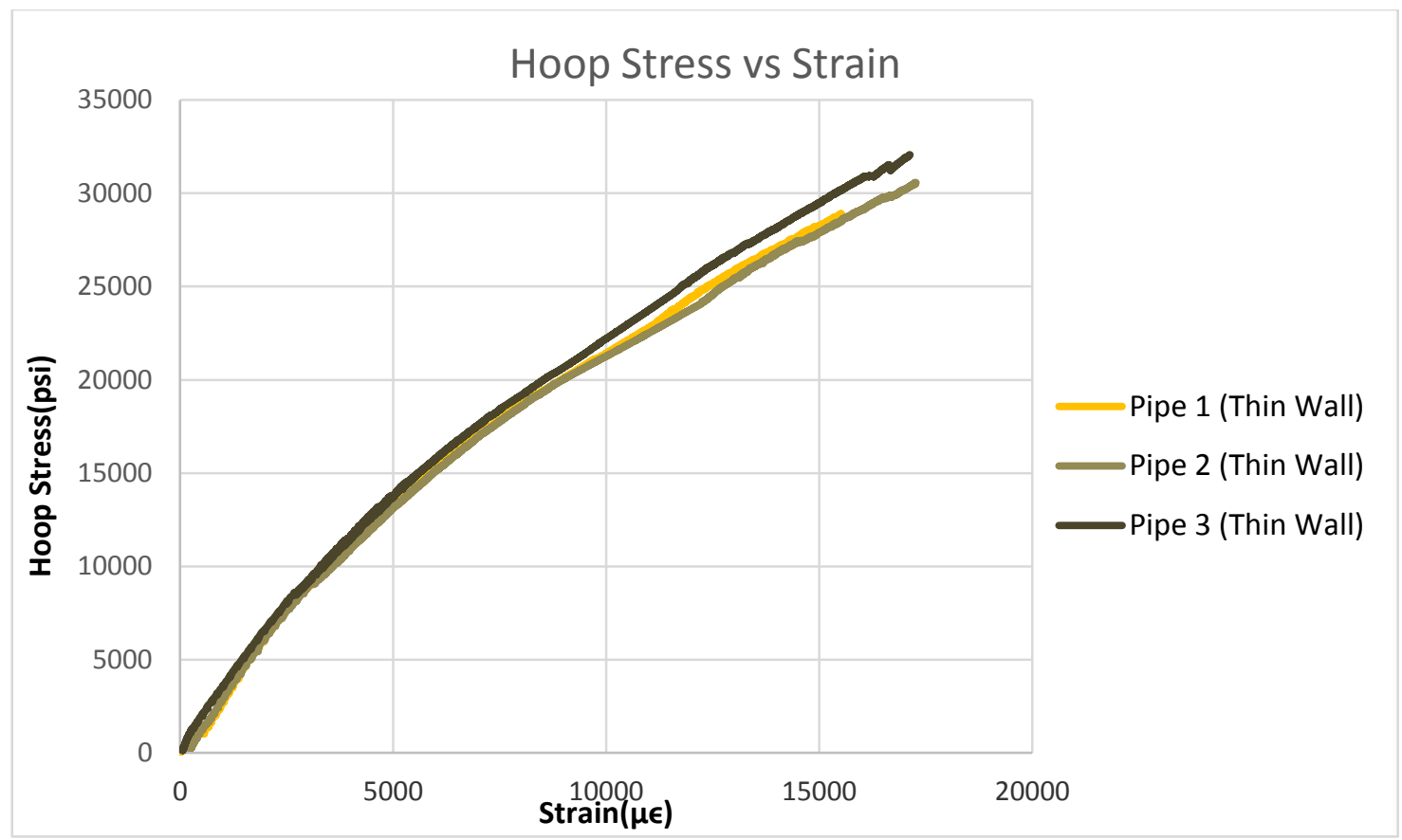

Figure 5-13: Stress/Strain Response of Thin Pipes

The failure mode of these pipes was not catastrophic, unlike typical mechanical testing of composite pipes or the catastrophic failure of the 6-inch diameter pultruded pipe. Once a significant amount of pressure was lost, the pipes contracted and the leaks were sealed. Figure 5-14 shows the pipe immediately after failure. No external damage was apparent, except a few small regions of discoloration, which typically indicates local delamination of layers. In some situations, one or two leaks appeared at the same moment, implying some degree of uniformity in damage progression. The light green region of the pipe in Figure 5-15 shows the local delamination of the layers in the wall. 


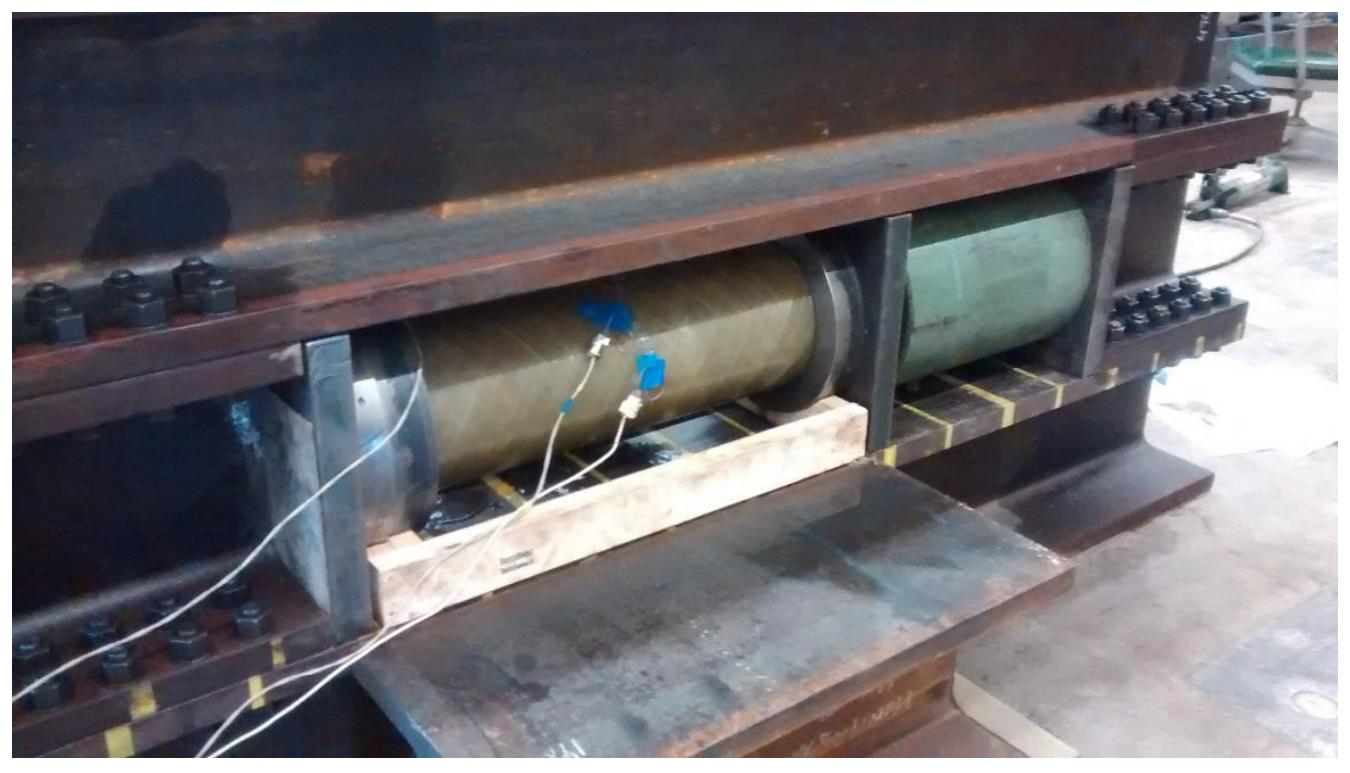

Figure 5-14: Pipe Leakage

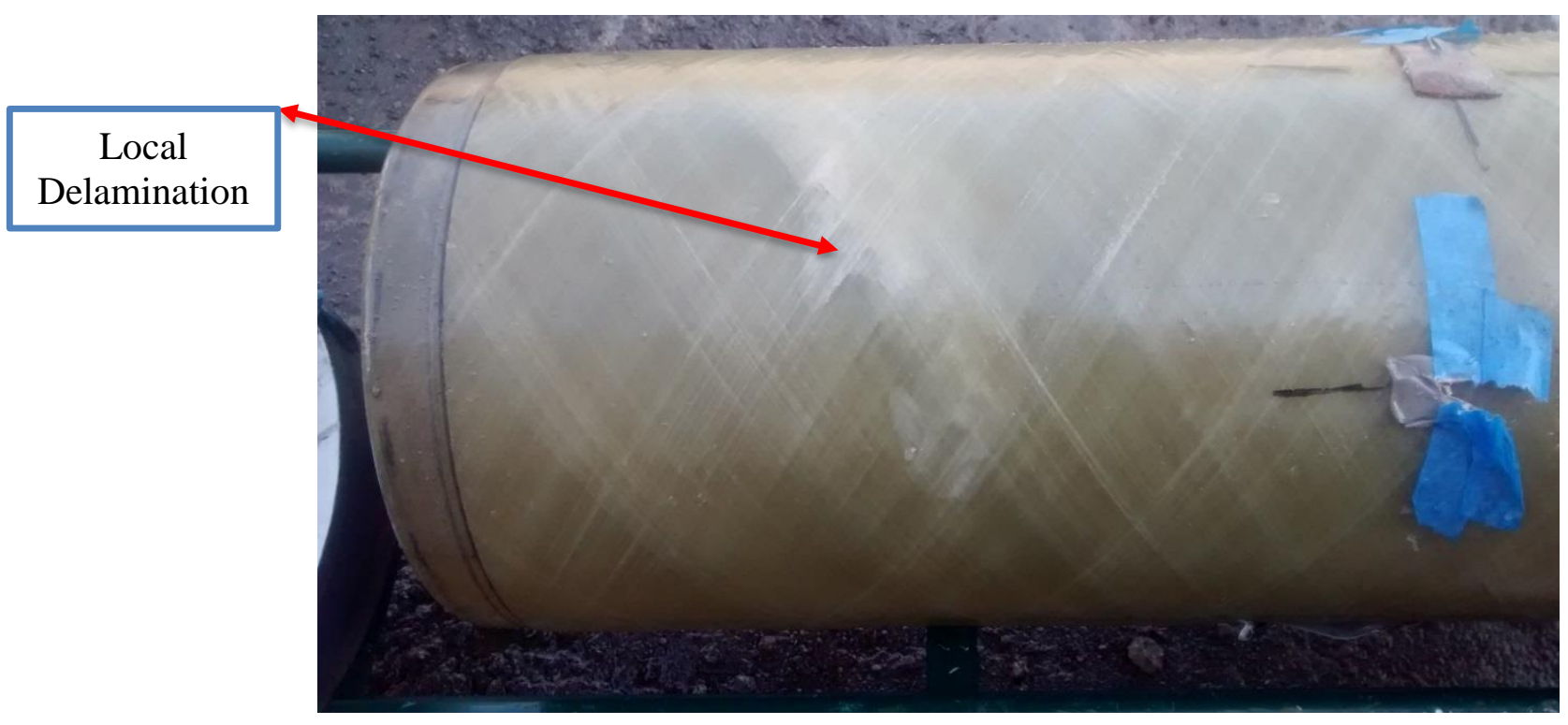

Figure 5-15: Local Delamination

By contrast, the interior corrosion barrier layer (mainly composed of chopped strand mat) displayed significant delamination. The leaks first appeared in areas where the interior laminae had delaminated. Therefore, the failure appears to be primarily related to the resin and shear stresses. While the pattern of internal damage was not always consistent, in a few occasions, the resin appears to have failed in a helical progression. This helical failure is likely due to torsion 
stresses generated by the unsymmetrical architecture. While this torsion does not appear to have caused fiber failure, the torsion may have been the cause failure for the corrosion barrier. Figure 5-16 shows the damage of the corrosion barrier layer.

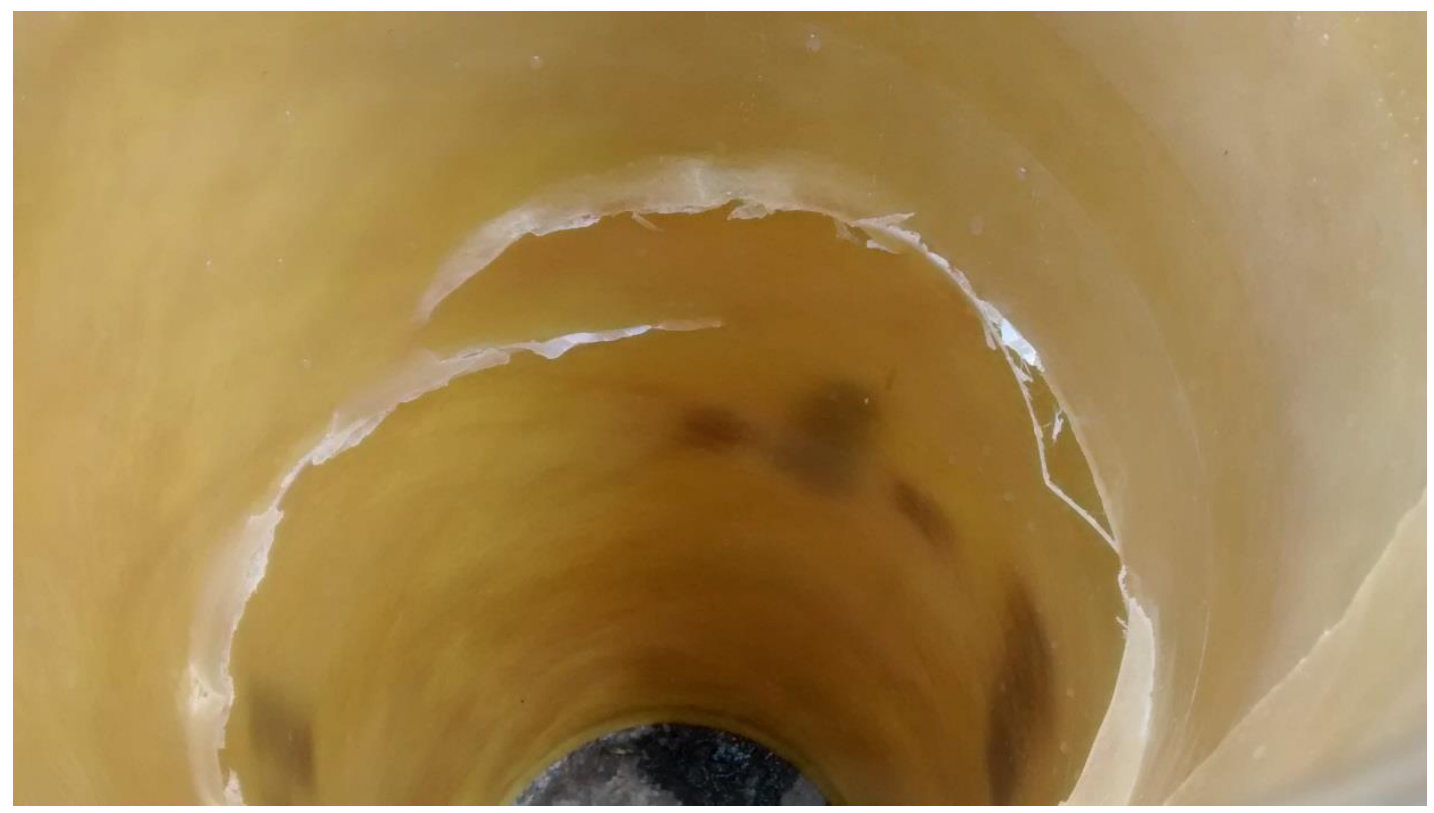

Figure 5-16: Damage to Corrosion Barrier

\subsubsection{Filament Wound Pipes -3/4 Wall Samples}

As has been mentioned previously (Chapter 4), a second set of pipes was tested to evaluate the effects of increased thickness. The second set of pipes had an average thickness of 0.80 inches, and are referred to herein as $3 / 4$ wall as the filament wound thickness is nominal $3 / 4$ of an inch. Since these pipes were made with double the wall thickness, the burst pressure was expected to double as well.

As shown in Table 5-3, specimens 1 and 2 failed at pressures near 5,200 psi (within 75 psi). However, specimen three failed at a much lower pressure of 4,000 psi. Furthermore, significant differences for the three samples in hoop and longitudinal strains at failure were observed (42 percent and 57 percent respectively). Differences in fiber angle strains differed in 
terms of tension/compression and magnitude. In general, greater variability of failure pressures, stresses at failure, and strains at failure were observed for the $3 / 4$ wall specimens than for the $3 / 8$ wall specimens. One explanation for the variation in results could be the differing times to failure of nearly 23 minutes. It is possible that a faster load rate caused quicker failures, while the slower load rate allowed for greater damage progression prior to failure (i.e. higher stresses and strains to failure).

Table 5-3: Hydrostatic Pressure Test Results-FW Thick Wall

\begin{tabular}{|l|c|c|l|c|c|c|c|}
\hline Specimen & $\begin{array}{c}\text { Burst } \\
\text { Pressure } \\
(\mathrm{psi})\end{array}$ & $\begin{array}{c}\text { Hoop A } \\
\text { Failure } \\
\text { Strain }(\mu \epsilon)\end{array}$ & $\begin{array}{l}\text { Hoop } \\
\text { Failure } \\
\text { Strain }(\mu \epsilon)\end{array}$ & $\begin{array}{c}\text { Average } \\
\text { Hoop } \\
\text { Failure } \\
\text { Strain }(\mu \epsilon)\end{array}$ & $\begin{array}{c}\text { Longitudinal } \\
\text { Strain at } \\
\text { Failure }(\mu \epsilon)\end{array}$ & $\begin{array}{c}\text { Fiber } \\
\text { Angle } \\
\text { Strain at } \\
\text { Failure }(\mu \epsilon)\end{array}$ & $\begin{array}{c}\text { Time } \\
\text { to } \\
\text { Failure } \\
(\min )\end{array}$ \\
\hline 1 & 5,172 & 26,477 & 23,045 & 24,761 & $-37,543$ & -467 & 34 \\
\hline 2 & 5,247 & 11,927 & 15,617 & 13,770 & $-18,938$ & 1,623 & 25 \\
\hline 3 & 4,024 & 14,816 & 13,889 & 14,352 & $-16,274$ & $-1,505$ & 11 \\
\hline
\end{tabular}

As with the $3 / 8$ wall specimens, the hoop stress equation (for thin walled pipes) was used to determine hoop stresses for the $3 / 4$ wall specimens. Hoop stresses at failure are $32,758,33,233$ and 25,487 psi for these pipes 1-3 respectively. Stress/strain curves for the three thick wall pipes are provided in Figure 5-17. Fairly consistent stress/strain results are observed for the three pipes in the elastic zone (10 to 30 percent of ultimate stress), although specimen 2 does appear to have a slightly higher hoop modulus. However, the three pipes differed in terms of failure progression and failure strains. As failure progressed, differences became apparent. Stress/strain responses of pipes 1 and 3 trend well, except that pipe three failed under a much lower pressure. Pipe 2 and 3 have similar failure pressures and stresses, but differ in stress/strain response and failure strains. 


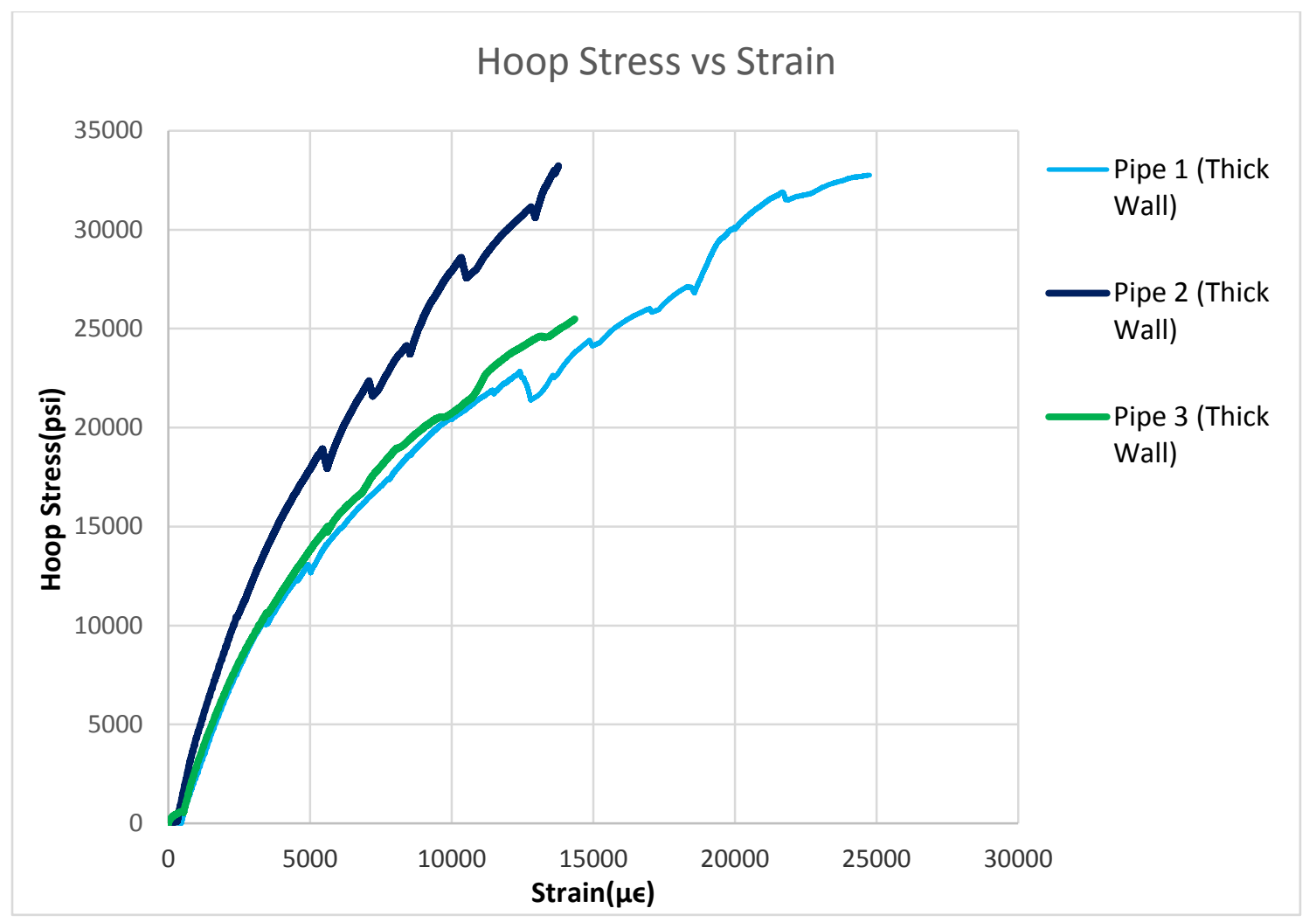

Figure 5-17: Stress/Strain Results of Thick Pipes

The $3 / 4$ wall pipes exhibited similar failure modes as the $3 / 8$ wall pipes. Once a leak developed, pressure was lost and the walls contracted. As with the $3 / 8$ wall specimens, the external fibers did not break. Significant discoloration (typically observed in interlaminar delamination) were observed for specimen 1. Although exterior fiber breakage was not observed, the extent of the delamination (in specimen 1) was uniform (as evidenced by uniform discoloration). However, specimens 2 and 3 displayed only minor exterior discoloration. Delaminations were only observed locally. 


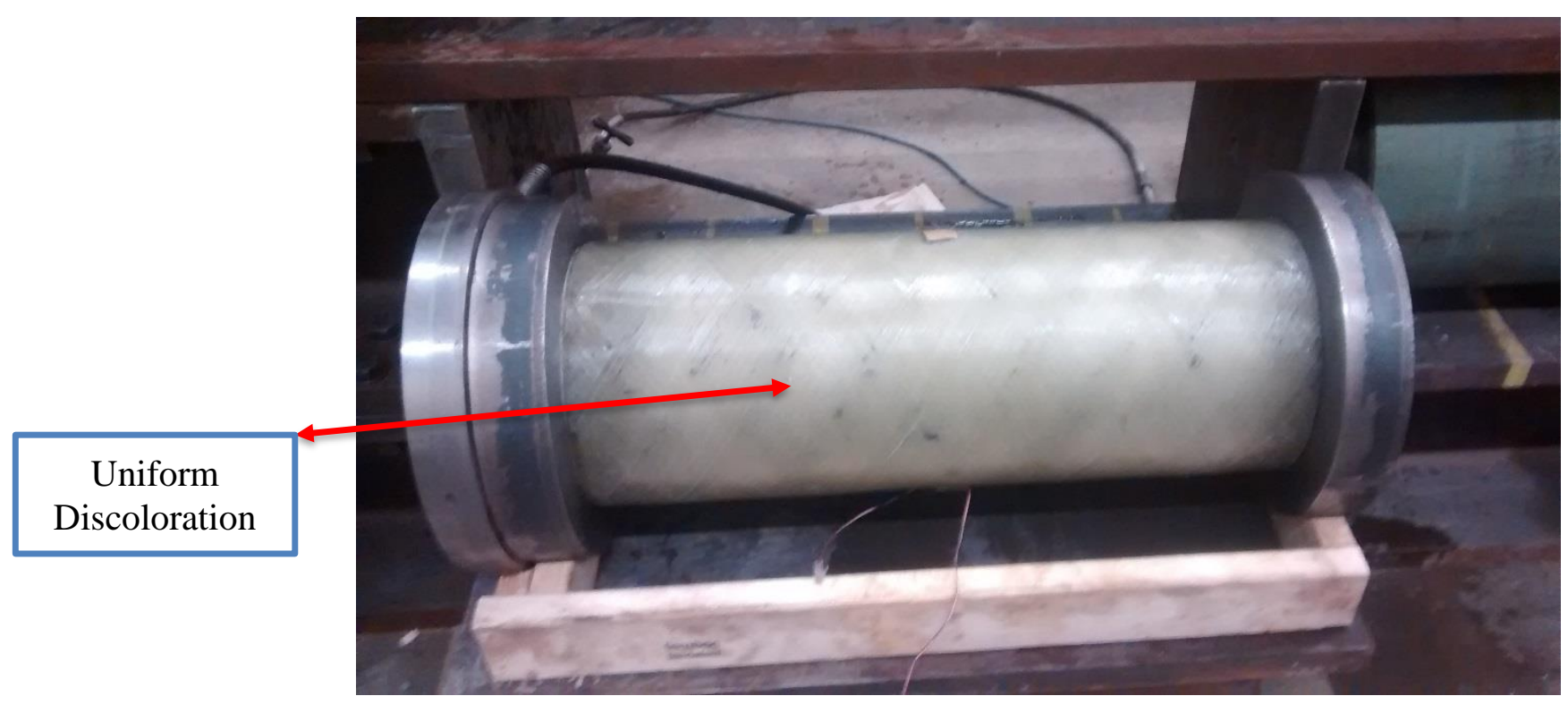

Figure 5-18: 3/4 wall Specimen 1 Discoloration

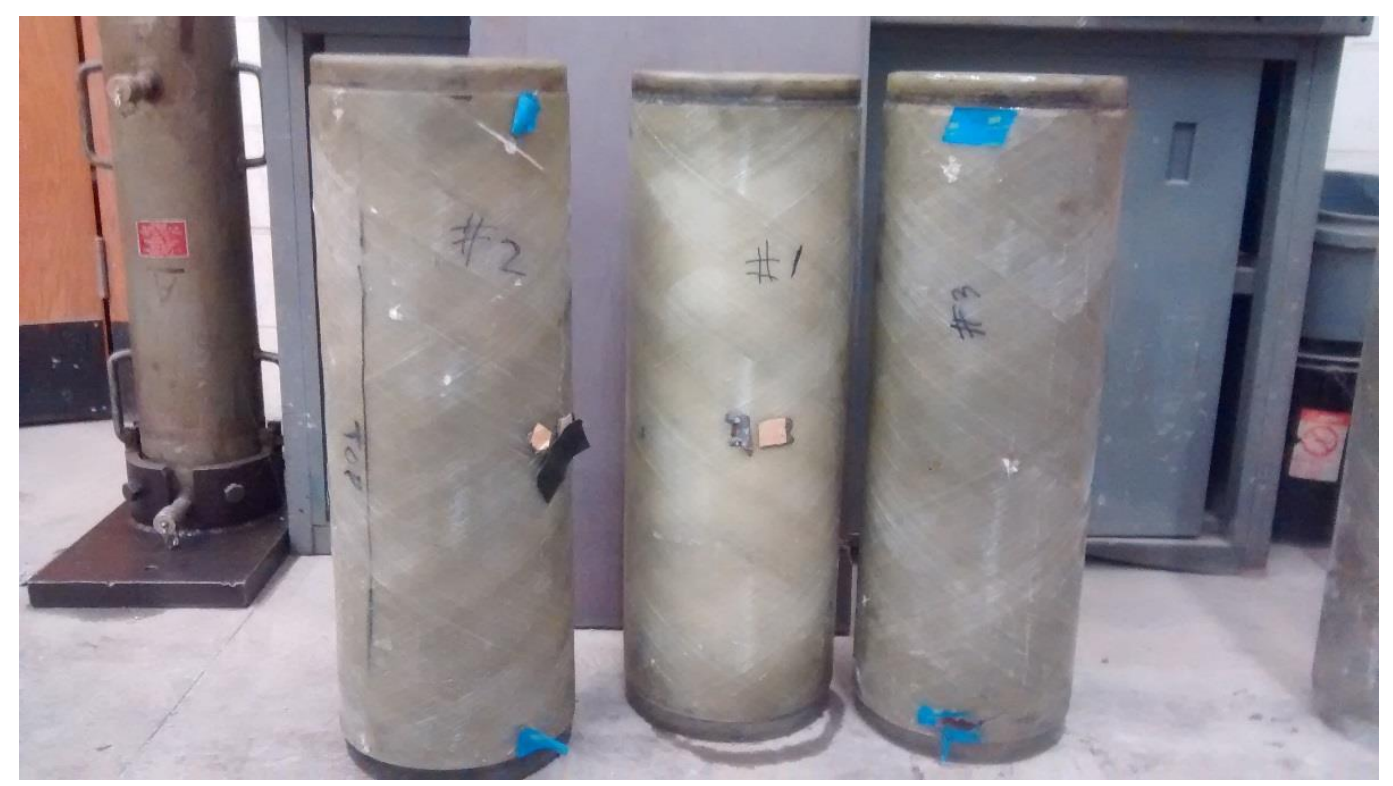

Figure 5-19: Exterior Damage of Thick Walled Pipes

The interior damage was also not consistent. Specimen 1, which exhibited the most exterior discoloration, displayed significant damage to the corrosion barrier layer. Specimen 2 displayed a small amount of interior damage and exterior discoloration. In comparison with specimens 1 and 2, specimen 3 appears to be an outlier. Specimen 3 displayed no interior damage and very little 
exterior discoloration. Specimen 3 developed only one leak and failed at an internal pressure 1,200 psi below that of specimens 1 and 2. Very likely, this could be due to manufacturing flaw. This is supported by the similar elastic behavior and failure progression to the specimen 1 , the only difference between the two failure pressure and failure strains. However, no external flaws were visible prior to testing. Additional testing is required to statistically determine how often these premature failures may occur. Therefore, the failure modes do not appear to be as consistent as the thin wall pipes. Furthermore, failure modes are not consistent with the thin-walled pipes. Torsional failure of the resin rich barrier was not evident in the thick-walled pipes. Figure 5-20 shows the interior damage of pipe two (left) and pipe one (right). Figure 5-21 shows the interior damage pipe one (left) and three (right).

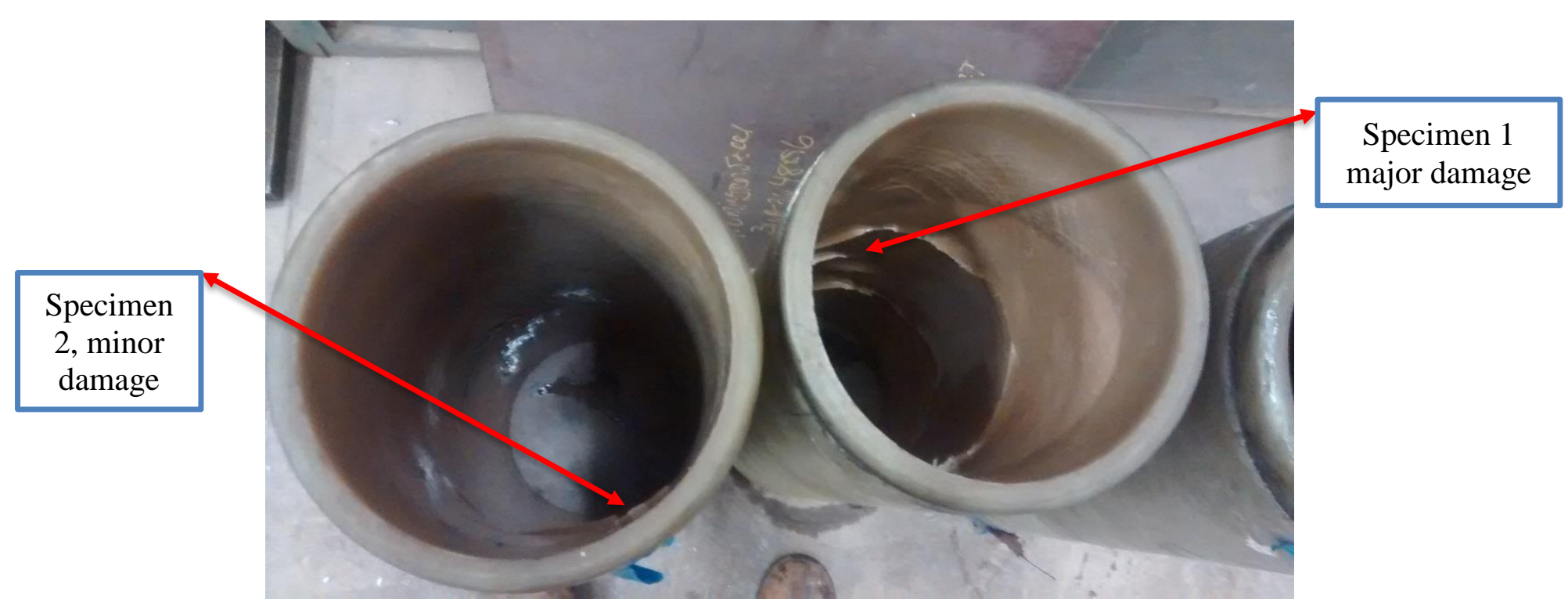

Figure 5-20: Interior Damage of Specimen 1 and 2 


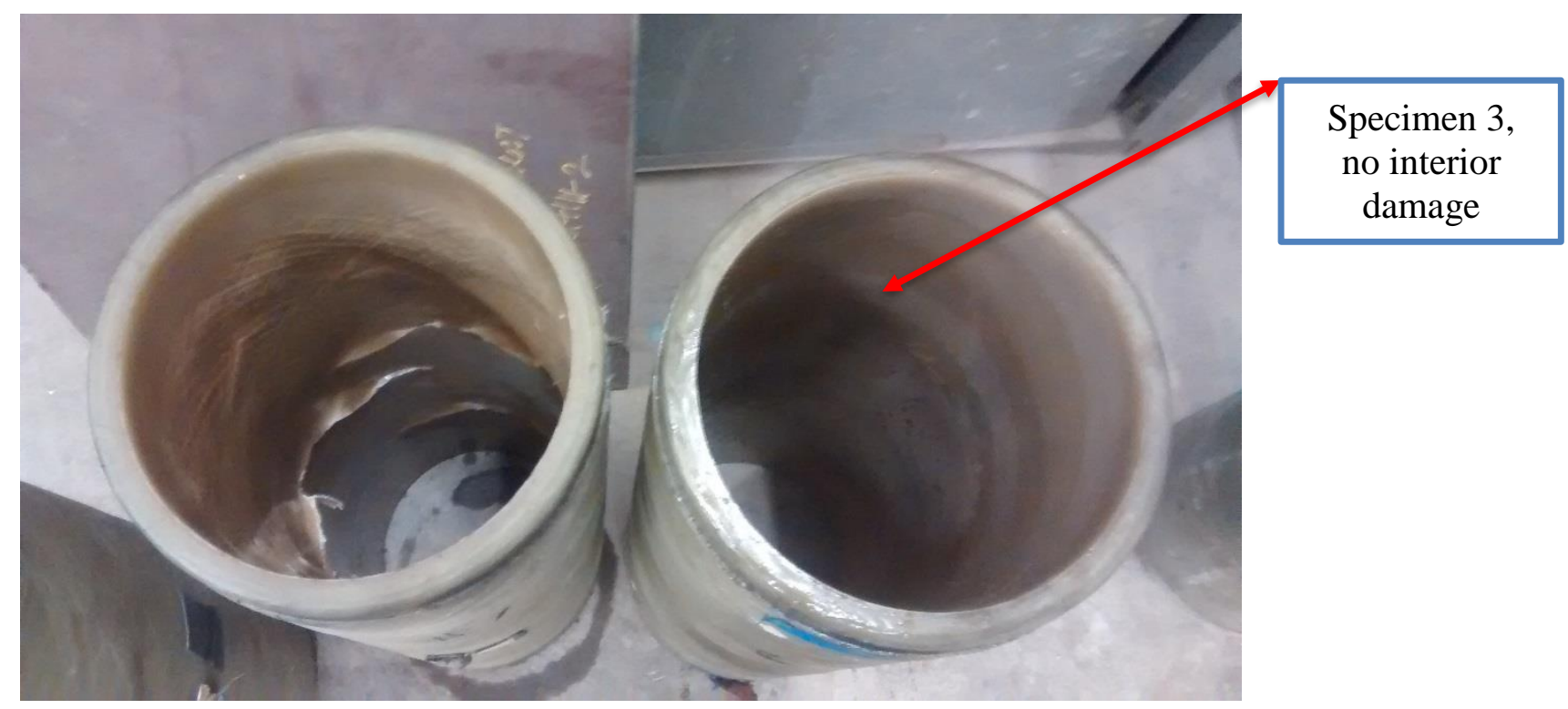

Figure 5-21: Interior Damage of Specimen 1 and 3

\subsubsection{GFRP Wrapped Butt Joints}

Two GFRP wrapped butt joint samples were tested under hydrostatic pressure, and both failed at $1 / 3^{\text {rd }}$ of the burst pressure due to water leaking between the external wrap and the outside of the pipe. Therefore, the bond of the GFRP wrap resin to the outside of the pipe was the limiting factor in the joint response. Figure 5-22 shows the failure at the edge of the wrap, as well as discoloration due to delamination. Figure 5-23 shows the wrap, which has pulled away from the outside surface of the pipe. 

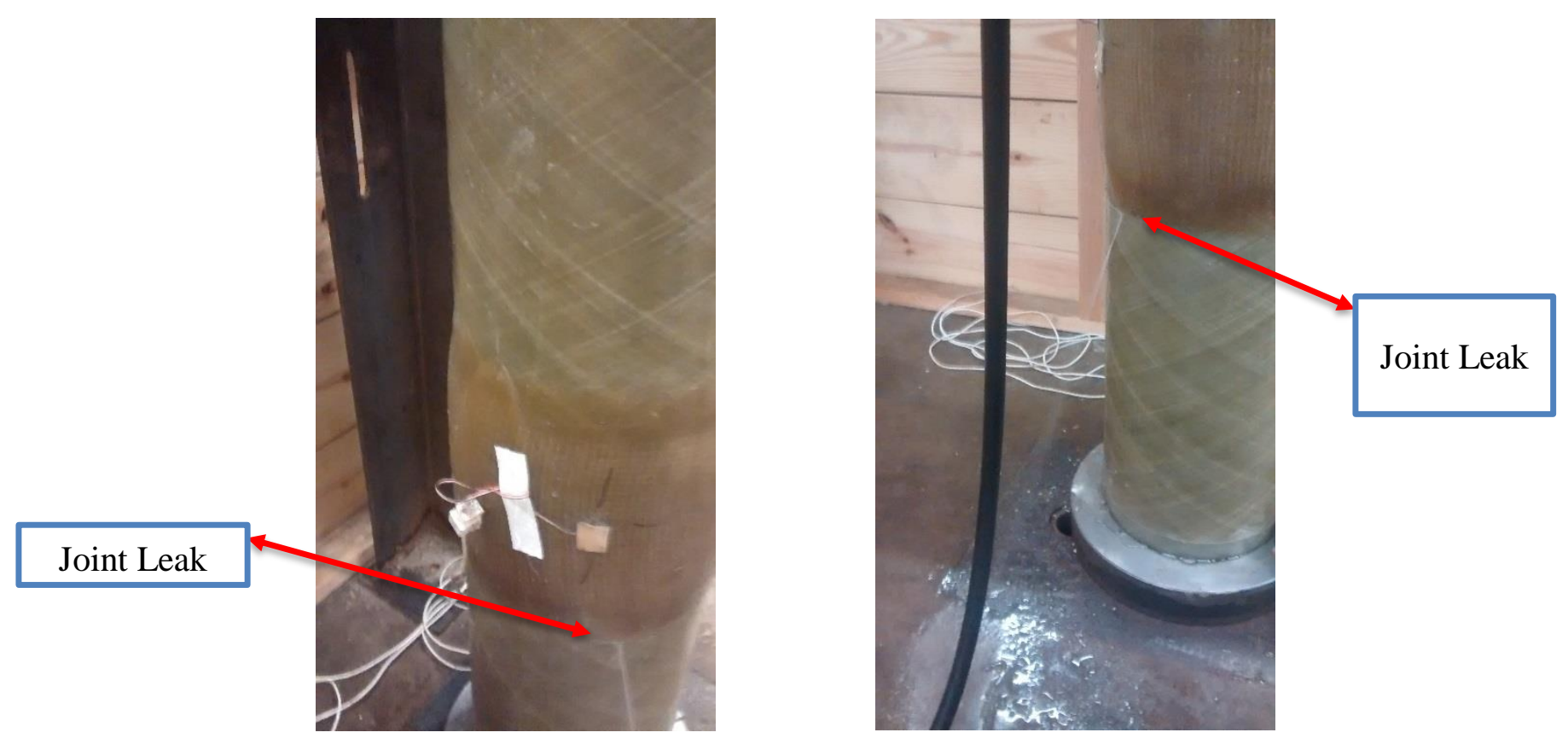

Figure 5-22: Butt Joint Failure

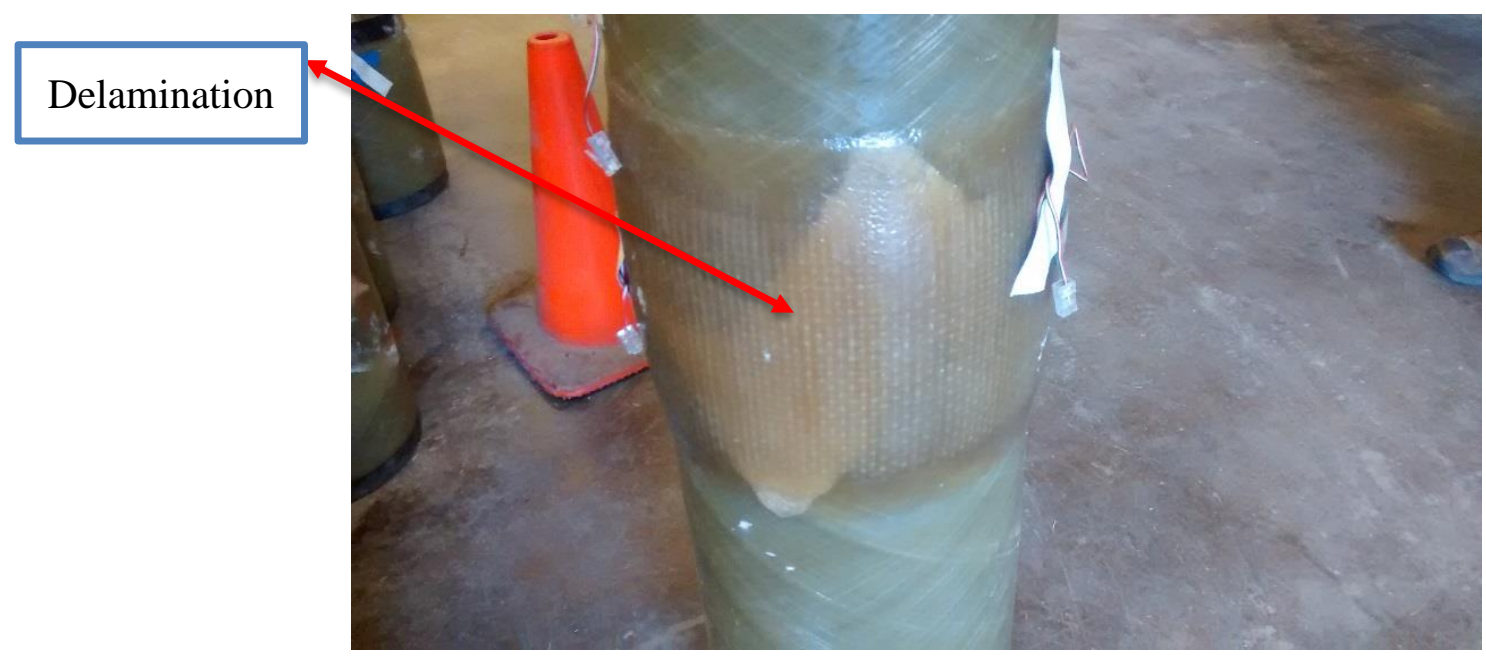

Figure 5-23: Delamination of Wrapped Butt Joint

Strain gages were installed on the pipe 2 inch from the wrap and on the wrap itself, with the results summarized in Table 5-4. The hoop strain in the pipe was greater than the hoop strain in the wrap, indicating that the pipe was expanding into the wrap which should result in a better seal. However, the test results show this mechanical advantage was not enough to prevent leakage. 
The longitudinal strains were also significantly lower in the wrap, indicating the pipe may be pulling out of the wrap.

Table 5-4: GFRP Wrapped Butt Joint Results

\begin{tabular}{|l|l|l|l|l|l|l|}
\hline Specimen & $\begin{array}{c}\text { Failure } \\
\text { Pressure } \\
(\mathrm{psi})\end{array}$ & $\begin{array}{c}\text { Pipe } \\
\text { Hoop } \\
\text { Strain at } \\
\text { Failure }\end{array}$ & $\begin{array}{c}\text { Pipe } \\
\text { Longitudinal } \\
\text { Strain at Failure }\end{array}$ & $\begin{array}{c}\text { Wrap } \\
\text { Hoop } \\
\text { Strain at } \\
\text { Failure }\end{array}$ & $\begin{array}{c}\text { Wrap } \\
\text { Longitudinal } \\
\text { Strain at Failure }\end{array}$ & $\begin{array}{c}\text { Time to } \\
\text { failure } \\
\text { (min) }\end{array}$ \\
\hline Joint 1 & 1,116 & 4,769 & $-3,417$ & 1,989 & -567 & 8.4 \\
\hline Joint 2 & 1,294 & 6,048 & $-4,554$ & 2,412 & $-1,737$ & 8.3 \\
\hline
\end{tabular}

Although the jointed pipes did not fail, their behavior can be compared to the burst test results. The hoop strain in the pipe for the joint samples was higher at the failure pressure than during the burst samples as the average strain in the burst samples was 4,105 at 1,116 psi and 4,953 at 1,294 psi. Similarly, the Poisson ratio for the joint tests during hydrostatic loading averaged 0.66 vs. 0.98 for the burst tests. Given the limited number of samples, it is not known if these differences are due to natural variability in the samples, test variations, or because of mechanical responses differences between a jointed and non-jointed pipe.

\subsection{Split Ring Test Methodology}

Split ring testing is employed so that the apparent hoop tensile strength of composite pipes can be determined in a cost effective and easily reproducible manner. Both pressure testing and split ring testing primarily evaluate the hoop strength of a pipe. Therefore, split ring testing was conducted to determine whether the split ring test would yield similar hoop stress/strain results to the burst pressure testing. The goal in the testing was to determine if the more economical and efficient split ring method corresponds to the pressure testing in terms of elastic behavior, failure progression, and failure stresses. 
Split ring testing for composite pipes is detailed in ASTM D2290. Apparent hoop tensile strength (rather than actual hoop tensile strength) is determined because split ring testing exerts a small bending stress in addition to tensile stress, but the fixture design seeks to minimize this effect. However, this bending stress may cause some degree of error in the hoop modulus, since strains at the location of strain gauges are caused by hoop tensile stress and bending stress (ASTM, 2016).

\subsubsection{Test Frame}

ASTM D 2290 provides several methods for hoop tensile strength evaluation. For this testing, procedure A was used. Procedure A applies to full-wall rings cut from reinforced thermoset resin pipe. The fixture used for this procedure is provided in Figure 5-24.

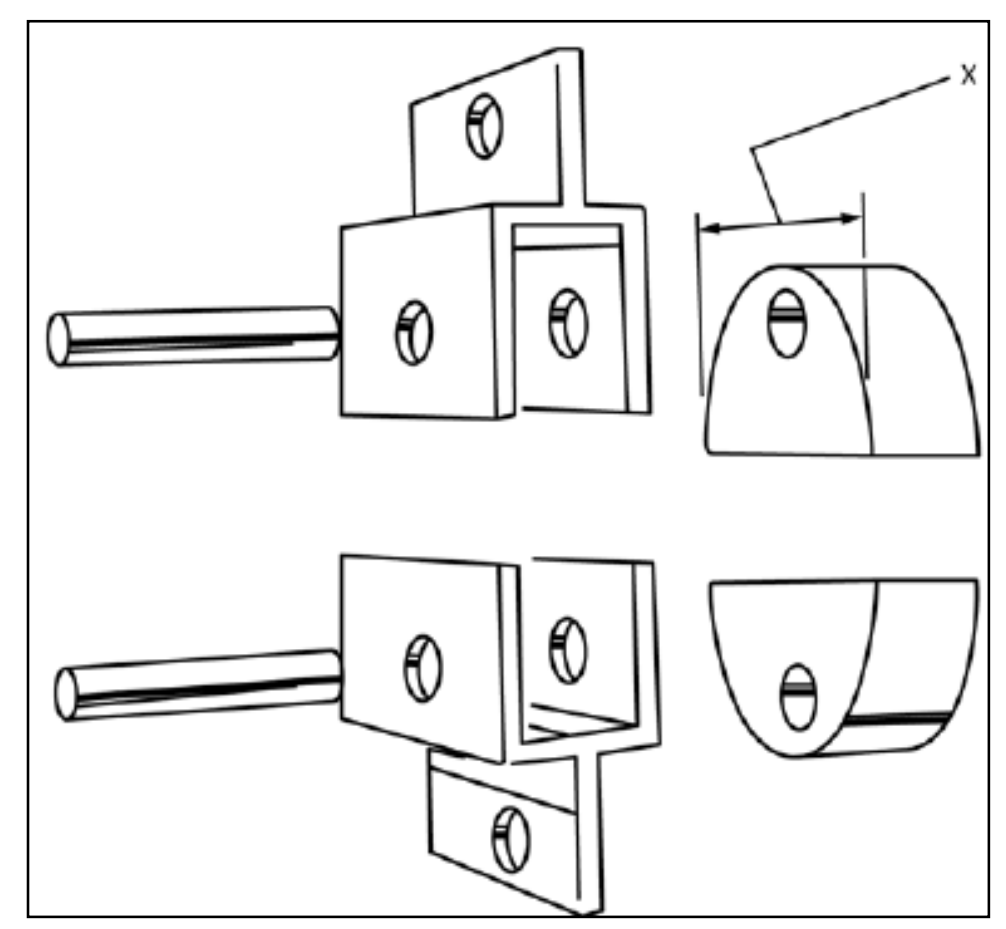

Figure 5-24: Split Ring Test Frame (D2290)

The fixture used in this research was designed to withstand 80 kips. It is comprised of two 2 inchesx 4 inchesx 15 inches grade 50 steel plates, two Grade 12.9, 1-inch diameter bolts and nuts, 
and two 2-inch thick, 4.65 -inch radius, grade 50 semi circles. One of each of the frame pieces can be seen in Figure 5-25. The semi circles were designed to handle specimens with widths ranging from 0.9 inches to 1.9 inches and thicknesses ranging from 0.1 inch to 1 inch. The Intron HDX1000 test frame, used to grip the fixture and apply tension, has a capacity of 220 kips.

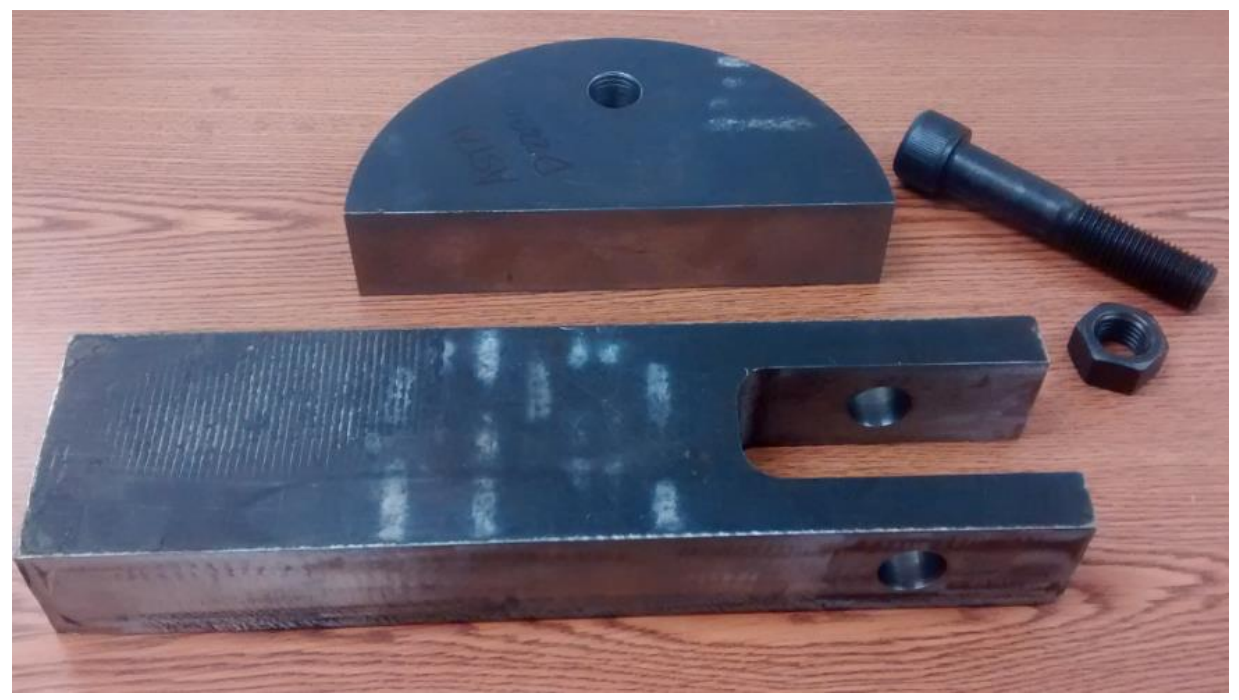

Figure 5-25: Split Ring Test Frame Fixture

\subsubsection{Sample}

Five samples were cut from the undamaged pipe sections of the butt wrapped joint samples (i.e. sample that failed in the joint well below the pipe burst capacity). The specimen is required to have at least one reduced area, rotated 2 inches from the split in the fixture in order to produce failure at a location other than the split. This allows researchers to determine hoop stress with minimum bending effects. In this research, sample widths were between 1.00 and 1.25 inches. The reduced width was 0.75 inches. A specimen is seen in Figure 5-26. 


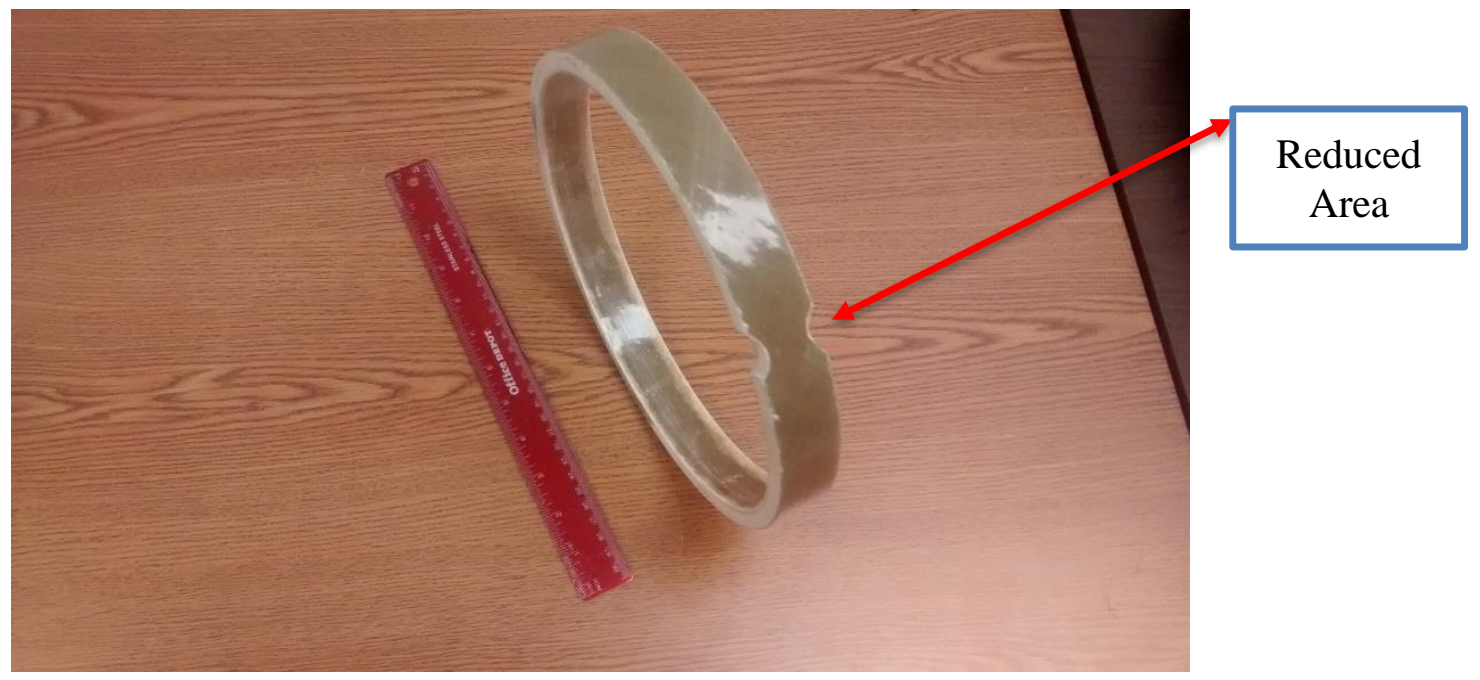

Figure 5-26: Split Ring Specimen

\subsubsection{Loading}

During testing, the fixture heads are separated at a rate of $0.1 \mathrm{inch} / \mathrm{min}$. As the fixture heads are separated, the fibers begin to experience hoop stress. This simulates the effect of a coupon under tensile loading. The load is carried by two sides of the ring, meaning that magnitude of stress is $1 / 2$ of the load, divided by the reduced area. Since the reduced section area is smaller by nearly 40 percent than the total cross sectional area, the stress is significantly increased at the reduced area. This means that failure occurs in the reduced area.

Strain gauges were placed in the hoop direction at the reduced area in each of the specimens. During testing, load and hoop strains were measured. The specimens were loaded until failure. The data was used to determine, hoop modulus, stress/strain curves, and failure stress. Figure 5-27 shows the test procedure at the moment loading was initiated. The reduced area can be clearly seen, rotated two inches from the split in the plates. 


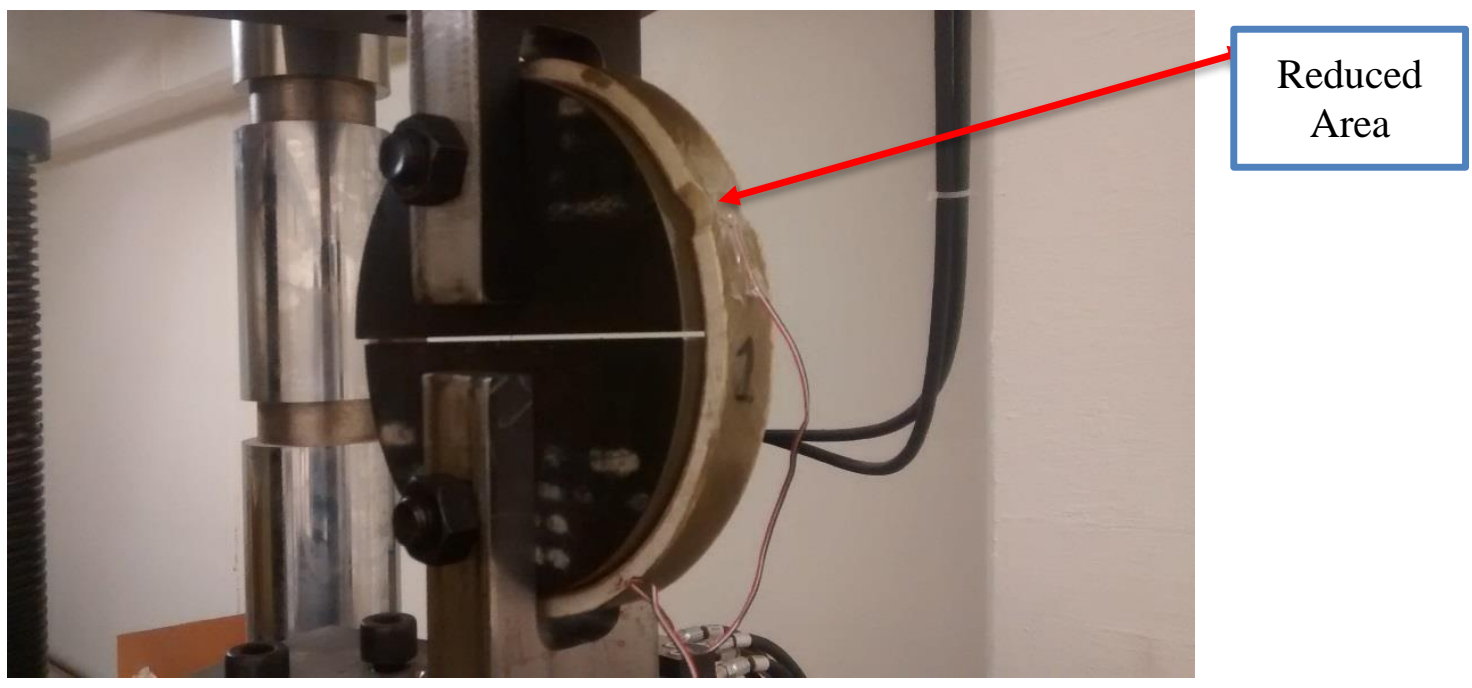

Figure 5-27: Split Ring Test Sample 1

\subsection{Split Ring Test Results}

Prior to testing, thickness and widths of each of the specimens were measured. After the samples were loaded to failure, the stress/strain results, hoop modulus (10 to 30 percent ultimate stress), and failure strengths were determined. The samples dimensions are provided in Table 5-5. The specimens differ in dimensions slightly due to differences in machining.

Table 5-5: Split Ring Specimen Dimensions

\begin{tabular}{|c|c|c|c|c|}
\hline Sample & Width(in) & $\begin{array}{c}\text { Reduced } \\
\text { Width(in) }\end{array}$ & Thickness(in) & $\begin{array}{c}\text { Reduced } \\
\text { Area(in }^{2} \text { ) }\end{array}$ \\
\hline 1 & 1.250 & .806 & .433 & .349 \\
\hline 2 & 1.248 & .828 & .429 & .355 \\
\hline 3 & 1.253 & .764 & .440 & .336 \\
\hline 4 & 1.259 & .801 & .350 & .280 \\
\hline 5 & 1.000 & .615 & .425 & .261 \\
\hline
\end{tabular}

The failures occurred consistently at the intended location, the elastic properties and failure properties varied very little. Specimen 4 was a section of the pipe that had been machined to fit into the end caps, and is excluded from the results as the machining resulted in significantly lower failure stresses. The measured moduli of elasticity, taken between 10 and 30 percent of the ultimate 
stress, were consistent for the first 3 samples, but the smaller Sample 5 differed by $23 \%$, indicating that the size of the sample plays a significant role in the results.. The failure stresses varied by as much as 4,300 psi (7 percent). Ultimate strains varied by nearly 5,300 micro strain (22.7 percent). The mechanical properties from the tests are provide in Table 5-6

Table 5-6: Split Ring Mechanical Properties

\begin{tabular}{|c|c|c|l|l|c|}
\hline Sample & $\begin{array}{l}\text { Ultimate Load } \\
(\mathrm{lbf})\end{array}$ & $\begin{array}{l}\text { Ultimate Stress } \\
(\mathrm{psi})\end{array}$ & $\begin{array}{l}\text { Ultimate } \\
\text { Strain } \\
(\mu \epsilon)\end{array}$ & $\begin{array}{l}\text { Elastic } \\
\text { Modulus } \\
(\mathrm{Msi})\end{array}$ & $\begin{array}{l}\text { Time to Failure } \\
(\mathrm{min})\end{array}$ \\
\hline 1 & 39,730 & 56,879 & 18,000 & 4.22 & 4.7 \\
\hline 2 & 41,423 & 58,425 & 19,500 & 4.55 & 4.8 \\
\hline 3 & 39,379 & 58,643 & 23,300 & 4.63 & 4.4 \\
\hline 5 & 31,986 & 61,217 & 23,210 & 3.42 & 4.6 \\
\hline
\end{tabular}

Stress/strain curves for the five split ring samples are shown in Figure 5-28. In general, the curves reveal very similar elastic behavior, as well as failure progression. The time to failure for each of the samples was very consistent, ranging from 4.4 to 4.8 minutes. The test appears to produce consistent data in terms of failure stresses and failure strains. 


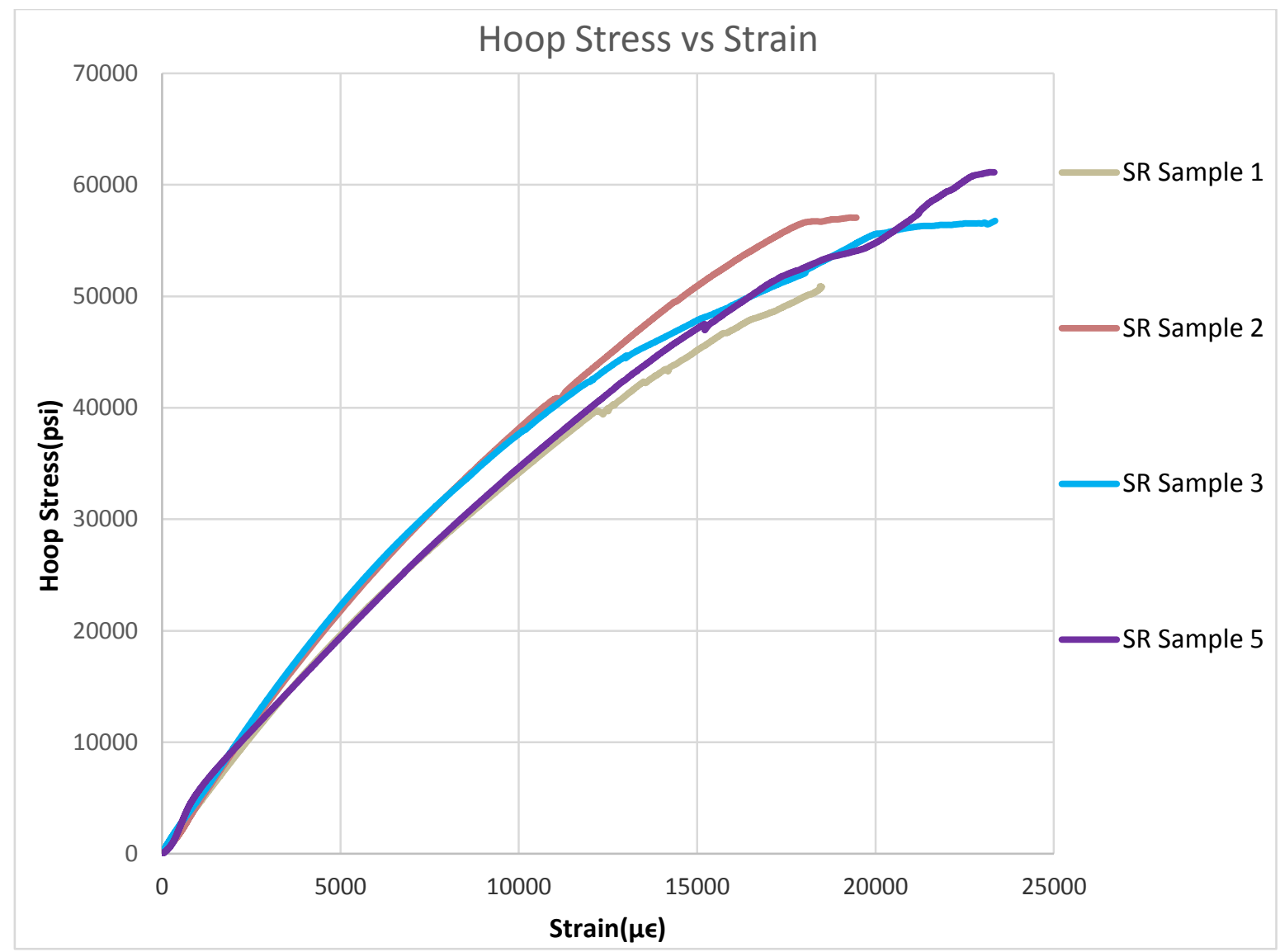

Figure 5-28: Split Ring Hoop Stress/Strain Response

The five specimens all failed by fiber breakage in the reduced area, which is the desired failure. In a few situations, the corrosion barrier layer debonded from the structural layer. It is not clear at what point during the test this behavior occurred. This debonding was often located away from the reduced area. Nonconforming failures occur when the breakage does not occur in the reduced area. Figure 5-29 shows the failure of sample two, in the reduced area. Figure 5-30 shows the failure at the strain gauge, as well as a clear view of the broken fibers. 


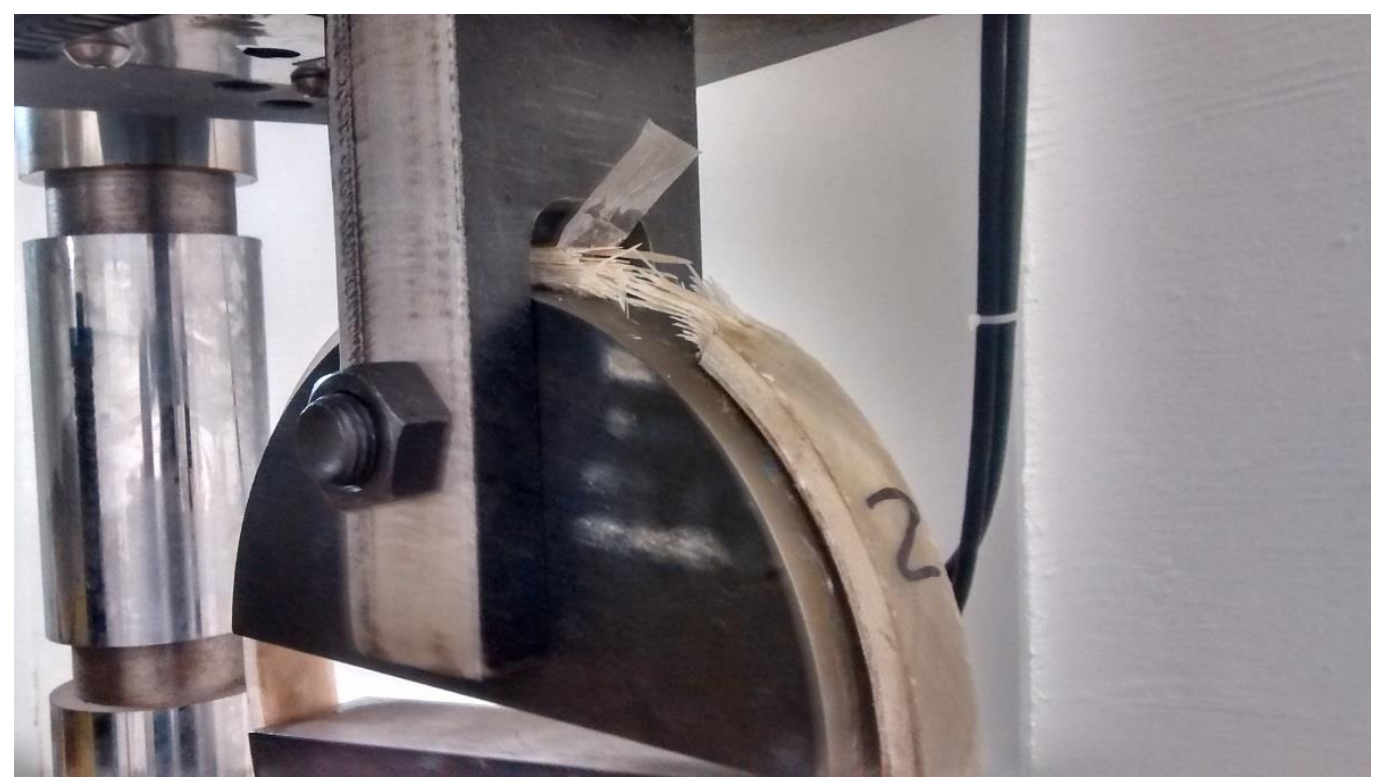

Figure 5-29: Split Ring Sample 2 Failure

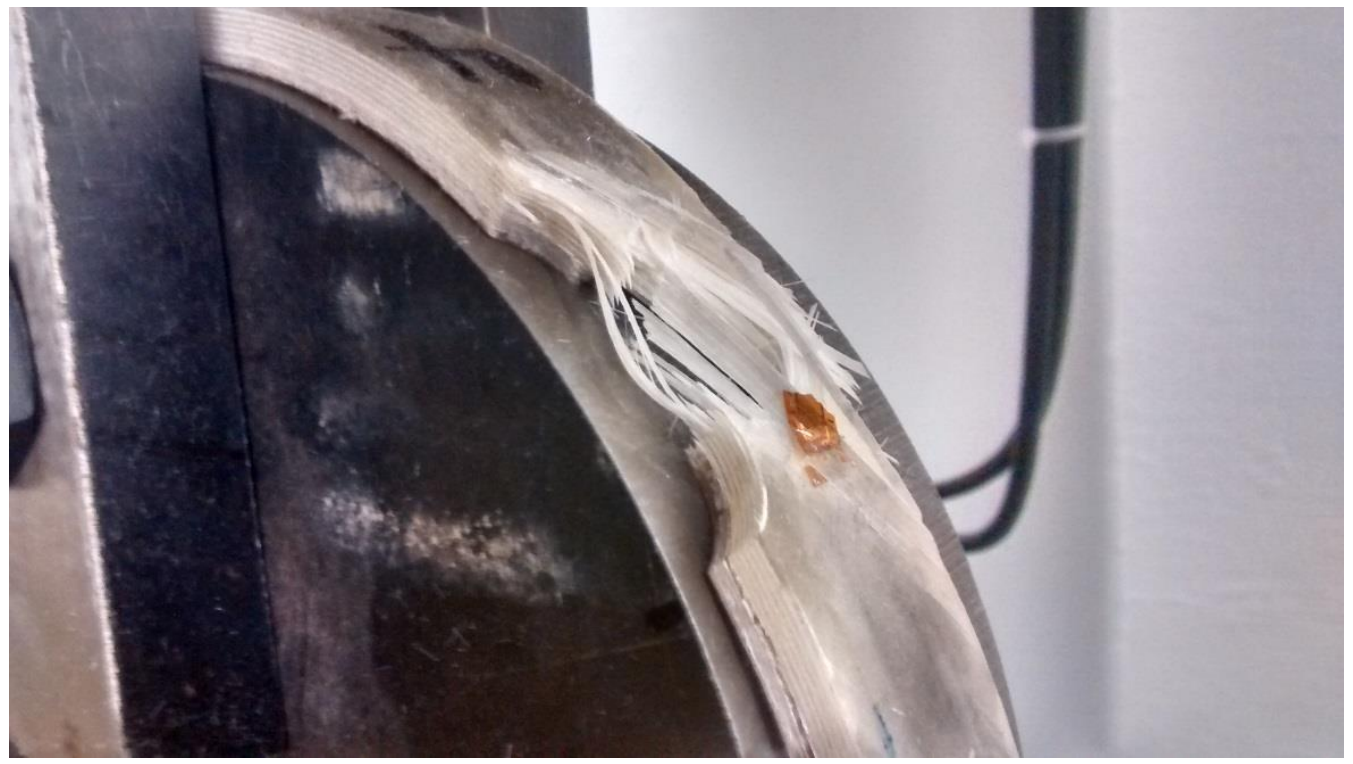

Figure 5-30: Split Ring Sample Failure

To investigate potential issues associated with the split ring test method (i.e. the accuracy of hoop modulus and strength predictions), two additional samples were also tested. These samples were not manufactured with a reduced area. The purpose of the additional testing was to determine whether the reduced areas played any role in determining elastic modulus and failure strength. The 
two samples failed at the split in the rings under around 41,000 psi hoop stress. The elastic modulus of the two samples averaged around 2.55. As a whole, the two additional samples only add complexity to the analysis and do not really help address the question of whether the hoop predictions are reliable. Thorough analysis is offered in Chapter 6.

\subsection{Conclusion}

Hydrostatic burst pressure testing was conducted to evaluate elastic behavior, failure progression, and failure strengths of 6-inch diameter and 10-inch diameter pultruded and filament wound GFRP pipes and joints. The pultruded pipes failed through seam failures and weeping failures at pressures between 300 and 1,200 psi. The three thin-wall ( 0.45 inches thick) filament wound pipes failed at an average pressure of 2,957 psi through leakage. Thick-wall filament wound (0.8 inches thick) specimens 1 and 2 failed at an average pressure 5,210 psi through leakage. Thickwall specimen 3 failed at 4,000 psi through leakage. The GFRP joints failed at pressures near 1,000 psi. The filament wound pipes and joints all failed at near hoop stresses of 30,000 psi.

Split ring testing was conducted on specimens cut from the thin-wall filament wound pipes. This testing was conducted to determine if the standardized split ring test could produce similar data and failure predictions as the hydrostatic burst pressure test. The split ring samples failed under average hoop stresses of 58,791 psi through fiber breakage. Thorough analysis of the test results, as well as comparison to the analytical models (Chapter 4) is provided in Chapter 6. 


\section{CHAPTER 6 BEHAVIOR ANALYSIS AND COMPARISON}

\subsection{Introduction}

In this chapter, the CLT from Chapter 4 is compared to the experimental data presented in Chapter 5. The focus is placed on elastic behavior, since pipes under operational pressure should never experience failure progression or approach failure stresses. The purpose of the analysis is to determine whether hydrostatic pressure testing results can be predicted through mechanics based methods or through simplified test methods (split ring). These alternative methods would allow design engineers to predict behavior and develop design methods for composite pipelines, without having to conduct hydrostatic pressure tests (either static, cyclic or burst pressure).

\subsection{Analytical Prediction vs Hydrostatic Burst Pressure Results}

\subsubsection{Caveats Regarding Testing and Analysis}

Accurate interpretation of results under hydrostatic testing and comparison of data with analytical models depends on a few key facets. Various simplifications of test effects and lack of material knowledge affect the test results and need to be addressed before addressing the analysis.

The hoop stress is typically calculated using thin-walled stress behavior (i.e. $\sigma=\operatorname{Pr} / \mathrm{t}$ ) due to the computational simplicity. However, greater accuracy can be obtained by using Lame's equations for hoop stress as these equations incorporate changes in stress through the wall thickness. Since both sets of pipes have an R/t ratio near 10, Lame's equations could be used for both sets of pipes (although the 3/8 pipes are considered thin wall). Using Lame's equations, the hoop stress inside the pipe is greater than the stress outside pipe as shown in, with the difference 
equal to the internal pressure. For the $3 / 8$ wall pipes, the difference in predicted stresses is around $5 \%$, but the error increases with the $3 / 4$ wall pipes by $\approx 8.5 \%$. As the strain gauges were applied to the outer surface, more accurate stress/strain results should be based on Lame's equations, particularly for the $3 / 4$ wall pipes. Therefore, the predicted hoop moduli for the pressure tests are not as conservative as possible, but are well within reason. Table 6-1 provides the comparison of stresses.

Table 6-1: Thin Wall vs Lame's Hoop Stresses

\begin{tabular}{|l|l|l|l|l|l|}
\hline Sample Name & $\begin{array}{l}\text { Lame's Outer } \\
\text { Hoop Stress } \\
(\mathrm{psi})\end{array}$ & $\begin{array}{l}\text { Lame's Inner } \\
\text { Hoop Stress } \\
(\mathrm{psi})\end{array}$ & $\begin{array}{l}\text { Thin Wall } \\
\text { Hoop Stress } \\
(\mathrm{psi})\end{array}$ & $\begin{array}{l}\text { Lame's Outer } \\
\text { vs Thin Wall } \\
\text { Difference }\end{array}$ & $\begin{array}{l}\text { Lame's Inner } \\
\text { vs Thin Wall } \\
\text { Difference }\end{array}$ \\
\hline 3/4 Sample 1 & 30362 & 35534 & 32759 & $-7.3 \%$ & $8.5 \%$ \\
\hline 3/4 Sample 2 & 30802 & 36049 & 33234 & $-7.3 \%$ & $8.5 \%$ \\
\hline 3/4 Sample 3 & 23623 & 27647 & 25488 & $-7.3 \%$ & $8.5 \%$ \\
\hline 3/8 Sample 1 & 27573 & 30352 & 28899 & $-4.6 \%$ & $5.0 \%$ \\
\hline 3/8 Sample 2 & 29156 & 32125 & 30571 & $-4.6 \%$ & $5.1 \%$ \\
\hline 3/8 Sample 3 & 30569 & 33711 & 32067 & $-4.7 \%$ & $5.1 \%$ \\
\hline
\end{tabular}

Secondly, the hydrostatic test methodology may have also influenced stress/strain results. A hand pump was used to apply the load so that cracking and/or leaks in the pipe walls could be easily heard, as opposed to using an electrical pump. The pump produced a non-uniform loading rate as the pump handle has to be retracted after each load, although this effect has been averaged out. Furthermore, the pump operated under two modes, high and low. In high mode, pressure was applied rapidly ( 0 to around 1,000 psi internal pressure in about two minutes). Beyond 1,000 psi the pump would kick over into low mode and the rate of loading was decreased (continued for 9 to 30 minutes). When analyzing the stress-strain curves, this change in load rate produced a change in slope, which is to be avoided when calculating the modulus. To account for the high/low pump speed and to more accurately match the ASME standard, the moduli were calculated only during 
the initial high load rate, which varied between 20 and 94 seconds. For the $3 / 8$ wall pipes, the moduli were computed when the stress was between 2 and $8 \mathrm{ksi}$, which corresponds to a stress range of $6 \%$ to $28 \%$ of ultimate stress. Similarly, the modulus was computed for the $3 / 4$ wall pipes when the stress was between 5 and $10 \mathrm{ksi}$, which corresponds to $15 \%$ to $30 \%$ of ultimate for the first 2 samples and $20 \%$ to $39 \%$ for the final sample that had a significantly lower ultimate load attributed to a local flaw.

Thirdly, it is unclear whether data used for the CLT predictions are reliable. The theory is based on constituent properties, fiber volume contents, and fabric architectures. While this data was obtained through available literature and manufacture reports, more accurate information could have been obtained, had in-house manufacturing and materials testing been possible. If the properties of the constituent materials were incorrectly modelled, the method may reflect much more poorly than is true. Although many researchers have verified CLT as an accurate predictor of elastic behavior of composite materials, the model used in this research may require fine-tuning.

Fourthly, the CLT-PSC prediction most certainly does not truly capture the effect of the restrained-end closures. At times during testing, endcaps were flush with the end of the pipe (i.e. no longitudinal compression stress). As the pipes expanded radially, the length contracted and the end of the pipes pulled away from the caps (i.e. longitudinal compression exists due to internal pressure compression stress). Theoretically, the true behavior is somewhere between the two CLTPSC prediction and the CLT-NPS prediction (refer to Chapter 4). Therefore, CLT-NPS assumes only hoop stress and the CLT-PSC assumes hoop tension and longitudinal compression due to end restraints. Again, CLT-PST assumes hoop tension and longitudinal tension, but only applies to systems with free-end closures. 
Finally, discussion in this section seeks to isolate analysis of longitudinal and hoop behavior. In reality, the fiber angle and Poisson effect interconnect the two. Therefore, reported moduli should be thought of as "apparent" moduli. The true modulus of the pipes in the principle directions and fiber directions do not change. However, the various loading vectors (CLT-PSC, CLT-NPS, and CLT-PST) have effects on both the longitudinal and hoop strains, meaning that the data in this section creates the appearance of differing moduli. In reality, it is difficult to isolate properties of a material subjected to plane stress.

\subsubsection{Elastic Prediction}

\subsubsection{3/8 wall pipes under hydrostatic loads}

This section compares stress/strain results of CLT and stress/strain results of the hydrostatic burst pressure test. The results are provided in Table 6-2. The hoop moduli were evaluated from 2 to $8 \mathrm{ksi}$. In this range, the stress/strain curve is almost perfectly linear $\left(\mathrm{R}^{2}=.996\right.$ to .999). The average modulus is $3.21 \mathrm{Msi}$, with a coefficient of variation of $4.8 \%$, indicating rather consistent results. However, errors in the CLT predicted values always lean on the conservative side.

In this case, it appears that the CLT prediction may need to be adjusted. This could be done by more accurately determining structural properties of the materials. Further resin content testing and strength testing could be conducted to more accurately predict properties of a laminae.

Table 6-2: Thin Wall Hoop Modulus Comparison

\begin{tabular}{|l|l|l|l|}
\hline Specimen & $\begin{array}{c}\text { Average } \\
\text { Hoop } \\
\text { Modulus } \\
\text { (Msi) }\end{array}$ & $\begin{array}{c}\text { CLT-PSC } \\
\text { Prediction } \\
\text { (Msi) }\end{array}$ & $\begin{array}{c}\text { Percent } \\
\text { Error } \\
(\%)\end{array}$ \\
\hline 1 & 3.36 & 2.39 & 28.9 \\
\hline 2 & 3.20 & 2.39 & 25.3 \\
\hline 3 & 3.06 & 2.39 & 21.9 \\
\hline
\end{tabular}


Table 6-2 shows the stress/strain response (up to failure) of the burst-pressure specimens, compared with the stress/strain prediction of the CLT-PSC (up to 1500 psi, 50 percent of burst pressure). This prediction is for a restrained-end test frame (i.e. longitudinal compression stress equal to internal pressure).Therefore, the restrained-end system was assumed to produce hoop stress and longitudinal compression stress.

The Figure 6-1 shows good agreement between the prediction and the experimental results up to a hoop stress of 8,500 to 10,000 psi (1,000-psi, internal pressure). Around this point, failure initiation is suspected. The hoop modulus of the pipe is reduced (due to suspected damage progression), and the CLT prediction ceases to be conservative. Beyond this range, the average hoop modulus (30 percent to 90 percent ultimate stress) is $1.62 \mathrm{Msi}\left(\mathrm{R}^{2}=.992\right)$. The CLT prediction was produced for stresses up to 50 percent of ultimate stress. This was done so that the nonconservative prediction (beyond 30 percent ultimate stress) could be observed. The data seems to show good agreement with the prediction at a hoop stress of $15,000 \mathrm{psi}$; however, this is misleading. In reality, the hoop modulus of the pipe has been degraded ( $E=1.62 \mathrm{Msi})$. Therefore, the CLT-PSC prediction is only considered valid up around 1,000 psi internal pressure, around 30 percent of the ultimate pressure. However, the pipes are expected to only be exposed to pressures $1 / 5^{\text {th }}$ of burst pressure, thus the CLT prediction matches well with expected operating conditions. However, this observation should be considered lightly, as the slope change may also have been influenced by the load rate (as mentioned in section 6.2.1). While there does appear to be a small change in slope around 8,500 to 10,000 psi, the change in slope may have been caused by the test method, as was mentioned in section 6.2.1. Around the same stress, the hydraulic would kick over 
in high mode and the load rate would change. Therefore, the change in slope is believed to be a result of failure initiation, as well as the change in pump mode.

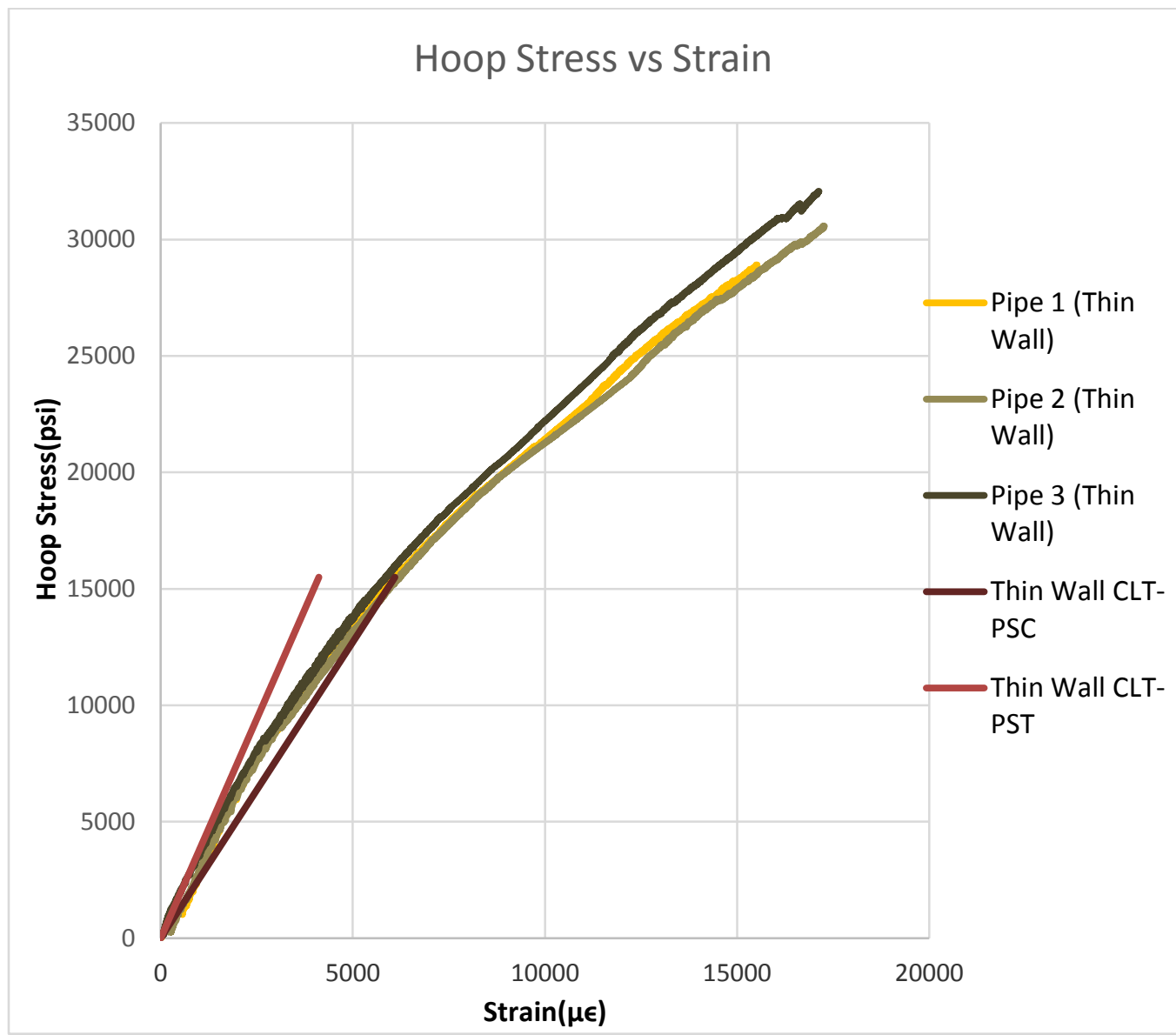

Figure 6-1: Thin Walled Stress/Strain Comparison

In addition, to the restrained-end prediction (Thin Wall CLT-PSC), a free-end prediction (Thin wall CLT-PST) was also provided. This prediction considers the effects of longitudinal tensile stress (due to attached endcaps) and hoop stress. Although unverified experimentally, this prediction is thought to be a good indication of pipe behavior in service (longitudinal tension and hoop tension). It can clearly be seen that the hoop modulus is higher for free-end systems. This additional stiffness is due to the effects of fabric architecture and Poisson's ratio. That is to say, the longitudinal tensile stress imposed by attached endcaps counteracts the hoop strain. In short, longitudinal stress causes the pipe to elongate axially and contract circumferentially. Conversely, 
hoop tensile stress causes circumferential elongation and axial contraction. However, it should not be assumed that fiber stresses are lower. While the longitudinal stresses limit the hoop strains, the longitudinal stresses also add tensile stress to the fibers. Therefore, a free- end test frame will yield a higher hoop modulus and a lower burst pressure. The above scenario may have to be revised when resin and shear stresses control; such as in situations where the ID/thickness ratio is smaller (i.e. thick walled pipes).

Comparison between predicted longitudinal moduli from the pressure test and CLT-PSC prediction was not conducted as easily because it was difficult to accurately determine longitudinal stresses. Therefore, pressure/strain relationships were compared. Strains of the pressure test and CLT-PSC were compared at 1,000 psi. As is seen in Table 6-3, the hoop and longitudinal prediction are both very conservative. Errors seems to be vary (17-36 percent) for the hoop and longitudinal predictions, suggesting that error may exist in the accuracy of the chosen material properties, fiber volume fractions, approximated fiber angles, and architectures, or in the measured longitudinal strain. Furthermore, error may have been introduced by manufacturing variances such as percent cure, percent void, and fiber tension during wrapping.

Table 6-3: Thin Wall Longitudinal Strain Comparison

\begin{tabular}{|l|l|l|l|}
\hline Specimen & $\begin{array}{l}\text { Longitudinal strain @ } \\
1,000 \mathrm{psi}(\mu \epsilon)\end{array}$ & $\begin{array}{l}\text { Longitudinal Strain } \\
\text { CLT-PSC } \\
\text { Prediction }(\mu \epsilon)\end{array}$ & $\begin{array}{l}\text { Percent Error } \\
\%\end{array}$ \\
\hline 1 & $-2,385$ & -3276 & 27.19 \\
\hline 2 & $-2,096$ & -3276 & 36.0 \\
\hline 3 & $-2,710$ & -3276 & 17.3 \\
\hline
\end{tabular}

\subsubsection{3/4 wall Pipes under Hydrostatic Load}

This section compares stress/strain results of CLT and stress/strain results of the hydrostatic burst pressure test, for the $3 / 4$ wall pipes (Table 6-4). The hoop moduli were evaluated from 5 to $10 \mathrm{ksi}$ hoop stress, equal to $15-30 \%$ of ultimate stress for the first 2 samples. This range 
of the stress/strain curve is fairly linear $(\mathrm{R}=.995$ to .999$)$. The third sample failed at a lower ultimate stress, likely due to a flaw, but the same stress range was used. The flaw is evidenced by the fact that the stress/strain curves of samples 1 and 3 match perfectly. The only difference in the two is that sample 3 failed at a much lower pressure and that specimen 3 displayed little interior or external damage. The primary influence on accuracy of results is from the assumptions based on the thin-walled analysis/theory. The stress equations used in the experiment are only estimates (in the case of thick wall specimens) and differ from actual stresses by as much as $8.5 \%$ (Table 6-1).

Errors between 24 percent and 47 percent were observed between hoop modulus for the pressure test using thin walled equations and the CLT-PSC prediction. However, for samples 1 and 3 using Lame's outer surface stress, the modulus differs by 2 and $9 \%$ respectively. This suggests that thick-walled equations should be used for these samples as they produce more accurate results. From both stress calculations (thin and thick wall), Sample 2 had a significantly higher modulus values than any other sample tested. Computing the hoop strains for each of the two gages also results in moduli that are significantly higher than the other samples, so gage error is ruled out. It is not clear why the modulus is so much greater for this sample.

Table 6-4: Thick-Walled Hoop Modulus Comparison

\begin{tabular}{|l|l|l|l|l|l|l|}
\hline Specimen & $\begin{array}{l}\text { Average } \\
\text { Hoop } \\
\text { Modulus } \\
(\mathrm{Msi})\end{array}$ & $\begin{array}{l}\text { CLT-PSC } \\
\text { Prediction } \\
(\mathrm{Msi})\end{array}$ & $\begin{array}{l}\text { Percent } \\
\text { Error } \\
(\%)\end{array}$ & $\begin{array}{l}\text { Lame's Outer } \\
\text { Surface Hoop } \\
\text { Modulus } \\
(\mathrm{Msi})\end{array}$ & $\begin{array}{l}\text { CLT-PSC } \\
\text { Prediction } \\
(\mathrm{Msi})\end{array}$ & $\begin{array}{l}\text { Percent } \\
\text { Error } \\
(\%)\end{array}$ \\
\hline 1 & 3.07 & 2.25 & 26.7 & 2.30 & 2.25 & 2.2 \\
\hline 2 & 4.26 & 2.25 & 47.2 & 3.74 & 2.25 & 39.8 \\
\hline 3 & 2.96 & 2.25 & 24.0 & 2.49 & 2.25 & 9.6 \\
\hline
\end{tabular}

Figure 6-2 shows the thin-wall stress/strain response (up to failure) of the burst-pressure specimens, compared with the stress/strain prediction of the CLT-PSC (up to $2500 \mathrm{psi}, 50$ percent of burst pressure). This prediction is for a restrained-end test frame (i.e. longitudinal compression 
stress p).The figure shows decent agreement(17 percent error in strains) between the CLT-PSC prediction and the experimental results up to between 8,500 and 10,000 psi hoop stress (1,665-psi, internal pressure). Again, the slope in this range appears to change, although it is hard to discern the precise location. Around this point (8,000 to 10,000 psi hoop stress), failure begins to initiate. The hoop modulus of the pipe is reduced (due to damage progression), and the CLT-PSC prediction becomes less conservative. Beyond this range, the hoop modulus (30 to 90 percent ultimate stress) is $1.56 \mathrm{Msi}(\mathrm{R}=.987)$.

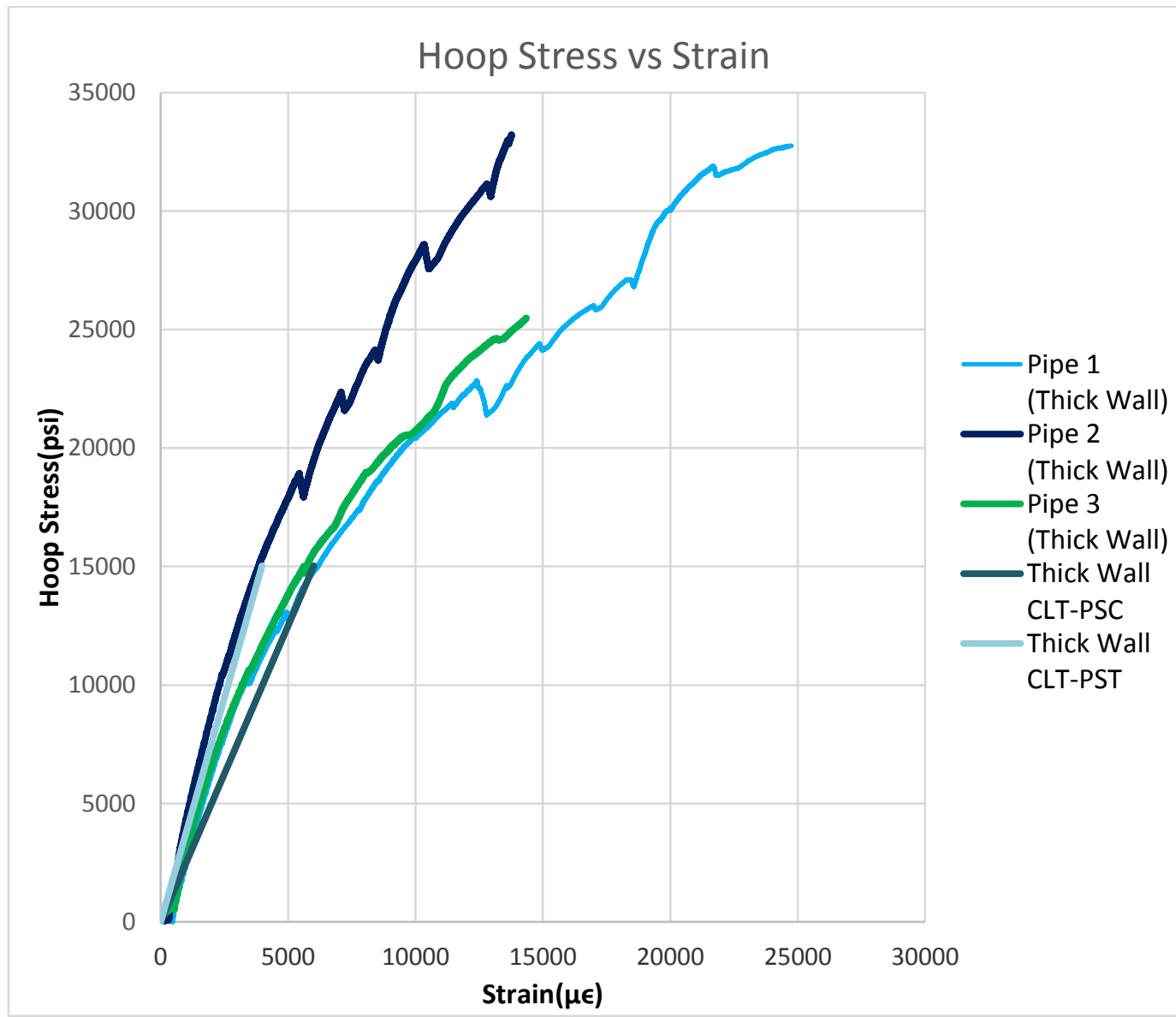

Figure 6-2: Thick Wall Stress/Strain Comparison

Again, a free-end prediction for plane stress was provided (CLT-PST), in addition to the restrained-end prediction (CLT-PSC). This free-end prediction considers effects of longitudinal tensile stress and hoop tensile stress. As with the thin-walled pipes, the free-end hoop modulus is 
higher than the restrained-end hoop modulus. Again, the CLT-PST model has been provided as a hypothesis of hoop stress/strain response of a pipe under longitudinal tension and hoop tension (i.e., this models the behavior of a pipe in service). This hypothesis should be tested in future research, through the development of a free-end test fixture.

Evaluating the pressure/longitudinal strain relationship, the analysis looks very different. In this case, specimen 1 appears to be the outlier. The prediction differs from the test data by at least 2 percent and as much as 30 percent. The 30 percent error is likely due to the model, since errors are about the same for the other hoop and longitudinal data. However, the incredible accuracy of the prediction for sample 1 is hard to explain. It is possible that pre-compression longitudinal stress (stress due to actuator load, discussed in section 5.2.2.2) may have played a factor, but this is hard to quantify and is unlikely. The hoop strain to longitudinal strain data ratio indicated that effects of pre-compression are not significant at the 1,665-psi pressure. The longitudinal strain comparison (taken at 1,665-psi internal pressure) are presented in Table 6-5.

Table 6-5: Thick Wall Longitudinal Strain Comparison

\begin{tabular}{|l|l|l|l|}
\hline Specimen & $\begin{array}{l}\text { Longitudinal strain @ } \\
1,665 \mathrm{psi}(\mu \epsilon)\end{array}$ & $\begin{array}{l}\text { Longitudinal Strain } \\
\text { CLT-PSC } \\
\text { Prediction }(\mu \epsilon)\end{array}$ & $\begin{array}{l}\text { Percent Error } \\
\%\end{array}$ \\
\hline 1 & -3778 & $-3,842$ & 1.7 \\
\hline 2 & -2716 & $-3,842$ & 29.3 \\
\hline 3 & -3001 & $-3,842$ & 21.9 \\
\hline
\end{tabular}

As a general observation, the $3 / 4$ wall specimens do not offer consistent results(errors between 2 and 20 percent). Specimens 1 and 2 are very similar in burst pressure, but differ in hoop stress/strain response and pressure/ longitudinal strain response. Specimens 1 and 3 are very similar in hoop stress/strain response, but differ in pressure/longitudinal strain response and burst 
pressure. Further testing is needed to determine the reliability of these results. As will be reasoned in section 6.3, specimen 2 appears to be an outlier.

\subsubsection{Failure Prediction}

A proposed progressive failure analysis has been proposed in Chapter 3. Due to lack of unidirectional lamina strength properties, this evaluation has not yet been conducted for any of the pipes. While many other researchers have performed these sort of analyses with good success, the accuracy of this method has not yet been verified for the filament wound pipes evaluated during this project. Therefore, classical lamination theory was used only to predict elastic behavior ( 0 to 30 percent of failure stress).

\subsection{Split Ring Prediction vs Hydrostatic Burst Pressure Results}

Split ring testing was conducted on specimens cut from $3 / 8$ wall pipes $(0.45$-inch wall thickness) to determine if it would be a good approximation of hydrostatic burst pressure testing, and to determine if the strain energy density model can be applied to predict failure. The hydrostatic test and split ring tests both primarily apply hoop stress. Furthermore, data from AEWC split ring testing matched well with data obtained from CFC's hydrostatic testing data. However, due to the different failure mechanisms, the split ring testing matched hydrostatic testing results poorly. Since split ring testing results in fiber breakage and hydrostatic testing does not, it was expected that hydrostatic pressure testing results in lower failure stresses than split ring testing.

The average hydrostatic failure stress was $30 \mathrm{ksi}$ for the $3 / 8$ wall pipes, while the split ring failure stress was almost exactly double at $58 \mathrm{ksi}$. This suggests that at roughly $1 / 2$ of failure stress based on split ring test, water is able to penetrate through the strained pipe walls, although much more testing is required to confirm this theory. Comparisons between the two methods were also 
conducted in the elastic loading zone, which for the split ring tests was $10-30 \%$ of failure stress ( $\sim 5$ to $18 \mathrm{ksi})$.

Table 6-6: Elastic Modulus Comparison for Thin Wall Pipes

\begin{tabular}{|l|l|}
\hline Analysis Method & $\begin{array}{l}\text { Average Hoop Modulus (Msi) } \\
\text { (10 to 30 percent ultimate stress) }\end{array}$ \\
\hline Hydrostatic Pressure Test & 3.21 \\
\hline Split Ring Testing & 4.21 \\
\hline CLT-PSC Prediction & 2.39 \\
\hline
\end{tabular}

The results in Table 6-6 show that the difference in modulus of the two test methods is 24 percent. The difference between the CLT-PSC modulus and hydrostatic pressure test modulus is 25 percent. The difference between the modulus of the split ring test and the CLT-PSC prediction is 43 percent. It is difficult to explain why the hoop modulus of the split ring test is so high, compared to the hydrostatic test. By conventional wisdom, the hoop stiffness of the pipe should be stiffer than that of the ring. In the ring, fibers are cut, and the bond length of the fibers is reduced. Simply put, the ring does not benefit from the 2-D effects of fabric architecture. The most likely explanation comes from the fact that the two test methods produce different loadings. The split ring test produces hoop tension as well as bending stress, while the hydrostatic test produces hoop stress, radial stress, and longitudinal compression stress. Furthermore, the split ring test was designed for the determination of hoop failure stress. It may simply not be an accurate representation of hoop modulus. The differences between the two test methods can be seen in Figure 6-3. 


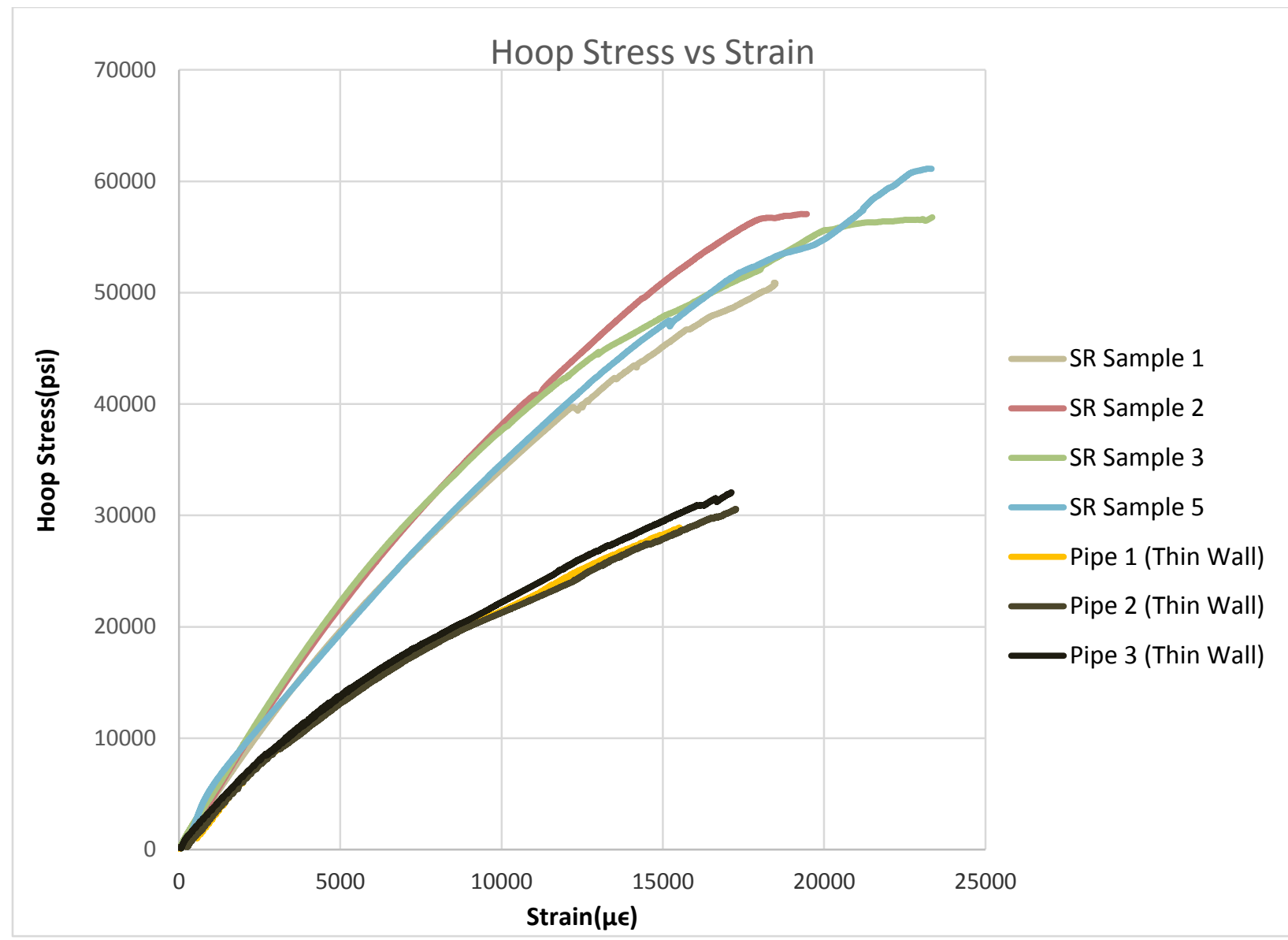

Figure 6-3: Stress/Strain Comparison for HBP and Split Ring Tests

Evaluating the two test methods from a failure progression and failure strength point of view, the two test methods differ greatly. The pressure tests seem to initiate a more severe failure progression and quicker ply degradation. This is evidenced by the fact that the hoop stiffness for the pipes under pressure decays more rapidly than the hoop stiffness of the split ring specimens. Furthermore, the split ring results do not indicate a clear bifurcation point, suggesting that the loading method in the hydrostatic tests may have played a large role.

The differences in failure progression and failure prediction may result from differences in loading. As was mentioned previously, differences in elastic properties could have been due to the different state of stresses imposed by the two tests. In the case of failure progression, the state of stresses probably also played a role. However, it is very likely that water infiltration (combined 
with radial stress) into the layers during pressure testing, also caused the stiffness to decay more rapidly for the hydrostatic test than the pure hoop tension of the split ring test. Therefore, the inconsistent results between the two tests may be a result of two test methods that do not produce similar loadings. Beyond this further testing is required to more accurately determine material properties.

\subsection{Summarizing Observations}

The comparison of results can be summarized well by Figure 6-4. The figure shows the hoop stress/strain results for the CLT-PSC predictions, the $3 / 8$ wall pipe, the $3 / 4$ wall pipes, and the $3 / 8$ split ring samples. With the exception of $3 / 4$ wall specimen 2 , which is an outlier, the following observations can be made based on the hoop stress/strain results:

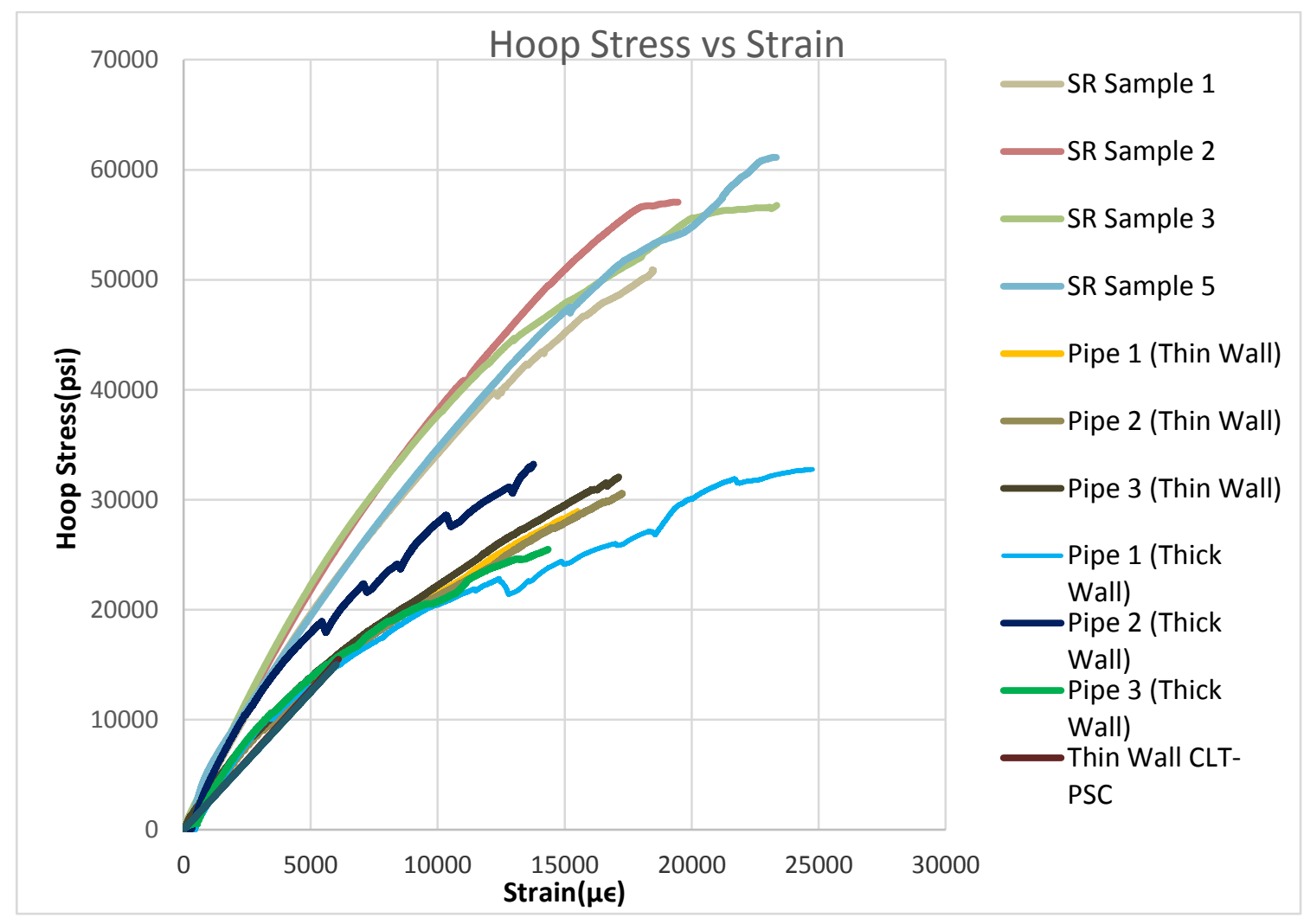

Figure 6-4: Hoop Stress/Strain Comparison 
Two test methods were used to determine elastic properties, failure progression, and failure strengths of GFRP pipe specimens. The strains and stresses were determined in the walls of the pipes for the hydrostatic test samples and for the split ring samples. The two test methods produced similar stress/strain results. Elastic hoop modulus values for the two methods only differ by around 25 percent. Contrastingly, the failure predictions significantly, differing by around 50 percent. The results from the two sets of hydrostatic tests indicate that these particular pipes fail under 30,000 psi of hoop stress. The hoop failure strengths predicted by the split ring test appear to be twice the hoop failure strengths predicted by the hydrostatic burst pressure test. Therefore, split ring testing methods would need to be modified if this method is ever to be used as a failure predictor.

Additionally, Classical Lamination Theory models were developed for the two sets of filament wound pipes. These models were used as predictors of elastic (10 to 30 percent of ultimate stress) hoop and longitudinal stress/strain relationships for pipes under internal pressure. The theory was found to be accurate (within 25 percent error for hoop modulus) for thin wall pipes. If Lame's equations are used, the model can also be used to predict elastic behavior in thick-walled pipes.

For the skilled researcher or designer, CLT (presented in AMSE BPVC) can provide accurate predictions of elastic behavior for pipes and pressure vessels under internal pressure. However, difference in constituent material properties, equations, approximations, and test properties provide many opportunities for error. Furthermore, the process is very time consuming. The return on investment for time and effort may not be acceptable. While there is tremendous opportunity presented in this research, further investigation of these methods is required. One model, matched to two sets of experimental data, is not enough to verify the accuracy of mechanics based predictions for the numerous material combinations, fabric architectures, and pipe diameters 
and thicknesses that are possible. Although lamination theory provides a strong base, from which failure prediction could be conducted, progressive failure predictions have yet to be produced.

Therefore, hydrostatic burst pressure testing may be the most effective way to evaluate burst pressure of composite pipes under internal pressure. These tests require fabrication of large, expensive, load frames. Furthermore, it may not be possible to develop a reusable sealing mechanism that produces hoop and longitudinal stresses. Such a mechanism is necessary because pipes in service experience plane stress. Testing methods exerting only hoop stress do not accurately reveal mechanical properties of pipes in service. Such methods likely produce nonconservative predictions of elastic behavior and burst pressure. 


\section{CHAPTER 7 CONCLUSION AND FUTURE WORK}

\subsection{Conclusions}

Literature review at the start of the project revealed a significant need in natural gas pipelines for new structural materials, with better strength, strength to weight ratio, and resistance to corrosion than steel. These materials need to be able to withstand stresses induced by operating pressures near 1,500 psi, for pipelines ranging from 10 inches to 48 inches in diameter. One such material that could meet this need is glass fiber reinforced polymer composite (FRP).

The purpose of this project was to investigate methods through which GFRP pipe behavior could be evaluated and predicted. This was done through the completion of several key objectives:

- Design and fabrication of a high strength burst pressure test frame

- Hydrostatic burst pressure testing of GFRP pultruded and filament wound pipes of 6 inch and 10 inch diameters

- Hydrostatic burst pressure testing of thin wall filament wound pipes to $3,000 \mathrm{psi}$

- Hydrostatic burst pressure testing of thick wall filament wound pipes to 5,2000 psi

- Hydrostatic burst pressure testing of GFRP butt joints to 1,000 psi

- Split ring apparent hoop tensile strength testing of filament wound rings

- Development of elastic stress/strain predictions using Classical Lamination theory

- Analysis and comparison of experimental results and theoretical predictions.

Hydrostatic burst pressure testing was conducted to determine elastic behavior, failure progression, and failure strengths of 6 inch and 10 inch diameter pipes. These pipes (thin wall) 
failed at internal pressures as high as 3,000 psi, suggesting that these pipes could operate at pressures near $500 \mathrm{psi}$. Split ring testing was conducted as a possible alternative to hydrostatic pressure testing. The results were found to be relatively accurate in the elastic zone (within 25 percent) and inaccurate in terms of failure prediction (50 percent error).

Lamination theory was used as an analytical method to predict elastic behavior for these pipes. The theory was computationally rigorous and time consuming, but was found to accurately predict (within 25 percent) behavior in the elastic region (10 to 30 percent of ultimate stress). While the split ring test and CLT prediction perform reasonably in the elastic zone, burst pressure testing appears to be the quickest and most accurate way to evaluate pipe behavior. Split ring testing methodology needs to be modified if accurate results are to be produced and CLT is not a practical tool for design engineers. Furthermore, CLT does not sufficiently model failure progression or failure strength, unless paired with failure criteria. Nonetheless, this research has opened up opportunity for meaningful future investigation of GFRP pipes and joints. A few suggested topics are provided below.

\subsection{Future Research}

- Expand CLT elastic predictions into failure progression and failure prediction by employing failure strengths of unidirectional lamina and failure criteria(sections 3.4.1 and 3.4.2)

- Investigate methods through which strain energy density data can be collected so that possible correlations with Valdmanis's proposed approach can be evaluated.

- Evaluate alternative methods to rapidly and affordably test hoop strength of composite rings 
- Further testing of GFRP pipes, with Diameter/thickness ratios greater than 20. Example, test 10 -inch diameter pipes with wall thickness of 0.25 inches. This increases the effect of hoop stress and decreases effect of radial stress

- Perform free-end burst pressure testing for filament pipes and make comparisons with CLT predictions.

- Fabricate and test GFRP pipes constructed from S-glass and evaluate burst pressure capacity.

- Investigate joint behavior and failure modes, towards the end that joint capacities can exceed 6,000 psi internal pressure. This would allow for composite pipelines operating at pressures near 5,000 psi. 


\section{REFERENCES}

Akovali, G. (2001). Handbook of Composite Fabrication. Shawbury: Rapra Technology Limited.

Argonne National Laboratory. (2007). Natural Gas Pipeline Technology Overview. Oak Ridge,TN.

ASME. (2015). Section X: Fiber Reinforced Plastic Pressure Vessels. In ASME, ASME Boiler and Pressure Vessel Code. New York, NY.

ASTM. (2012). D2992 Standard Practice for Obtaining Hydrostatic Design Basis for Fiberglass (Glass-Fiber-Reinforced Thermosetting-Resin) Pipe and Fitting.

ASTM. (2014, April 15). D1599 Standard Test Method for Resistance to Short-Time Hydraulic Pressure of Plastic Pipe, Tubing, and Fittings. Conshocken, Pa: ASTM International.

ASTM. (2016, August 1). D2290 Apparent Hoop Tensile Strength of Plastic or Reinforced Plastic Pipe. West Onshohocken, Pa: ASTM International.

Barbero, E. J. (1998). Introduction to Composite Materials Design. Philadelphia, PA: Taylor \& Francis Inc.

Boresi, A. P., \& Schmidt, R. J. (2005). Advanced Mechanics of Materials, Sixth Edition. New Delhi: John Wiley and Sons Inc.

Deaton, L. (2015). Fiber Wrapped Steel Pipes for High Pressire Pipelines. In V. Karbhari, Rehabilitation of Pipelines Using Fiber-reinforced Polymer(FRP) Composities. Waltham, MA: Elsevier Ltd.

Fiberspar. (2010, December 07). Fiberspar LinePipe: The Leader in Spoolable Pipeline Systems. Retrieved from https://www.circac.org/wp-content/uploads/fiberspar-pipe-info.pdf 
GangaRao, H. (2011). Infrastructure Applications of Fiber Reinforced Polymer Composites. In M. Kutz, Applied Plastics Engineering Handbook: Processing and Materials (pp. 565-576). Elsevier.

GangaRao, H. (2016). Glass-Polymer Compsite Pressure pipes and Joints-Design, Manufacture, Characterize. Morgantown, WV.

GangaRao, H., Taly, N., \& Vijay, P. (2007). Reinforced Concrete Design with FRP Composites. Boca Raton: Taylor and Francis Group.

Guo, B., \& Ghalambor, A. (2012). Natural Gas Engineering Handbook(2nd Edition). Houston, Tx: Gulf Publishing Company.

Gupta, R. (2008). Fundamentals and Use of Hydrogen as Fuel. In Hydrogen Fuel: Production, Transport, and Storage (pp. 1-12). CRC Press.

Hearn, E. (1997). Mechanics of Materials 1: An Introduction to Mechanics of Elastic and Plastic Deformation of Solid and Strucutral Materials. Woburn, MA: Butterworth-Heinemann.

Helms, J. (2010). Composite Materials for Pressire Vessels and Pipes. In Encylopedia of Life Support Systems (pp. 2-7). Baton Rouge.

Kassapoglou, C. (2010). Design and Analysis of Composite Structures with Applications to Aerospace Structures. Chichester,UK: John Wiley and Sons Ltd.

Knight, N. F. (2008). Factors Influencing Progressive Failure Analysis Predictions for Laminated Composite Structure. Chantilly, VA: American Institute of Aeronautics and Astronautics.

Kuo-Shih, L., \& Tsai, S. W. (1996). A Progressive Quadratic Failure Criterion for a Laminate. Composites Science and Technology, 1023-2031.

Laney, P. (2002). Use of Composite Pipe Materials in the Transportation of Natural Gas. Idaho Falls. 
Legault, M. (2012, July). Next-generation pressure vessels. Retrieved from Composites World: http://www.compositesworld.com/articles/next-generation-pressure-vessels

Mallick, P. (2007). Fiber Reinforced Composites: Materials, Manufacturing, and Design. Boca Raton, FL: CRC Press.

Oil and Gas Journal. (2003). TransCanada Installs Demonstration Section of Composite Reinforced Line Pipe. Oil and Gas Journal.

Parker Hannaflin Corporation. (2007). Parker O-Ring Handbook. Retrieved from https://www.parker.com/literature/ORD\%205700\%20Parker_O-Ring_Handbook.pdf

PHMSA. (2016). Pipeline Basics. Retrieved from Pipeline Safety Stakeholder Communications: https://primis.phmsa.dot.gov/comm/PipelineBasics.htm?nocache=8874

Roy, A. K., \& Tsai, S. W. (1988). Pressure Vessels. In S. W. Tsai, Composites Design. Dayton, OH: Think Composites.

Smith, B., Eberle, C., \& Frame, B. (2005). New Materials for Hydrogen Pipelines. Oak Ridge, TN.

Title 49 CFR 192. (2018, February 20). Transportation of Natural or Other Gas by Pipeline: Minimum Federal Safety Standards.

U.S. Energy Information Administration. (2016, June 03). U.S. Energy Facts Explained. Retrieved $\begin{array}{llll}\text { from } & \text { Energy } & \text { Information }\end{array}$ https://www.eia.gov/energyexplained/?page=us_energy_home

U.S. Energy Information Administration. (2017). Annual Energy Outlook.

U.S. Energy Information Administration. (n.d.). About U.S. Natural Gas Pipelines. Retrieved from eia.gov: 
https://www.eia.gov/pub/oil_gas/natural_gas/analysis_publications/ngpipeline/process.ht $\mathrm{ml}$

US Department of Energy. (2013, February). History of Natural Gas. Retrieved from Fossil Energy: https://fossil.energy.gov/education/energylessons/gas/index.html

Vadlamani, D. (2007). Strain Energy Density Based Failure Criterion For GFRP Coupons Under Tension and Bending. Morgantown, WV: West Virginia University.

Walsh, T. (2017). The Plastic Piping Industry in North America. In M. Kutz, Applied Plastics Engineering Handbook-Processing, Materials, and Applications(2nd edition) (pp. 697716). Elsevier.

Xia, M., Takayangagi, H., \& Kemmochi, K. (2001). Analysis of Multi-Layered Filament-Wound Composite Pipes Under Internal Pressure. Composite Structures. 


\section{APPENDIX A - Classical Lamination Theory}

\section{A.1 Coordinate Systems}

A brief explanation of classical lamination theory is provided in this section. Two different coordinate systems, the global coordinate $(\mathrm{X}, \mathrm{Y}, \mathrm{Z})$ system and the fiber coordinate system $(1,2$, Z) are employed in this theory. This consideration is important because fiber orientation does not always align with the global orientation of an FRP member. Figure A-0-1 shows a common coordinate system for FRP laminae. However, this system is not universally accepted. Some organizations define the fiber direction as the XYZ system and the global system as the $12 \mathrm{Z}$ system. For example, the ASME Boiler and Pressure vessel code follows this alternative coordinate system. However, most authors define the coordinate systems in accordance with the figure below.

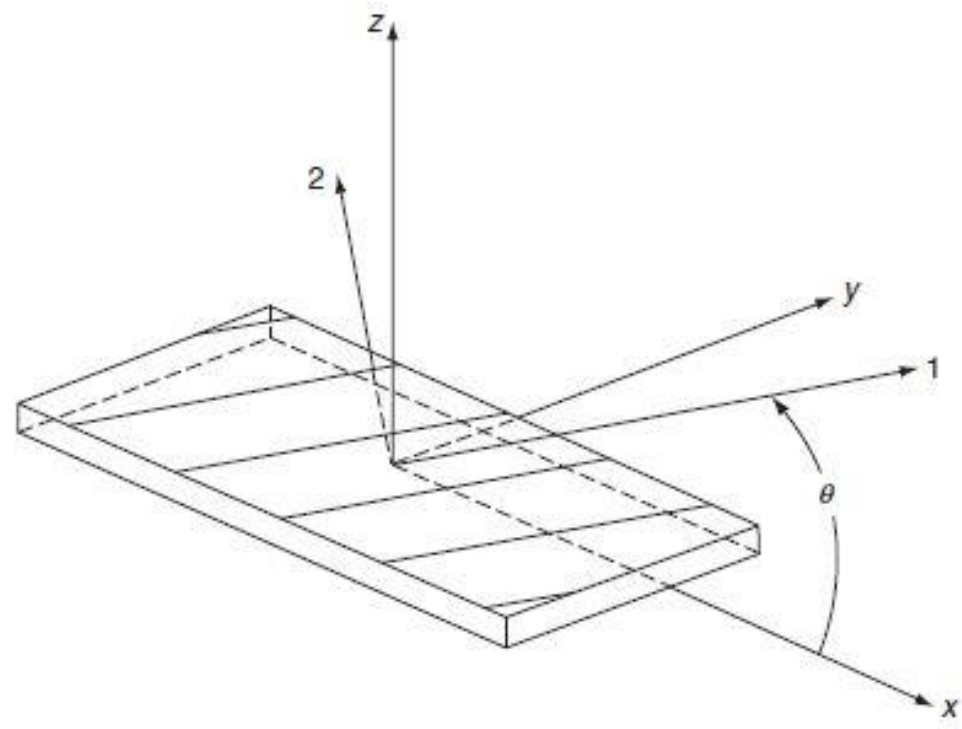

Figure A-0-1: Lamina Coordinate System 


\section{A.2 Stiffness Matrices}

\section{A.2.1 Specially Orthotropic Lamina}

The first step in the classical lamination theory is to determine the stiffness matrix for a unidirectional lamina. Therefore, the five elastic constants must be determined. There are many equations, mechanics based and empirical, that aid in this process. The equations provided in this section were determined to be the most appropriate for this particular research.

\section{A. Longitudinal Modulus of Elasticity}

$$
E_{11}=E_{f} * V_{f}+E_{m} *\left(1-V_{f}\right)
$$

Where:

$\mathrm{E}_{11}=$ Modulus of Elasticity of the lamina in the fiber direction

$\mathrm{E}_{\mathrm{f}}=$ Modulus of Elasticity in the fiber direction

$V_{f}=$ Fiber volume fraction

$\mathrm{E}_{\mathrm{m}}=$ Modulus of elasticity of the matrix

\section{B. Transverse Modulus of Elasticity}

$$
E_{22}=E_{m} * \frac{1+\zeta * \eta * V_{f}}{1-\eta * V_{f}}
$$

Where:

$\mathrm{E}_{22}=$ Modulus of Elasticity of the lamina transverse to the fiber direction

$\zeta=$ empirical parameter for curve fit of experimental data $=2$ for circular fibers

$\eta=\left(E_{f} / E_{m}-1\right) /\left(E_{f} / E_{m}+\zeta\right)$ 


\section{Major Poisson Ratio}

$$
v_{12}=v_{f} * V_{f}+v_{m} *\left(1-V_{f}\right)
$$

Where:

$v_{12}=$ Major Poisson ratio of the lamina

$v_{\mathrm{f}}=$ Poisson Ratio of the fibers

$v_{\mathrm{m}}=$ Poisson Ratio of the matrix

\section{Minor Poisson Ratio}

$$
v_{21}=\frac{E_{22}}{E_{11}} * v_{12}
$$

Where:

$v_{21}=$ Major Poisson Ratio of the lamina

\section{E. Shear Modulus}

$$
G_{12}=\left[\frac{\left(1+V_{f}\right)+\left(1-V_{f}\right) * G_{m} / G_{f}}{\left(1-V_{f}\right)+\left(1+V_{f}\right) * G_{m} / G_{f}}\right]
$$

Where:

$\mathrm{G}_{12}=$ Shear Modulus of the lamina

$\mathrm{G}_{\mathrm{f}=}$ Shear Modulus of the fibers

$\mathrm{G}_{\mathrm{m}}=$ Shear Modulus of the matrix

\section{A.2.2 Unidirectional Lamina}

Based on these terms, generalized Hooke's law gives the equation for the stiffness matrix

of unidirectional, specially orthotropic lamina. The stiffness terms in this matrix apply to the fiber 
coordinate system. Therefore, strains along the length of the fiber and transverse to the fibers can be determined for a unidirectional lamina.

$$
\left\{\begin{array}{l}
\epsilon_{11} \\
\epsilon_{22} \\
\gamma_{12}
\end{array}\right\}=[Q] *\left\{\begin{array}{l}
\sigma_{11} \\
\sigma_{11} \\
\tau_{12}
\end{array}\right\}=\left[\begin{array}{ccc}
Q_{11} & Q_{12} & 0 \\
Q_{21} & Q_{22} & 0 \\
0 & 0 & Q_{66}
\end{array}\right] *\left\{\begin{array}{l}
\sigma_{11} \\
\sigma_{11} \\
\tau_{12}
\end{array}\right\}
$$

Where:

$$
\begin{aligned}
& Q_{11}=E_{11} /\left(1-v_{12} * v_{21}\right) \\
& Q_{22}=E_{22} /\left(1-v_{12} * v_{21}\right) \\
& Q_{12}=Q_{21}=\frac{E_{22} * v_{12}}{\left(1-v_{12} * v_{21}\right)}=\frac{E_{11} * v_{21}}{\left(1-v_{12} * v_{21}\right)} \\
& Q_{66}=1 / G_{12}
\end{aligned}
$$

\section{A.2.3 Transformed Unidirectional Lamina}

Once the stiffness matrix for a specially orthotropic lamina is determined, the stiffness properties can be transformed to the out-of plane (global XYZ) coordinate system. This is done through the transformation matrix $(\mathrm{T})$ and the angle of rotation $(\Theta)$.

$$
[T]=\left[\begin{array}{ccc}
\operatorname{Cos}^{2}(\theta) & \operatorname{Sin}^{2}(\theta) & 2 * \operatorname{Sin}(\theta) * \operatorname{Cos}(\theta \\
\operatorname{Sin}^{2}(\theta) & \operatorname{Cos}^{2}(\theta) & -2 * \operatorname{Sin}(\theta) * \operatorname{Cos}(\theta \\
-\operatorname{Sin}(\theta) * \operatorname{Cos}(\theta) & \operatorname{Sin}(\theta) * \operatorname{Cos}(\theta) & \operatorname{Cos}^{2}(\theta)-\operatorname{Cos}^{2}(\theta)
\end{array}\right]
$$

The transformed stiffness matrix for a lamina is given by

$$
\bar{Q}=\left[\begin{array}{lll}
\bar{Q}_{11} & \bar{Q}_{12} & \bar{Q}_{16} \\
\bar{Q}_{12} & \bar{Q}_{26} & \bar{Q}_{26} \\
\bar{Q}_{16} & \bar{Q}_{26} & \bar{Q}_{66}
\end{array}\right]=[T]^{T} *[Q] *[T]
$$




\section{A.2.4 Stiffness Matrix of Chopped Strand Mats}

In addition to filament wound unidirectional fibers, many composite pipes also contain mats comprised of small strands of chopped fiber. Depending on the densities and volume content, mats can contribute a significant amount of stiffness. Since mats are composed of randomly oriented chopped strands, the stiffness can be approximated by the stiffness matrix for isotropic materials. Where $\mathrm{E}, \mathrm{v}$, and $\mathrm{G}$ are given by:

A. Modulus of Elasticity of CSM

$$
E=3 / 8 * E_{11}+5 / 8 * E_{22}
$$

B. Shear Modulus of Elasticity of CSM

$$
G=1 / 8 * E_{11}+1 / 4 * E_{22}
$$

C. Poisson Ratio of CSM

$$
v=\frac{E}{2 * G}-1
$$

D. Stiffness Matrix of CSM

$$
[Q]=\left[\begin{array}{ccc}
1 / E & -v / E & 0 \\
-v / E & 1 / E & 0 \\
0 & 0 & 1 / G
\end{array}\right]
$$

\section{A.2.5 ABD Stiffness Matrix}

In the laminate, the individual laminae are stacked and identified in accordance with the figure below. This stacking sequence can be applied to laminates of $n$ number of layers. 


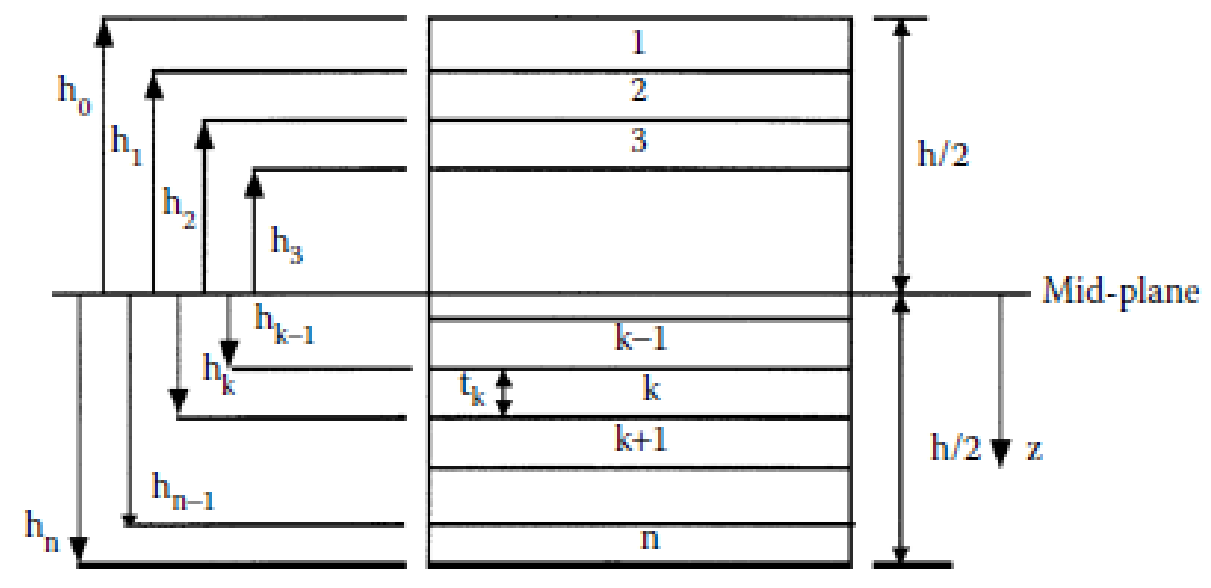

Figure A-0-2: Laminate Layup

The ABD stiffness matrix is determined so that a composite laminate may be analyzed for stresses and strains in the global directions. Therefore, the effects of the individual laminae must be compiled into a single matrix. The $\mathrm{ABD}$ matrix is assembled from the in-plane stiffness matrix ([A]), the coupling matrix ([B]), and the bending matrix ([D]). These are assembled in accordance with the laminate geometry and A, B, D matrix equations.

$$
\begin{gathered}
A_{i j=} \sum_{k=1}^{N}\left(\bar{Q}_{i j}\right)_{k} *\left(Z_{k}-Z_{k-1}\right) \\
B_{i j=} \frac{1}{2} \sum_{k=1}^{N}\left(\bar{Q}_{i j}\right)_{k} *\left(Z_{k}^{2}-Z_{k-1}^{2}\right) \\
D_{i j=} \frac{1}{3} \sum_{k=1}^{N}\left(\bar{Q}_{i j}\right)_{k} *\left(Z_{k}^{3}-Z_{k-1}^{3}\right)
\end{gathered}
$$




\section{APPENDIX B - Pultruded Fabric Architectures}

\section{6" \\ DIE \# 6429-1 C, PART \# TU43ロ.7ᄃ3 \\ ㅁB-28-14 DCH}

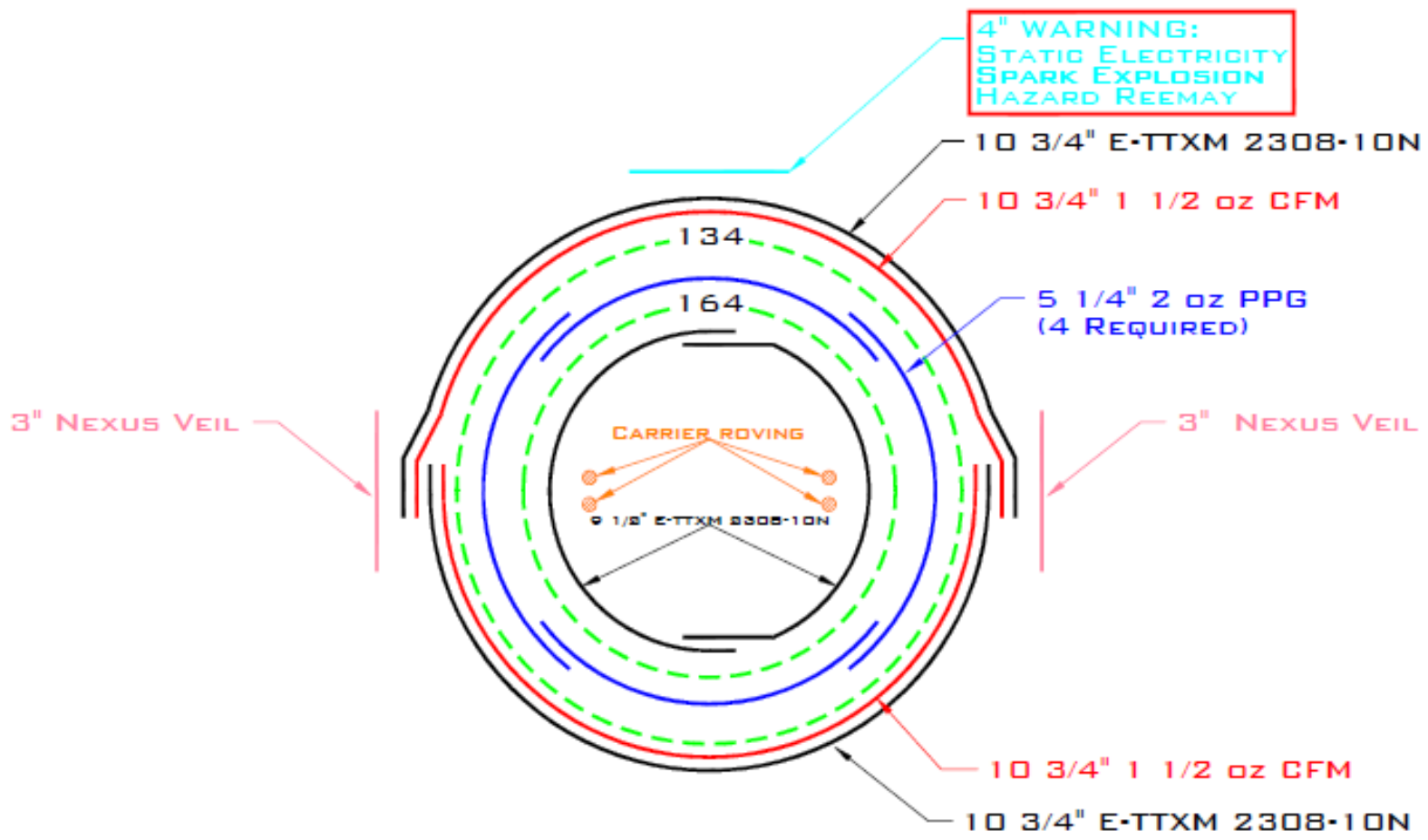

Notes: All Mats averlap Approximately 1 "

All Raving are 56 Yield (Tatal af 302)

E-TTXM 2308-10N IS A

23 口Z TRIAXIAL FABRIC WITH 8.1 GZ/YD^ 2

CHIP AND A NEXUS SEWN TO IT 
1 "םD X 3/8" WALL RLUND TUBE CINSTRUCTION DIE \#6489-1 P, PART \# TU44D

\section{DATE: $11-6-15$ TEW}

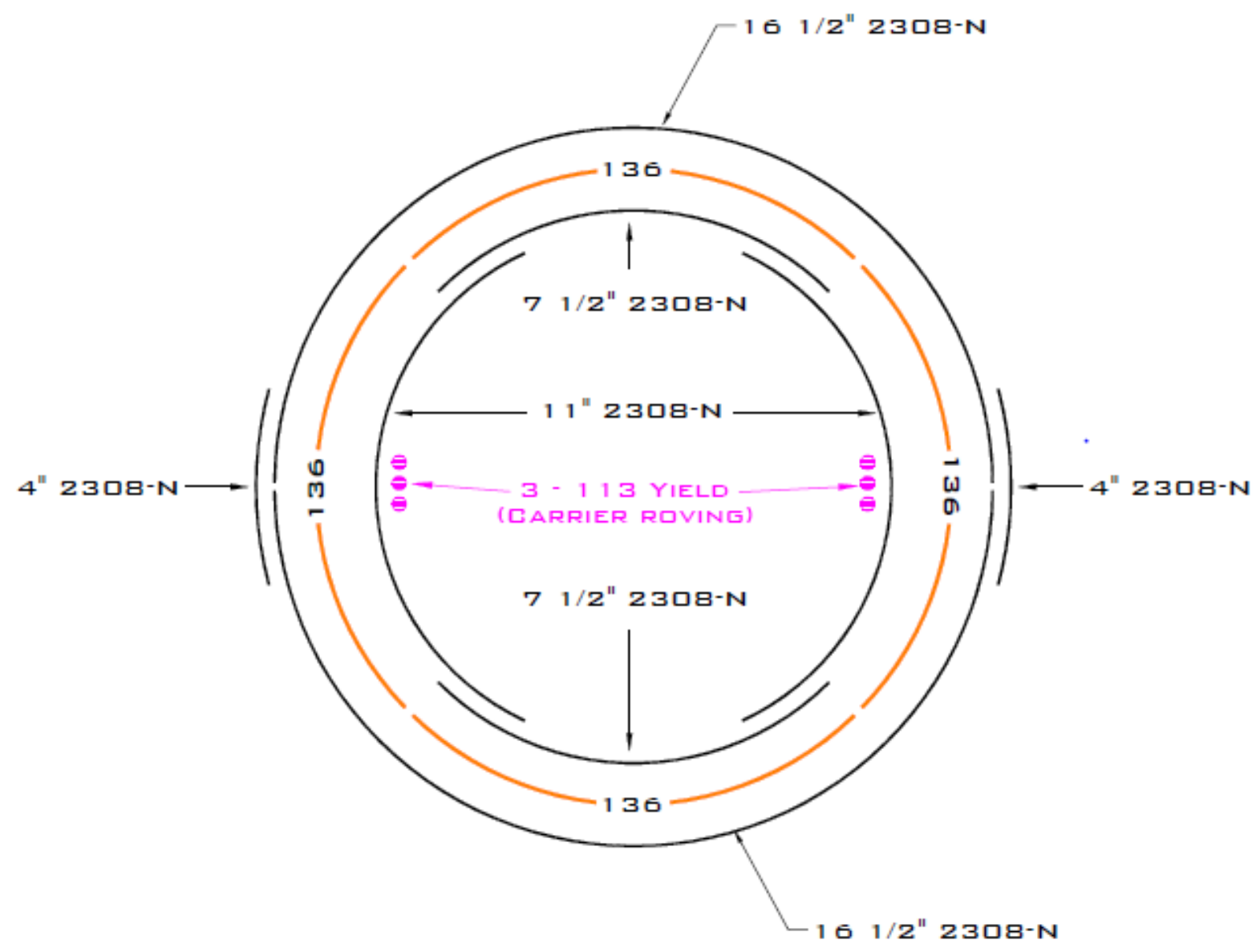

CIRE RIVING ARE 28 YIELD (TITAL IF 544) CARRIER RIVING ARE 113 YIELD (TITAL af 6) 


\section{APPENDIX C - Frame Drawing}

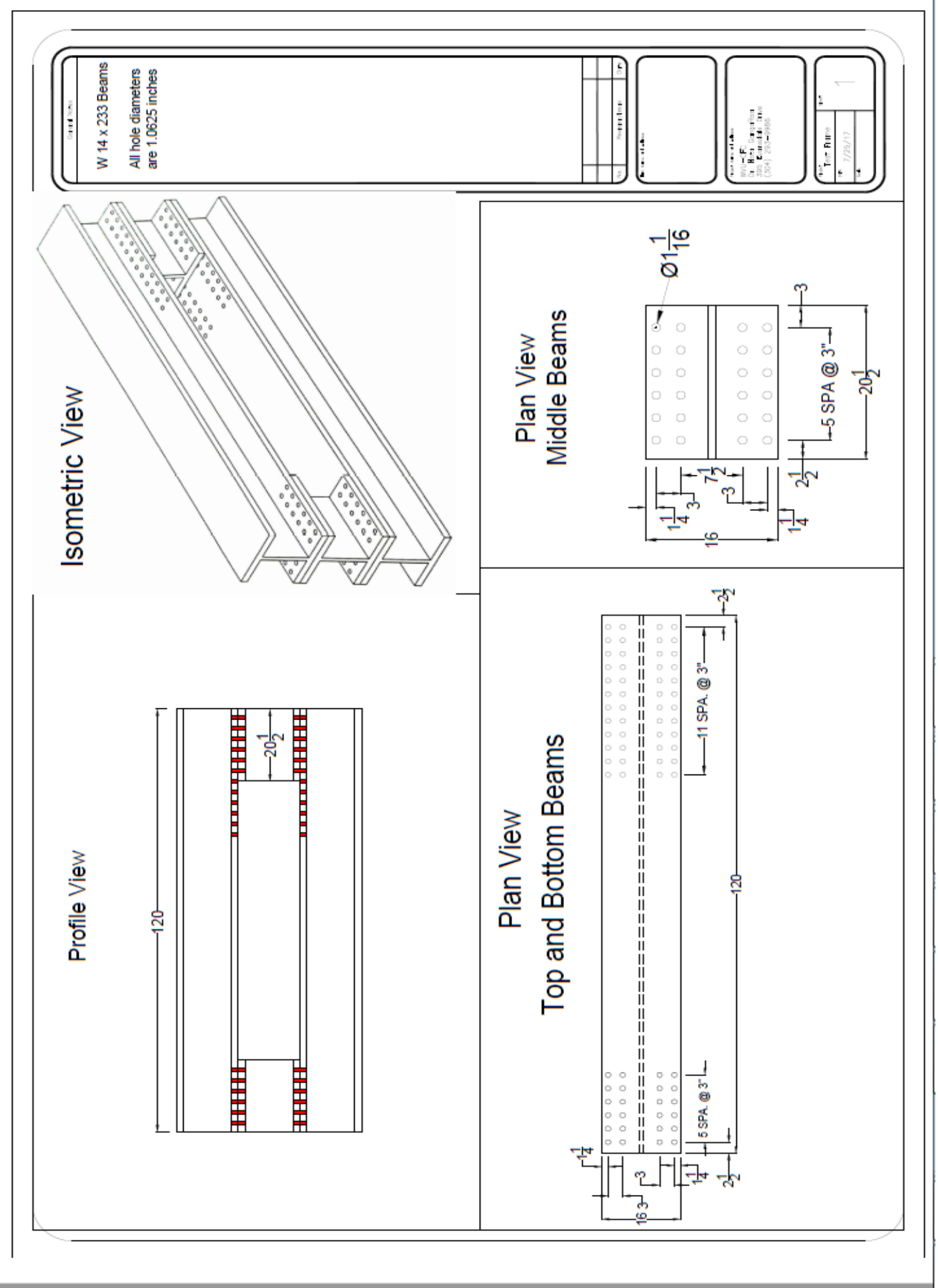




\section{APPENDIX C - Frame Design Calculations}

\section{Burst Test Rig Design ASD}

\section{Section Properties}

$$
\begin{aligned}
& \text { Member: W14x233 could be A992 or A572 } \\
& d:=16 \text { in Area Gross }=68.5 \mathrm{in}^{2} \\
& t_{\mathrm{y}}:=1.07 \mathrm{in} \quad F_{y}:=50000 \mathrm{psi} \\
& t_{f}:=1.72 \mathrm{in} \\
& b_{f}:=15.9 \mathrm{in}
\end{aligned}
$$

2.Loads and Demands

$$
\begin{aligned}
& \text { Length }:=36 \text { in } \quad \text { Innerdiameter }:=\mathbf{~} \quad 10 \text { in } \\
& \text { Area }_{\text {Pipe }}:=\left(\frac{\text { Outerdiameter }}{2}\right)^{2} \cdot \pi=78.5398 \mathrm{in}^{2} \\
& \text { Pressure } \operatorname{Max}:=10000 \mathrm{psi} \quad \text { Load }_{\text {Endcaps }}:=\text { Pressure }_{\mathrm{Max}} \cdot \text { Area }_{\text {Pipe }}=785398.16341 \mathrm{bf} \\
& \text { Based on the calculations above, each end cap will have 785,398 lbf acting on it at } \\
& \text { max pressure. }
\end{aligned}
$$




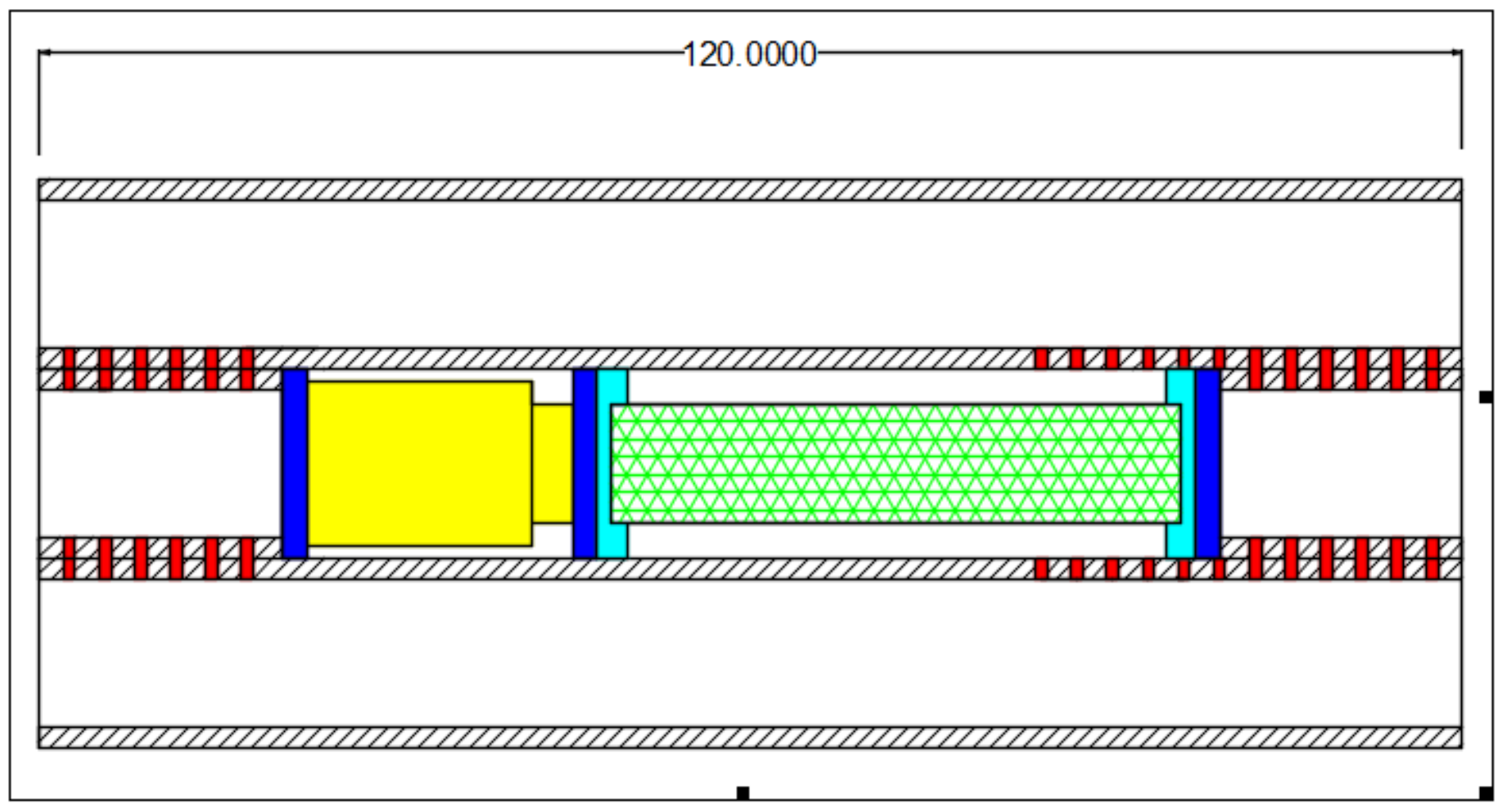




\section{Tension(Top and Bottom WF Beams)}

$$
\text { Demand }_{T}:=392699 \mathrm{lbf} \quad P u_{T}:=\text { Demand }_{T}=392699 \mathrm{lbf}
$$

ASD Appraoch: AISC

Steel Manual page 2-10

1.4D would be the requirment for Pu if LRFD was used. For ASD there is no load factor

Slenderness Needs to be $\mathrm{L} / \mathrm{r} \leq 300$

$+$

$$
I_{x}:=3010 \text { in }^{4} \quad I_{y}:=1150 \text { in }^{4}
$$

$$
\begin{aligned}
& \frac{(10 \mathrm{ft}) \cdot 12 \frac{\mathrm{in}}{\mathrm{ft}}}{r_{x}}=18.1027 \\
& \left(\frac{(10) \mathrm{ft} \cdot\left(12 \frac{\mathrm{in}}{\mathrm{ft}}\right)}{r_{y}}\right)=29.2872
\end{aligned}
$$

Therefore, requirments Met

$$
\begin{aligned}
& \text { Area }_{\text {Net }}:=\text { Area }_{\text {Gross }}-4 \cdot t_{f} \cdot \text { Diameter }_{\text {Hole }}=61.19 \mathrm{in}^{2} \\
& \text { Area }_{\text {Effective }}:=U \cdot \text { Area }_{\text {Net }}=55.071 \mathrm{in}^{2}
\end{aligned}
$$

U determined by Table D3.1 case 7. Reference pg 16.1-286

Limit states: $\Omega_{y}:=1.67 \Omega_{u}:=2.00$ Safety factor for ASD

$$
\begin{array}{lll}
\text { Yielding: } & p n_{y}:=F_{y} \cdot \text { Area Gross } & \frac{p n_{y}}{\Omega_{y}}=2050898.20361 \mathrm{bf} \\
\text { Rupture: } & p n_{u}:=F_{u} \cdot \text { Area } & \\
& \frac{p n_{u f f e t i v e}}{\Omega_{u}}=1789807.51 \mathrm{bf}
\end{array}
$$

\section{Shear lag Factor}




\section{Block Shear Rupture-Based on Tension Demands}

$$
\begin{aligned}
& \Omega:=2.00 \\
& \text { Area }_{g v}:=20.5 \text { in } t_{f}=35.26 \text { in }^{2} \quad \quad \text { Area }_{n V}:=\text { Area }_{g V}-\left(\left(1 \text { in }+\frac{1}{8} \text { in }\right)\right) \cdot t_{f} \cdot 6=23.65 \text { in }^{2} \\
& \operatorname{Area}_{n t}:=\left(6.13 \mathrm{in} \cdot t_{f}\right)-1.5 \cdot t_{f} \cdot\left(1 \mathrm{in}+\frac{1}{8} \mathrm{in}\right)=7.6411 \mathrm{in}^{2} \quad U_{b s}:=.5 \\
& \text { Part1 }:=.60 \cdot F_{u} \cdot \text { Area }_{n v}+U_{b s} \cdot F_{u} \cdot \text { Area }_{n t}=1170685.751 \mathrm{bf} \\
& \text { Part2 }:=.60 \cdot F_{y} \cdot \text { Area }_{g v}+U_{b s} \cdot F_{u} \cdot \text { Area }_{n t}=1306135.751 \mathrm{bf} \\
& R_{\text {nbs }}:=\text { if Part } 1 \leq \text { Part } 2 \\
& \text { else } \\
& \text { Part2 } \\
& R_{\text {nbs }}=1170685.751 \mathrm{bf} \quad \frac{R_{\text {nbs }}}{\Omega}=585342.87 \mathrm{lbf} \\
& \text { Not sure about Ubs here. } \\
& \text { Could be .5. } 5 \text { is more } \\
& \text { conservative } \\
& \text { All done in Accordance with } \\
& \text { Section } \mathrm{J} 4 \\
& \text { Total BSR strength is } 1170685 \mathrm{lbf} \text { Meets the factor of safety of } 2
\end{aligned}
$$

Bolts are A490, group B. On the conservative side, Fnv=68 ksi

Fnv is found through imperical relatations. Shear rutpure is . 625 of the tensile rupture. Then a. 9 factor $i s$ applied to account for differnetial strains. So for thread included, A490 bolts with fun $150 \mathrm{ksi}$, Fnv $=.625^{*} .9 * 150 * .8=68 \mathrm{ksi}$. Not need to include load distribution per 16.1-403. Hota's concern was that perhaps leading bolts would take too much stress.

$$
\begin{aligned}
& \text { Area }_{\text {Bolt }}:=\left((.5 \mathrm{in})^{2} \cdot \pi\right)=0.79 \mathrm{in}^{2} \quad \operatorname{Load}_{\text {Bolt }}:=\frac{P u_{T}}{24}=1.64 \cdot 10^{4} 1 \mathrm{bf} \\
& \text { Stress } \text { Bolt }:=\frac{\text { Load }_{\text {Bolt }}}{\text { Area }_{\text {Bolt }}}=20833.33 \frac{1 \mathrm{bf}}{\text { in }^{2}} \quad \text { FS }:=\frac{68000 \mathrm{psi}}{\text { Stress }_{\text {Bolt }}}=3.264001 \\
& \begin{aligned}
\text { AllowableCapacity } & \text { AISC table } 7-1 \\
\text { in }^{2} & \text { This includes a safety factor of } 2 .
\end{aligned}
\end{aligned}
$$




\section{Bolt Bearing}

$$
\begin{aligned}
& R_{n b}:=\text { if } 1.2 \cdot I_{c} \cdot t_{f} \cdot F_{u} \leq 2.4 \cdot d_{b} \cdot t_{f} \cdot F_{u} \\
& 1 \cdot 2 \cdot I_{c} \cdot t_{f} \cdot F_{u} \\
& \text { else } \\
& 2 \cdot 4 \cdot d \cdot t_{f} \cdot F_{u} \\
& I_{c}:=3 \mathrm{in}-2 \cdot\left(\frac{\text { Diameter }_{\text {Hole }}}{2}\right)=1.9375 \mathrm{in} \\
& d_{b}:=1 \text { in }
\end{aligned}
$$

$$
\frac{R_{n b}}{\Omega}=129967.51 \mathrm{bf}
$$

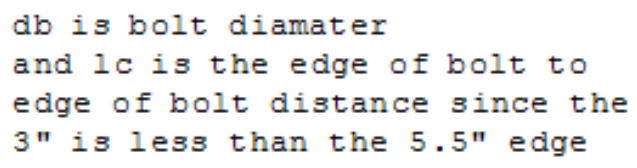

Rnb is the nominal bearing strength. Vs Rnbs which is for block shear.

$\mathrm{Rnb}$ with the factor of safety of 2 exceeds the $1 \mathrm{bf}$ on each bolt.

\section{Compression(Stocky center W Beams)}

Compression should be fine. Member is restrained so buckling should be ok. Compression stress should be fine too.

$p_{n c}:=F_{y} \cdot$ Area $_{\text {Gross }}=34250001 \mathrm{bf}$

This may not be comepletely accruate. However, without considering the factor of। factor of safety, the compression capacity is sufficeint, provided that we place gauges during testing. 